\title{
SEX EDUCATION IN THE DIGITAL ERA
}
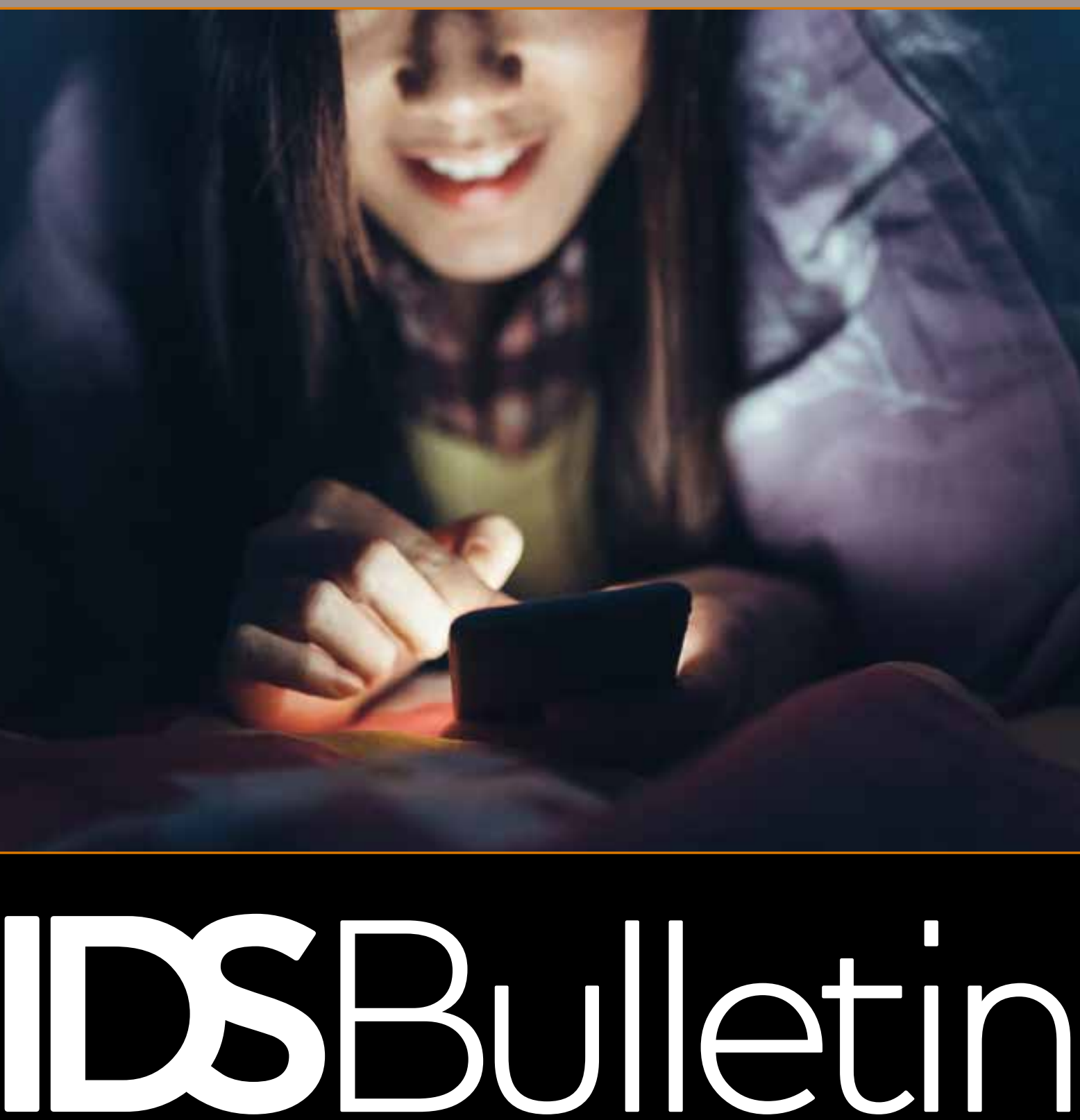

Transforming Development Knowledge 
IDS Bulletin The IDS Bulletin is an open access, peer-review journal exploring emerging international development challenges. It is published bi-monthly and is the flagship publication of the Institute of Development Studies, a leading global institution for research, teaching and learning, and impact and communications, based at the University of Sussex. Progressive economic, social and political change for everyone needs new kinds of action and relationships, shaped by new kinds of research and engagement. The IDS Bulletin aims to transform development knowledge, through its unique thematic issues developed by global learning partnerships that bridge academic, practice and policy discourse.

Publishing Manager/Bulletin Editorial Coordinator Alison Norwood Marketing and Production Officer Gary Edwards

Publisher The IDS Bulletin is published by the Institute of Development Studies, Library Road, Brighton BN1 9RE, UK. Tel: $+44(0) 1273606261$.

Cover photo Woman texting on smartphone under the bed sheets.

Photographer Yiu Yu Hoi/The Image Bank/Getty Images

Disclaimer The Publisher and Issue Editors cannot be held responsible for errors or any consequences arising from the use of information contained in this journal; the views and opinions expressed do not necessarily reflect those of the Publisher and Issue Editors, neither does the publication of advertisements constitute any endorsement by the Publisher and Issue Editors of the products advertised.

Copyright and photocopying IDS Bulletin (c) Institute of Development Studies

\section{(c) BY This issue is published under a CC BY licence.}

This is an Open Access issue distributed under the terms of the Creative Commons Attribution 4.0 International licence, which permits unrestricted use, distribution, and reproduction in any medium, provided the original authors and source are credited. http://creativecommons.org/licenses/by/4.0/legalcode

Online open access This journal is available online at bulletin.ids.ac.uk. Visit the site to search for articles and authors and register for table of contents email alerts.

Information for subscribers The IDS Bulletin is published in six issues per year. Institutional subscription price for 2017 is $£ 430$ (no VAT applicable).

Advertising enquiries Gary Edwards, Marketing and Production Officer, IDS Communications and Engagement Unit, idsbulletin@ids.ac.uk 


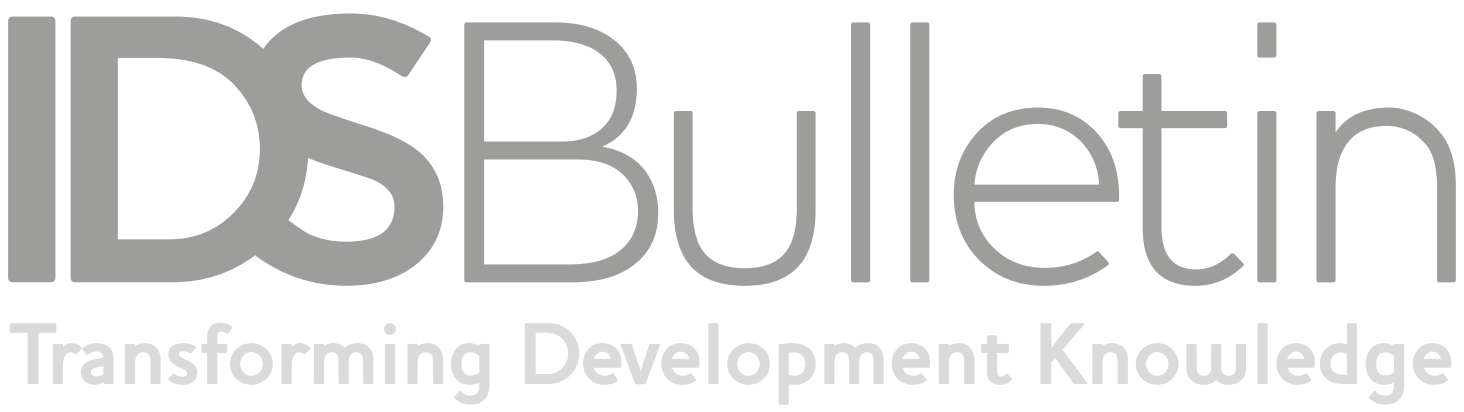

Volume 48 | Number 1 | January 2017

\section{Sex Education in the Digital Era Editors Pauline Oosterhoff, Catherine Müller and Kelly Shephard}

Introduction: Sex Education in the Digital Era

Pauline Oosterhoff, Catherine Müller and Kelly Shephard

Enabling Online Safe Spaces: A Case Study of Love Matters Kenya

Maaike van Heijningen and Lindsay van Clief

New Digital Ways of Delivering Sex Education: A Practice Perspective Linda Waldman and Isabelle Amazon-Brown

\#ByeTaboo: Expanding Access to Sexual and Reproductive Health and Rights Education

Natalia Herbst

Digital Pathways to Sex Education

Catherine Müller, Pauline Oosterhoff and Michelle Chakkalackal

Feeling 'Blue': Pornography and Sex Education in Eastern Africa

Kristen Cheney, Annah Kamusiime and Anteneh Mekonnen Yimer

Blurring the Boundaries of Public Health: It's Time to Make Safer Sex Porn and Erotic Sex Education

Anne Philpott, Arushi Singh and Jennie Gamlin 
105 Acknowledgements

Development Sudies. We would like to thank the reviewers of the articles for their extremely valuable comments and suggestions:

Pam Baatsen, Evangelia Berdou, Michelle Chakkalackal, Natalia Herbst, Elizabeth Mills, Thea Shahrokh, Kelly Shephard, Patta Scott-Villiers, Erin Stern, Linda Waldman, Stephen Wood. Without their input this IDS Bulletin would not have been possible.

The co-editors gratefully acknowledge financial support from Love Matters.

As collaborators we gratefully acknowledge the financial support from RNW Media for the production of this issue of the IDS Bulletin, as well as contributing the Love Matters staff time of Katie Thompson, Mart Kok, Luke Gilder, Erik Hillen, Benjamin Dalmulder and Lindsay van Clief, and for the funding of research, which Müller et al. is based on.

RNW Media is a media organisation for social change. In parts of the world, where change is hard to achieve because freedom of speech is restricted, we use media to make lives better. Love Matters is a sexual health reproductive and rights programme that uses web, mobile and social media platforms to offer young people information that can help them have a safe and healthy sex life.

\section{Disclaimer}

The views expressed in this publication do not necessarily reflect the official policies of RNW Media, Love Matters or our funders.

Vol. 48 No. 1 January 2017: 'Sex Education in the Digital Era'

DOI: 10.19088/1968-2017.100 


\section{Notes on Contributors}

Isabelle Amazon-Brown is Head of Programme Design at Every 1 Mobile, a 'mobiles4good' organisation working with the charitable and development sectors to implement digital solutions across education, health and livelihoods in Africa. Isabelle has designed and managed online communities for clients including the Department for International Development (DFID) and the United States Agency for International Development (USAID), with a focus on sexual and reproductive health and rights (SRHR) and gender. Most recently, she led on the design of a gender empowerment mobile course for Nigerian youth, an online community for Kenyan shopkeepers and a digital literacy site for South African teenage girls. She is interested in taking participatory approaches to solution design, working with end users to co-develop solutions.

Michelle Chakkalackal is a public health researcher, strategist and writer. Michelle is co-founder and global content strategist for the award-winning Love Matters programme. She is fascinated by what data can tell us about people's health needs, and turns these insights into products people can use to improve their lives. Love Matters delivers SRHR information to young people in countries where these topics are censored or taboo. It operates in five languages and six countries, and its sites have had more than 50 million visits over the past five and a half years.

Kristen Cheney has been conducting child and youth participatory research in eastern Africa since 2000, including several studies that explore issues of youth sexual and reproductive health. Her work takes an explicitly child-centred approach that considers how children experience and respond to various hegemonic institutional and structural elements of global and local development practices. Her book, Crying for Our Elders: African Orphanhood in the Age of HIV/AIDS (University of Chicago Press, 2017) draws on youth participatory ethnographic research with orphans and vulnerable children (OVC) to examine issues of social exclusion, policy, and protection for children affected by HIV/AIDS.

Jennie Gamlin is a Wellcome Trust Society and Ethics Research Fellow at the UCL Institute for Global Health, London where she has been based since 2004. For two decades Jennie has worked between the UK and Mexico on the overlap between anthropology, development and global health. She worked for several years in reproductive and sexual health non-governmental organisations (NGOs) in Mexico before developing her own research on maternal health in indigenous communities. Jennie is currently developing new research on sexuality, gender and structural violence, and leading a partnership between UCL and Latin American universities on critical medical anthropology and its role in global health research. 
Natalia Herbst holds a MA in Development Studies (IDS, University of Sussex) and a BA in International Studies (Universidad Torcuato Di Tella, Argentina), and is former Fulbright scholar. Natalia has worked in the Government of the City of Buenos Aires where she led a team of advisers on diversity and inclusion policies, with a focus on youth, sexual diversity and SRHR. She has extensive research experience in Latin American international relations. She has focused on Haiti, Brazil, South-South cooperation, international health cooperation and the emergence of rising powers. She has published in Foreign Affairs Latinoamérica and the Iberoamerican Fournal of Development Studies, among other journals.

Annah Kamusiime is a lecturer at Bugema University Kampala and Programmes Manager with Nascent RDO. She is a social development worker with over ten years' experience in social development, advocacy, and research. She holds a MA in Gender Studies and a BA in Social Sciences from Makerere University, graduating in 2010 and 1997 respectively, and a postgraduate certificate in research and writing from the Center for Basic Research in Kampala. Annah is also a CODESRIA laureate of 2015. Her experience involves implementation of research and development projects related to girls' education, child labour, SRHR, child protection and Early Childhood Care and Development (ECCD).

Catherine Müller is a Research Fellow at IDS. As a trained economist and applied researcher, she has gained in-depth knowledge of both quantitative and qualitative research design and data analysis methodologies in many different country contexts in Europe, Africa, the MENA region, South Asia and Latin America. Her main research interests are gender-based violence in general, and violence against women and girls in conflict and humanitarian crisis settings in particular; women's (economic) empowerment; unpaid care work; and sexual and reproductive health issues, particularly in relation to sex education.

Pauline Oosterhoff is a Research Fellow at IDS. She has over 20 years' international experience in research, advisory services and media production on sexuality and SRHR working with international NGOs, the United Nations, bilateral donors, private foundations, universities and the private sector. She is interested in the ways research and public engagement can support progressive, inclusive and effective policy and practice. Pauline relishes using mixed and participatory methods linking online and offline settings and works in multidisciplinary teams. In addition to her research and advisory work, she produces documentary films, installations and immersive interactive events.

Anne Philpott has worked and lived in the UK, South Africa, Sri Lanka, India and Thailand for NGOs, front-line service delivery and management of large donor programmes. She ran the UK's first teenage pregnancy prevention project, initiated many of the world's first female condom national programmes, and worked in South Africa during the 
first years of the AIDS epidemic. She has often innovated ideas that then become accepted, most relevantly inclusion of pleasure dialogues in sex education. She has a degree in Psychology and an MSc in Health Policy from the London School of Hygiene \& Tropical Medicine, and is published widely in peer-reviewed journals and the media.

Kelly Shephard is Head of Open Knowledge and Digital Services at IDS. Kelly is a storyteller. Her prime interest lies in the thoughtful use of technology to share and shape information. After spending 16 years working for BBC World Service, Kelly transferred her journalistic skills to the world of international development. Her move to IDS in 2011 was led by a desire to be as much involved in the process as the product. Her skills, which were shaped in a multimedia environment, enable her to see clarity in complex material and present it in compelling and relevant ways.

Arushi Singh is a pleasure and sexual rights advocate with The Pleasure Project. She works with several international NGOs and United Nations agencies on programme design, capacity building, and qualitative evaluation for SRHR. Her main interests are in sexuality, gender, rights, and sex-positive, pleasure-based approaches to sexual health, especially for adolescents and young people. Arushi has formerly worked with the International Planned Parenthood Federation's Asia Regional Office, Amnesty International's India Office, and the Commonwealth Youth Programme's Asia Centre. She has worked mainly in South Asia, and more recently in South-East Asia, and East and Southern Africa.

Lindsay van Clief is a sex educator living and working in the Netherlands. She works as a Content Producer at Love Matters where she oversees the creation of SRHR content. She has a master's degree from the University of Amsterdam in Gender and Sexuality studies.

Maaike van Heijningen is an anthropologist and digital media specialist working for Love Matters. She is a recent graduate from Utrecht University with a master's degree in New Media and Digital Culture, and previously graduated from Leiden University with a master's degree in Anthropology, specialising in visual methods, media and culture.

Linda Waldman is a Research Fellow in the Health and Nutrition Cluster, and Director of Teaching and Learning at IDS. As a social anthropologist, her research is focused on the intersections between health, poverty, gender and policy. She has researched indigenous people, farm workers and adolescence, peri-urban ecosystems and sustainability; asbestos-related diseases; zoonotic disease; and ICTs and health systems. Linda has research experience in Africa, South Asia and the UK.

Anteneh Mekonnen Yimer has a Masters of Social Work (MSW) from Addis Ababa University. He has a wide range of experience in teaching, consultancy and research planning, coordination, monitoring, evaluation, analysis and report writing in social work for government 
institutions, universities and humanitarian organisations such as the Ethiopian Civil Service University, the United Nations Population Fund (UNFPA) and the International Institute of Social Studies - Erasmus University Rotterdam. He has conducted various youth-focused research as a national consultant on comprehensive sexuality education (CSE) and trainings for youth - such as university students, volunteers and youth leaders - on topics including C.SE, sexual and reproductive health, HIV/AIDS and gender. 


\title{
Introduction: Sex Education in the Digital Era
}

\author{
Pauline Oosterhoff, Catherine Müller and \\ Kelly Shephard
}

\begin{abstract}
Young people all over the world are keen to learn about sex and relationships but are not finding the information they seek in their immediate environment. The internet provides them with a welcome alternative. In response to the rapid increased connectivity of young people, international organisations that work on comprehensive sex education for young people have moved online. While there are new opportunities to reach young people in these digital spaces, sex educators also encounter restrictions. They face the immense power of new supranational commercial digital gatekeepers such as Facebook and Google and must respond to digitally mediated sexual and gender-based violence. This article introduces a special issue of the IDS Bulletin on experiences with internet-based sex education in 14 countries. The authors explore how familiar forms of exclusion and inequality, as well as empathy and solidarity, manifest themselves in these new digital spaces in highly diverse national settings.
\end{abstract}

Keywords: Sex education, sexual health, ICT, digital, internet, pornography, youth, gender.

\section{Sex education: who has it?}

It is an understatement to say that exploring sex and sexual relationships is an important part of adolescence: for many young people, it is the most important part. Besides its central role in adolescent emotional development, sex education is also a crucial public health issue. Among other things, good sex education improves maternal and child mortality by helping to prevent unwanted, early and risky pregnancies, and sexually transmitted diseases. Yet in many parts of the world, unmarried teenagers are excluded from receiving information and sexual health services because, according to unrealistic and conservative religious and sociocultural norms, they are not supposed to be sexually active.

In many countries, traditional cultural forms of organised sex education have disappeared or become commercialised. If information about sex is available, it comes too late or in inaccessible formats. Too often, 
modern sex education focuses exclusively on warnings about risks. It rarely offers any practical suggestions on what young people really want to know: how to give and receive pleasure, and how to engage in sexual relationships in ways that make them happy. In many parts of the world, even providing scholars with information on sex is seen to encourage immoral sexual behaviour.

In this context, the internet and digital technology provide welcome, portable and readily available alternatives for seeking 'personalised' responses to questions about sex and relationships. For many young people all over the world - including in villages in Bangladesh, Ethiopia or Uganda - pornography is the primary source of information about sex. Attempts to restrict access to porn seem futile when more than 52 per cent of the world population and 41 per cent of those in low-income countries have access to the internet (ITU 2016).

In the last decade, in an attempt to offer more responsible information on sex over the internet, digital sex education initiatives have been launched all over the world. Such initiatives often gather millions of users and hits. Compared to traditional, interpersonal offline sex education, these numbers are impressive, and they have changed the field of sex education. Yet very little is known about the effectiveness of online sex education, or about how digital technologies affect young people's access to wanted or unwanted information. The internet provides not only freedom but also new forms of gender-based violence such as 'revenge porn' that sex educators have to face. Much of the research on sexuality in the digital era is moralistic and slanted. For practitioners and academics working on sexual and reproductive health, youth and digital development issues, learning more about sex education in the digital era is a major challenge.

\section{Exploring global digital sex education and porn to meet global goals}

There has never been a collection of scholarly work on this topic for a mixed audience of researchers, policymakers and practitioners. This is remarkable given the size of the populations affected and the money and political attention allocated to sexual and reproductive health and rights (SRHR). Unless policymakers, researchers and practitioners deal with the contested issues of young people's sexuality and sex education, globally-agreed goals such as a reduction of maternal mortality and teen pregnancy will not be reached.

This IDS Bulletin is a collaboration between Love Matters, an international organisation dedicated to online sex education for youth, and the Institute of Development Studies (IDS). In this issue we discuss experiences with digital sex education in Argentina, Ghana, Kenya, India, Nigeria, Tanzania, South Africa, Zambia, Zimbabwe, Uganda, Ethiopia, China, Egypt and Mexico. The range of settings is diverse, as are the issues confronted. Yet the common themes encountered across these varied settings are often as striking as the differences. 
Linda Waldman and Isabelle Amazon-Brown (this IDS Bulletin) explore how sex education for adolescents in sub-Saharan Africa is enabled by them having access to mobile phones. Examining the history of online health information platforms, they conclude that in contrast to formal, traditional sources of sex education, the internet offers many advantages, including portability, anonymity, informality, personalised responses, and the ability to interact with peers who are not local and not part of face-to-face networks. However, online sex education has not yet achieved an improvement in actual sexual and reproductive health status, due to weak or non-existent integration of online information with on-the-ground services. Online education programmes must comply with national legislation, which often restricts the provision of services to young people, who can thus not act upon the information they receive about these services.

\section{Sex, the state and social media}

Most sex education is provided by non-governmental organisations (NGOs) - often in partnership with commercial partners such as mobile phone companies. An exception is Argentina where the state is involved in a successful digital sex education website. Natalia Herbst (this IDS Bulletin) describes how state-led sex education is part of its broader strategy to improve access to education on sex and reproductive rights. But the state's ability to influence the religious and sociocultural sexual beliefs held by parents is limited. And the Argentinean case highlights the power of the new supranational commercial digital gatekeepers such as Facebook and Google. Even the state cannot circumvent the restrictions and censorship imposed by these commercial social media companies. Censorship on nudity on Facebook does restrict public health efforts. A campaign for breast examination, for example, had to use photos of a man with large breasts, since images of women's breasts are censored on Facebook. Another concern is the lack of accountability in the digital space: anonymous users often feel free to engage in sexually aggressive or abusive communication. Gender inequality, social exclusion, and the possibility of harassment exist in the digital environment just as they do in the offline one.

For this reason, digital sex educators must pay attention to gender and power dynamics when establishing online spaces. Safety is a prerequisite for information exchange and open dialogue on sexuality. Maaike van Heijningen and Lindsay van Clief's case study in this IDS Bulletin on enabling safety in an online sex education space in Kenya shows that online spaces can appear safe enough to share very personal experiences, but in reality they remain highly risky. Interactivity and the ability to provide peer-to-peer information make social media a valuable tool for sex education. But real-world gender inequalities manifest themselves, for example in sexual harassment and bullying, also in the online world. Hence, such spaces must be carefully managed. Creating a safe space requires guidance by trained and supervised moderators who can create a community atmosphere that enables friendships to grow, and who establish some form of digital accountability for users. 
Service providers have a duty care to participants but for them to create worthwhile spaces they also need to think about and resource robust discussion spaces. The findings also suggest that users must remain free to create anonymous online personas in order to protect themselves.

\section{Examining pornography}

Research on the effects of pornography in developed countries is still rare, but the available studies have found that pornography is ubiquitous and can create unrealistic ideas about sex. Kristen Cheney, Annah Kamusiime and Anteneh Mekonnen Yimer (this IDS Bulletin) decided to explore porn consumption among youth in Uganda and Ethiopia, after observing that in both countries greater access to information and communications technology (ICT) had resulted not just in greater consumption of Western-produced pornography, but in more production of home-grown pornography. Their research suggests that this growth was not entirely voluntary: girls expressed discomfort at being asked to record themselves in sexual situations, and often felt under social pressure to consent. Some reported that boys sometimes film sex without their partners' consent. However, both boys and girls said they consume pornography to get ideas for new sexual styles and positions, to explore and release sexual feelings, and to bond with peers by talking about the porn they have seen. Most young people believed that pornography was realistic. As a result, girls complained that pornography and sexually explicit messages (SEM) created difficult sexual expectations, such as female ejaculations and extended labia. Although boys might be more active in seeking SEM and porn, girls are also aware of it, especially through mobile phones, as well as internet cafes, video shops and video halls.

Anne Philpott, Arushi Singh and Jennie Gamlin (this IDS Bulletin) argue that sex educators have so far been reluctant to respond to pornography and SEM. Research has been largely biased towards the negative aspects of porn. They propose a more realistic approach, blurring the boundaries of public health and sex education by making porn that both includes safer sex and challenges the restrictive, violent, racist and sexist scripts currently portrayed. There are initiatives to produce more inclusive and realistic porn, including efforts by feminist porn directors and other innovative examples. Rather than seeking (futilely) to ban porn, public health should focus on reforming it, aiming to show wider ranges of sexual identity and types of relationships. Sex education professionals need to engage and educate to ensure that viewing porn can help promote safe sex choices, and consent, as well as pleasure.

\section{How do young people find online sex education?}

Catherine Müller, Pauline Oosterhoff and Michelle Chakkalackal (this IDS Bulletin) examine this landscape further by exploring digital pathways into sex education. We know that online sex education platforms reach millions of young people in countries where they cannot access trustworthy information. But we do not know how young people reach these sites. How does censorship of porn or 'obscene' 
images by invisible sentinel guards such as Facebook and Google restrict access to these sites? Knowing more about different user pathways into sex education sites would help to understand what the effective entry points for sex education are.

Using data from Love Matters, Müller et al. conclude that it is extremely difficult to know how young people reach sex education sites and whether or not porn can be an entry point. Invisible gatekeepers in online spaces specifically restrict access to information about porn, sex education and pleasure (Anderson et al. 2016). For example, social media networks such as Facebook and Google may impose strict rules, such as banning nudity, while implementing such rules unpredictably; and sites may be blocked or posts deleted for unclear reasons. Access to data on the online search behaviour of users of social media is restricted due to ethical and security concerns. Online sex educators thus find it hard to gather the information they need in order to design outreach strategies to provide target groups with realistic, healthy and supportive sex education environments. More collaboration with online gatekeepers would be helpful. Furthermore, sex educators need to understand the importance of creating online content in local languages, and making it accessible and youth-friendly.

One of the key lessons from all of these contributions is the urgency of developing digital literacy skills for academics and practitioners. Young people need help in learning to critically examine the sexual messages they are getting in their digital environments. This is true both of the pornography they view, and of the riskier, more participatory digital sexual activities they engage in, such as SEM. They also need access to new types of digital sex education environments that are realistic, emotionally attuned, non-judgemental and open to the messages they themselves create. Sex educators cannot help build such environments until they understand how they work.

\section{References}

Anderson, Jessica; Stender, Matthew; Myers West, Sarah and York, Jillian C. (2016) Unfriending Censorship: Insights from Four Months of Crowdsourced Data on Social Media Censorship, OnlineCensorship.org, https://s3-us-west-1.amazonaws.com/onlinecensorship/posts/ pdfs/000/000/044/original/Onlinecensorship.org_Report_-_31_ March_2016.pdf? 1459452553 (accessed 13 January 2017)

ITU (2016) ICT Facts and Figures, International Telecommunication Union, www.itu.int/en/ITU-D/Statistics/Documents/facts/ ICTFactsFigures2016.pdf (accessed 1 February 2017) 
This page is intentionally left blank

6 Oosterhoff et al. Introduction: Sex Education in the Digital Era 


\title{
Enabling Online Safe Spaces: A Case Study of Love Matters Kenya
}

\author{
Maaike van Heijningen and Lindsay van Clief
}

\begin{abstract}
For sexual health organisations, establishing a safe space to talk about sensitive topics is an important prerequisite for information exchange and open dialogue. With the popularity of social media and mobile phones, these safe spaces are moving online. This article examines one of these spaces, the Love Matters Kenya Facebook page, as an example of a sexual health organisation using social media to discuss sexuality with young people. We observed interactions on the Facebook page over a period of six weeks, and also led an online focus group discussion. The results showed that the key elements of a safe space are: good moderation; users' ability to create their own online personas; and a community atmosphere that enables trust and social relationships to grow.
\end{abstract}

Keywords: safe spaces, moderation, online communication, sex education, social media, Kenya, youth-centred, SRHR.

\section{Introduction}

Love Matters: How was your 'first time??

Audrey: I never had sex, I am still a virgin.

Peter: Come here, and I will break your virginity.

Ben: I wish I could get $u$.

Andrew: Looking for a virgin lady, well educated.

Maria: I would like to forget my first time, but I can't. I hate doing it, even with my hubby, I feel so dirty.

Celia: It seems like it was forced on u, but if you are married and feel dirty, you need counseling, so you can get over what happened. And start to enjoy every moment of $i{ }^{1}$

The above conversation is taken from the Love Matters Kenya Facebook group, where young Kenyans discuss love, sex and relationship issues. People exchange messages openly on the Facebook group's wall, but also send questions and concerns privately through the Facebook Messenger instant messaging app. Some, like Maria, a 35-year-old Kenyan woman, publicly share their personal concerns. Others, like 20-year-old Audrey, share experiences or confessions: in this case, that she is still a virgin. Unlike Maria, who received a sympathetic 
reply to her comment and advice, Audrey had to deal with sexually explicit comments. While we cannot make any assumptions regarding how Audrey may have felt about this, it illustrates how online spaces can be both 'safe' enough to share very personal experiences and at the same time be very risky.

This article illustrates the key elements of an online safe space in the context of social media. It examines the lived experiences of young Kenyans in online spaces as they discuss sensitive topics on Facebook. It can be risky to share personal views on social networking sites generally, as these spaces are not always as safe as they appear. This article explores the opportunities and challenges of creating an online safe space for young people to talk freely about sexuality. In addition, it discusses the challenges for sexual health organisations in creating safe spaces, and suggestions about how such organisations can use them to improve online learning.

Social media has become an integral part of everyday life for young people throughout the world. Kenya has a high internet penetration rate of 68.4 per cent, ${ }^{2}$ with 11 per cent of the population using Facebook, a percentage that has been steadily increasing over the past five years with the spread of mobile phone use. ${ }^{3}$ Some sexual health organisations, like Love Matters, make use of this widespread adoption to provide young Kenyans with a safe online environment to learn and share information on sexuality, love and relationships. Love Matters Kenya is part of the global Love Matters project, which is active in several countries: India, China, Mexico, Venezuela, Egypt and Kenya. Each region uses several new media platforms to engage its audience, including a website, email, Facebook page, and Twitter. For Kenyan users, Facebook is an important gateway to the Love Matters website. With over 800,000 fans in 2015, it is a place to have conversations with peers and the organisation itself.

Sexuality is regulated by social norms that limit self-expression for young adults everywhere in the world, but these norms are particularly rigid in Kenya. It is unusual to discuss sexual matters in public, and silence is the norm for Kenyan families (Mbugua 2007). This can create barriers that prevent experimentation, which is an important period in adolescent development (Gupta 2000). Social media is thought to lower these barriers and help young adults talk more freely. Freedom enables conversations about sensitive topics, as it provides a space to experiment with their sexuality and sexual values; however, it can also create space for bullying and online harassment (McKenna, Green and Smith 2001). It is therefore important to examine the way Love Matters Kenya facilitates an online safe space on Facebook for its audience members to renegotiate sex and relationship taboos.

Social media is increasingly used as a tool for engaging people about sex and relationships. There are several reasons for this development: social media makes the information easily accessible; there are a lot of 
different sources to choose from; there is less social stigma attached to obtaining information through semi-anonymous communication; and people can discuss things safely with peers as well as experts (Baelden, van Audenhove and Vergnani 2012; Ralph et al. 2001). ${ }^{4}$ Digital interactivity and online peer-to-peer information sharing are valuable benefits of using social media for sex education. With this participatory approach, the goal is to create a social learning environment where success depends on establishing online interpersonal communication, in the hope that this communication will continue in the offline world and spark off conversations among families and peer groups (Baelden et al. 2012). Young people are not only consuming information passively, but also reflecting on it critically.

Although social media can be an effective way to engage young people, the online world can also be a hostile place where people overwhelmingly women - are bullied, controlled and silenced (Pearce and Vital 2015; Katzer, Fetchenhauer and Belschak 2009). For example, Katzer et al. (2009) observed that verbal and psychological bullying in online spaces is a common practice, and that various hostile behaviours are practised online, including blackmailing, spreading rumours, and systematic exclusion of others. Threats of bullying and stigma also affect peer-to-peer sharing on social media (Evers et al. 2013), so it is important to research how sexual health organisations can foster a safe online space that minimises the effects of these negative behaviours. The creation of free, safe spaces is an essential aspect of optimising online learning.

So what is a safe space and how do organisations or people create one? Gender studies often define safe spaces as sites that are free from harassment and violence, where 'one can speak and act freely, form collective strength, and generate strategies for resistance' (Kenney 2001: 24). Safe spaces are 'any environment in which individuals feel free and able to communicate and express ideas without fear of retribution, intimidation, marginalization or silencing' (Brown 2011: 7). Both definitions stress the ability to speak freely; they are spaces for self-expression. In general, this involves monitoring who can join the group and keeping track of discussions, but in some online spaces such as a Facebook page - this is impossible. It is an open space, and as such the administrators cannot make it completely 'safe'.

A distinction can be made between safe spaces that are 'separative' and those that are 'inclusive' (Rosenfeld and Noterman 2014). A separative safe space is a space where people who share similarities close themselves off from mainstream society and norms, not allowing others in (ibid.). A problem with separative safe spaces is that they are depoliticising; a complete separation also means losing a voice and influence in the dominant public sphere. For Love Matters, completely closing the group would go against its goals to create an online space where people from different backgrounds can learn from each other's differences and openly discuss love and relationship issues. 
Inclusive safe spaces, on the other hand, are understood as an egalitarian ideal. In various theories of education (Brown 2011) the classroom is a space where every student, even those with marginalised identities, can develop and voice their opinions. This kind of safe space is more in tune with what Love Matters is trying to create online. Nevertheless, these inclusive safe spaces are arguably as problematic as separative safe spaces; by focusing solely on safety they risk becoming conformist, which undermines real dialogue and debate (ibid.; Rosenfeld and Noterman 2014). With lots of diverse perspectives it is often difficult to maintain respectful communication and reflect critically on each other's opinions. It is inevitable that power differences emerge in the group, as not everyone can make themselves heard (Rosenfeld and Noterman 2014). Thus, the space becomes risky for some members of the group, who may not feel completely free to express themselves.

There are also specific aspects of online safe spaces on Facebook that differ from the offline context. First, it is not easy to control who can participate in an online safe space on Facebook. This has its advantages and disadvantages. One advantage of the online environment is that it enables individuals to observe and learn from the group without the other members knowing that they are present (Crawford 2009). Listening while being silent is a valid strategy for young adults to mitigate the risk of voicing their opinions online (Pearce and Vital 2015). A disadvantage, however, is that you never know who your audience is, because you never know who is listening in. Offline communication is safer, in some circumstances, because you know who is present and your message is not visible to a large network. Second, different social media platforms have different design functions that influence how people communicate with each other; these influence interactions and the way people build online relationships and trust. For example, on Facebook people can 'like' comments on the Facebook wall. The more 'likes' a comment receives, the higher it is displayed in the comment thread, making it more visible.

While we acknowledge that online spaces are inherently complex and paradoxical, we must also remember that they are emerging spaces (Rosenfeld and Noterman 2014). Safe spaces, both inclusive and separative, are necessary when people feel they have no voice in society or safe place where they can share their experiences. They are an important and useful means of minimising the risk that voices are not heard.

Love Matters offers an opportunity to observe conversations online and to directly interact with audience members. As researchers we 'listened' to conversations, but also connected and talked to people directly through a private Facebook group that we set up. Based on these observations, we created a theoretical framework as an initial understanding of how people communicate on Love Matters social media platforms. This formed the basis for the topics discussed in an online focus group consisting of audience members from the Facebook page. This method of online ethnography (Kozinets 2009) enabled 
us to collect in-depth data about how audience members of Love Matters Kenya use the Facebook page as an online safe space. Instead of focusing on statistical data, these methods deal with how and why people considered it to be 'safe' (Postill and Pink 2012).

\section{Methods}

This study was conducted as a partnership between a master's student at Utrecht University, Netherlands, and the Love Matters team. Various Love Matters members gave their input to shape the research and allowed access to all communication platforms. The researchers had relative autonomy to choose the research scope and direction. Through the partnership with the team, it was also possible to turn to other team members who were part of the online interaction to 'validate, dispute or expand upon the interpretations' (Kozinets 2009: 75).

We collected observation data during a six-week period in March-April 2015. During this time, we listened to conversations and observed naturally occurring behaviour online. We analysed the data using open and axial coding, then modified the approach to a more participatory one, establishing a separate Facebook group where we could ask participants questions about their experience of the main Love Matters page (Hennink, Hutter and Bailey 2011). We collected this 'co-created' data during a one-week online discussion group in October 2015.

In traditional ethnographies the standard fieldwork method is participant observation. This also applies to online ethnography, and through participant observation a researcher can collect data that are 'co-created with culture members through personal and communal interaction' (Kozinets 2009: 98). Only through this method can we reach a culturally embedded understanding. However, because the focus of the study was a community that discusses sensitive subjects online, by doing covert observation at the beginning of the fieldwork, it provided an opportunity to understand various online behaviours.

Online fieldwork has challenged the traditional understanding of ethnography. With classic fieldwork, an ethnographer can remain immersed in a culture or specific field site for extended periods of time. With online fieldwork, however, what it means to be physically immersed has changed (Hine 2000). Because we did not travel to Kenya, we were unable to have any face-to-face interaction with the people we encountered online. Hine (ibid.) would call the study incomplete, but as Boellstorff (2008) argues, researchers can study online sociability and virtual worlds on their own terms. Every ethnography, both online and offline, involves some degree of partiality, because doing ethnography is always 'socially constructed and contextually determined' (Kozinets 2009: 62).

For the participatory approach, as mentioned above, we created a focus group on the Facebook platform. The Love Matters Kenya Facebook group is an active community where members are used to participating 
in discussions about numerous topics related to sex and relationships. It was therefore quite easy to find enthusiastic volunteers to participate in the focus group, and group discussion was an effective way to learn more about their views, beliefs, and experiences. Since we had already analysed and collected observations on Love Matters audience interactions, we used the focus group to clarify, extend or challenge these data. In addition, it is important to mention that the researchers' participation in the focus group influenced the discussion. In comparison to the Love Matters Facebook page, the power dynamics shifted in the focus group. Although we were still in the role of expert and researcher, guiding the discussion, participants now had the option of introducing their own topics of interest. During the discussion week respondents would, for example, post questions they had about why women or men cheat on their partners.

For this research, we used purposive sampling to recruit the respondents for the group (Hennink et al. 2011), and selected the respondents based on gender, age, country and engagement levels with Love Matters. The process of finding Facebook respondents lasted just over a month, and in the end we recruited 33 people: 19 men and 14 women. The respondents were all from urban areas, mostly the capital Nairobi and coastal city Mombasa. This is not surprising; living in an urban area increases the likelihood of having access to an internet connection. During this time we also engaged in private conversations with some of the respondents. Some of the stories they shared in these conversations are also discussed in the findings.

\subsection{Discussing sexuality in Kenya: anonymity and friendship}

Before examining the way people interact online, it is important to understand how young Kenyans feel about open discussions of sexuality in an offline context. All respondents agreed that it could be difficult to discuss sexuality in their culture. One male respondent stated: 'For women it's a shame to talk about it'. No one clearly addressed specific issues that men face when discussing sexuality, focusing instead on women, but two male respondents stated that talking about sex is difficult for everyone. A female respondent shared: 'It's a taboo; women are fined and punished if they dare share such topics. Women who do talk about it are considered to be prostitutes'. Another woman added:

Many communities share belief that women cannot talk about sex as then they are unfaithful. There is also poor introduction about sex; many of us grew up knowing that sex was an evil act hence you can't talk about it. And the first encounter very few people share how they felt about it, they prefer to remain silent (female respondent \#1).

By using words such as 'punished' and 'shame', they confirmed that Kenya is a society that avoids any verbalisation of sexuality; this is something that affects both men and women.

Online interaction is thought to lower barriers that prevent people from discussing sexuality openly, and anonymity is often cited as an important 
factor in creating an online safe space for self-expression. When people feel anonymous, they find it easier to share more personal information online (Ralph et al. 2011). Anonymity, however, provides a freedom that can also encourage participants to post offensive comments (Reader 2012). This in turn can make others feels less 'safe'. But in the context of social media, where anonymous communication is quickly becoming a thing of the past, the dynamic shifts. Facebook in particular has been successful in linking online profiles to real-world identities (Boyd 2012). Given this complexity, it was important to explore what role anonymity plays and how it is understood in enabling an online safe space for respondents.

Respondents in the Facebook group reported that they valued the ability to stay anonymous. They had different understandings of what this actually meant, however, because many were using profiles that revealed their real-world names and pictures. But anonymity is not always understood as being completely unidentifiable; for some group members, the physical distance of being online - whether or not they were using their real name to comment - was a form of anonymity in itself. Most respondents felt less secure about speaking openly in offline spaces than they did online, although one female respondent was very vocal about the confidence she felt in speaking out, whatever the situation. The majority, however, felt more comfortable in an online environment simply because they could write things down rather than speaking to someone directly. Online communication is not face to face and therefore feels less confrontational, whether anonymous or not. Complete anonymity for our respondents was therefore a relatively unimportant factor in creating an online safe space; rather, it was the physical distance and asynchronous communication that provided a sense of safety. In addition, the ability to choose when to be online and what personal information to share in their profile or comments boosted respondents' feelings of safety and supported self-expression.

Safety is closely connected to the sense of community, and communities cannot develop if members are completely unidentifiable. Social networking sites such as Facebook enable users to create a profile; with these profiles people present their identities online. This identity provides opportunities that can support and increase information-sharing, because it is easier for people to relate to one another, and build connections and trust in an online environment (Donath 1999). If communication is purely anonymous there is no build-up of past interactions. With an online identity people can build an online reputation, and this is a major source of online trust (Henderson and Gilding 2004: 504). A message from someone with an online identity contains a wealth of information about the sender (Donath 1999). On the Love Matters Kenya Facebook page some members build reputations as sexual health and relationship experts, commenting on Love Matters posts every day to increase their visibility. Two of these 'super-users' participated in the focus group and said that they often received and answered private messages from other audience members seeking advice. 
Online social relationships have become an important motivation for members to participate in the Facebook group. Access to information is often cited as the reason why people join virtual communities (Ridings and Gefen 2004; Wellman et al. 1996). However, finding social support and friendship are also crucial motivations for people to join communities and continue community membership (Ridings and Gefen 2004). While observing the Love Matters Facebook group, we noticed that finding new friends was a common online behaviour. People would often comment underneath a quote or remark they liked, 'please add me to your friends list', or 'I send you a pm'. The respondents in the focus group also emphasised the importance of friendships:

\section{People can become friends and that this friendship can lead through Love} Matters (female respondent \#2).

I can get a variety of answers and advice, meet friends. And if a problem of mine is something negative I won't feel alone in my problem (male respondent \#1).

Friendship and the ability to gain and earn trust can explain why social media is such a potentially powerful tool for sexual health organisations. Personal relationships in daily life are an important source of information on sexuality, love and relationships. Research has shown that young people share information on issues related to sexuality with their friends (Bleakley et al. 1992; Barker and Rich 1992) and that peer-to-peer learning can be more effective than learning from adults (Medley et al. 2009). These friendships are not confined to an online space, but often extend into the real world as young people experience the offline and online as 'mutually constituted' (Pascoe 2011; Evers $e t$ al. 2013). Respondents in the Facebook group confirmed this statement as they discussed the friendships they had developed through the Love Matters Facebook page.

\subsection{Facebook as a village square}

Sharing and commenting has become part of the information experience on Facebook. This is also what we observed on the wall of the Love Matters Kenya group. Being able to have fun with comments, connect with others, and share opinions - and to find people who listen, share information and engage in discussion about it - is exactly why people value Facebook groups. Engaging with information becomes a social activity, and this relationship between learning and socialising drives information-sharing across Facebook and other new media platforms. Since participating in this social information experience is an essential part of creating a safe space, it is essential for sexual health organisations to be aware of it. People in the Facebook community use the comment function to connect, often assessing their trustworthiness and viewing them as a potential source of information. In this space they exchange user-generated content with each other.

Yeah I like reading comments, because by reading them I get to learn different ideas and options which helps in decision-making (female respondent \#3). 
In these comments where you get to know how people can freely talk, share their experience thus you gain some information maybe on how to abstain, or how to remain faithful (female respondent \#4).

Through the comments they can see what other people are thinking. The comments are also a source of laughter and fun; as a female respondent noted, 'laughing is always healthy; some comments leave you in a joyful mood'.

Yet not all comments and connections made on the Love Matters Kenya Facebook page are supportive and trustworthy; there is a lot of misinformation, and negative, mean or pornographic content is also exchanged as part of peer-to-peer communication. It is important for sexual health organisations to understand how these comments influence online safe spaces. As with physical, offline spaces, the safety of a particular place always depends on the people who occupy it. As social media raises the issue of community and space, it creates discussions about what constitutes appropriate behaviour (Carey 2015). Respondents in the focus group, when asked about disruptive behaviour, commented:

I feel bad when people use some pages to joke or tease others, it's not good (female respondent \#5).

I hate it especially when a girl comments her opinion then u see all men reply as they thought she's lonely, I know they even inbox [send private messages to] girls but most of them are jokers (male respondent \#2).

To show that this kind of behaviour is not indicative of what the Love Matters Kenya Facebook group stands for, the respondents started talking about the friends they had made and social support they had received by participating. As one respondent pointed out:

Not all people have bad intentions, some became friends, then lovers, and finally they got married. I made several friends through Love Matters, real friends who I can call and seek advice (female respondent \#6).

If the goal is to create a safe space for people to express opinions, then a supportive community dynamic is important. In a supportive community setting, people share more information and are more responsive towards each other's viewpoints and opinions. For example, if Audrey's comment about her virginity, quoted in the introduction, had received a more supportive reaction, she could have responded and continued the conversation online.

Nonetheless, negative behaviours affect the community dynamic and make some people feel too uncomfortable to share their opinions with the group. We observed that when a topic was more transgressive, disruptive behaviour on the Facebook wall was more likely. This meant that there was less consensus in the post thread, and also less friending and small-talk conversations. 
People were more likely to make threatening comments when a topic was controversial; when discussing homosexuality or sex before marriage, for example, people often commented that anyone involved in these activities should go to hell. This creates a dilemma for sexual health organisations: how can they raise controversial issues while also fostering a supportive community? There is no perfect solution to this question, but one of the key elements is good moderation.

\subsection{The importance of moderation}

Moderation is a set of rules for social media managers on how to facilitate interaction and prevent abuse (Grimmelmann 2015). These codes of conduct are used to create an online community where everyone feels safe contributing to the discussion. It is a central factor in creating safe and supportive online spaces. An alternative approach to having a moderator is to encourage self-moderation: this is when members of a group with a strong belief in community values address unwanted behaviour themselves. Effective community or self-moderation is often hard to achieve. It relies on a group dynamic and often leads to reactive moderation, responding to comments after they are made.

While codes of conduct help social media managers make decisions about how to interact online, community guidelines communicate social norms to audience members. Members of the Love Matters Kenya Facebook page are asked to abide by these community guidelines, which aim to keep the conversation respectful; those who violate the guidelines get three warnings before they are permanently blocked. The Love Matters Kenya community guidelines consist of a vision of respectful online interaction and a warning about what will happen if you post anything offensive, abusive or graphic:

We want our Facebook page to be an open forum, so please keep comments and wall posts respectful. Remember, sex is a sensitive subject for many people, so tell us what's on your mind, but be mindful of others! To keep this page a safe and positive place, we will remove offensive, abusive or overly graphic posts. You can read our terms of use here: https://lovematters.co.ke/terms-use (Love Matters Africa Facebook 2016). ${ }^{5}$

Although moderation can be an important tool for minimising abuse and harassment and making online cooperation possible, it can be a difficult balancing act. If moderation is done too often and too strictly, it sends a signal that freedom of speech is not allowed (Wright 2006). Each Love Matters Kenya social media manager has some leeway to decide which comments to allow, which to block, and how to interact with followers. Sometimes these moderation decisions are easy, while at other times it can be difficult to know where to draw the line. For example, Love Matters routinely removes and bans people who post pictures of naked bodies and pornographic images. Comments where people post personal information, such as phone numbers or an address, are also deleted, as is commercial spam. Moderation decisions can be 
much more complex, however, as in the case of the comment below on a Facebook article where a man wrote about his attraction to both men and women:

\section{I think you should come and kiss me, then I will give you the best beating ever after that $u$ will know what want and what $u$ are, confused idiot (male respondent \#3).}

Love Matters does not delete comments like this on Facebook, even though these conversations are not respectful and may be even classified as abusive. Social media managers do not want to censor people, but also recognise that abusive comments have a negative effect on the community atmosphere.

Moderators can avoid excessive censorship and reduce the destructive influence of offensive comments by understanding the importance of small talk among the group and making sure that supportive comments are more visible. Rather than deleting comments, organisations can make use of conversations in the comments that are essentially small talk rather than information exchange. For example, comments such as 'lol', 'I agree', 'great comment', 'hi' or the 'like' button can be useful for the social media manager to guide online interaction. These small-talk conversations are called 'phatic communication': exchanges that are primarily concerned with forming social bonds and opening up lines of communication. The content itself is secondary, but it opens up channels for further conversation. For Love Matters, small talk is how audience members safely engage with information and with a wider community of peers. For example, if someone posted a comment on Facebook confessing their attraction for both men and women, the social media manager could 'like' the message or write a supportive comment underneath, such as 'thank you for sharing'. This acts as a signal to the Facebook community that the organisation and the experts are listening and paying attention to the online interaction. In addition, this supports the role of the social media manager as a gatekeeper to discussions of sensitive issues within the community. When audience members see that someone from the organisation is engaged in the conversation, they feel able to send private Facebook messages asking moderators to post about a particular issue on the timeline.

Love Matters has to connect with its audience on personal and emotional levels, and does this by supporting small-talk conversations and supportive, informative comments. Misinformation is often found in comment threads, and sometimes abuse, but moderators can minimise their impact by promoting more positive responses. It is this personal connection that makes people decide to enter into conversations and remain engaged with the central messages that Love Matters stands for. Moreover, it can motivate them to share and create content, while still remaining respectful of other people's opinions and viewpoints. It is therefore crucial for organisations such as Love Matters to build strong connections with their audience base. 


\section{Conclusion}

Young people experience the online and offline social worlds as 'mutually constituted' (Pascoe 2011): they share information, connect, and build relationships that move from offline to online and back again. If sexual health organisations want to influence the behaviour and attitudes of young people, they have to go to the places where young people spend time - both offline and online - and take part in their conversations (Ralph et al. 2011). For Kenyan youth, Facebook has become one of these places: 11 per cent ${ }^{6}$ of the population have a Facebook account and this percentage is steadily increasing. This study has limited itself to a discussion of safe spaces on Facebook and how sexual health organisations mitigate the challenges of creating and maintaining these spaces. Further research is needed to understand how sexual health experts can best participate in online spaces and how this influences digital peer-to-peer communication. In addition, the design and capabilities of other social media platforms, such as Twitter, influence whether or not young people perceive them as 'safe'. Cultural differences are also an important factor in understanding the way young people discuss sexuality, whether online or offline.

Through observing the Love Matters Kenya Facebook group, we found that peer-to-peer sharing and trust-building online were everyday activities. For young people, personal friendships are a credible source of sexual information, and Facebook connects these social relationships with reliable information. This makes it a powerful tool. Other studies have found that peer-to-peer sharing on social media can be difficult due to social stigma surrounding sexuality (Evers et al. 2013). However, the Love Matters Kenya Facebook group has been generally successful in creating an online safe space for young people to discuss love and relationship issues with their peers and the organisation. The element of safety is crucial, because it has such a strong influence on the quality of the learning experience.

A safe space is a place where people can share their experiences and voice their opinions without fear of abuse. This is not always easy to establish; on the Love Matters Kenya Facebook page people could be supportive, but we also observed abusive and controlling behaviours. So how is it possible to create an online safe space that also fosters free expression? This research led us to conclude that there are three central features of a positive, dynamic online group where learning about sexuality can thrive: (1) the ability to remain distanced, if not completely hidden; (2) online identities that enable users to form friendships; and (3) a sensitive and informed approach to moderation, taking into account the importance of small talk and everyday interactions.

In the context of a Facebook group, the first two criteria have already been met. Good moderation is therefore particularly important as a focus for sexual health organisations. This requires an effort to understand, support and invest resources in online community-building. However, the question emerges, are sexual health programmes actually 
allocating budget for maintaining online community-building while the community keeps growing, as they would if the community was offline? This study therefore recommends more research to understand the costs and benefits for sexual and reproductive health and rights (SRHR) programmes when investing in online communities.

\section{Notes}

1 We have given respondents pseudonyms.

2 www.internetworldstats.com/stats.htm.

3 www.internetworldstats.com/stats.htm.

4 See also: Marcotte (2015); Bay-Cheng (2001); Cooper and Griffin-Shelley (2002); Magee et al. (2012); Obono (2011).

5 www.facebook.com/LoveMattersAfrica/.

6 www.internetworldstats.com/stats.htm

\section{References}

Baelden, D.L. van Audenhove, L. and Vergnani, T. (2012) 'Using New Technologies for Stimulating Interpersonal Communication on HIV and AIDS', Elsevier Telematics and Informatics 29: 166-76

Barker, G.K. and Rich, S. (1992) 'Influences on Adolescent Sexuality in Nigeria and Kenya: Findings from Recent Focus-Group Discussions', Studies in Family Planning 23.3: 199-210

Bay-Cheng, L.Y. (2001) 'SexEd.com: Values and Norms in Web-Based Sexuality Education', Fournal of Sex Research 38.1: 241-51

Bleakley, A.; Hennessy, M.; Fishbein, M. and Jordan, A. (2009) 'How Sources of Sexual Information Relate to Adolescents' Beliefs about Sex', American Fournal of Health Behavior 33.1: 37-48

Boellstorff, T. (2008) Coming of Age in Second Life: An Anthropologist Explores the Virtually Human, Princeton NJ: Princeton University Press

Boyd, D. (2012) 'The Politics of Real Names: Power, Context, and Control in Networked Publics', Communications of the ACM 55.8: 29-31

Brown, E.K. (2011) 'Safe Spaces in Online Learning: The Role of Faculty Perception in Design and Practice', $\mathrm{PhD}$ dissertation, Graduate School, University of Georgia, https://getd.libs.uga.edu/ pdfs/brown_eric_k_201105_phd.pdf (accessed 24 April 2016)

Carey, J. (2015) 'Digital Media and the Transformation of Space', in G. Einav (ed.), The New World of Transitioned Media Digital Realignment and Industry Transformation, New York NY: Springer

Cooper, A. and Griffin-Shelley, E. (2002) 'Introduction. The Internet: The Next Sexual Revolution', in A. Cooper (ed.), Sex and the Internet: A Guide Book for Clinicians, New York NY: Brunner Routledge

Crawford, K. (2009) 'Following You: Disciplines of Listening in Social Media', Continuum 23-4: 525-35

Donath, J. (1999) 'Identity and Deception in the Virtual Community', in M.A. Smith and P. Kollock (eds), Communities in Cyberspace, New York NY: Routledge

Evers, C.W.; Albury, K.; Byron, P. and Crawford, K. (2013) 'Young People, Social Media, Social Network Sites and Sexual Health Communication in Australia: "This is Funny, You Should Watch It", International fournal of Communication 7: 263-80 
Grimmelmann, J. (2015) 'The Virtues of Moderation', Yale Fournal of Law and Technology 17: 42-109

Gupta, G.R. (2000) 'Gender, Sexuality and HIV/AIDS: The What, the Why, and the How', Plenary Address XIIIth International AIDS Conference: International Center for Research on Women (ICRW): 1-8, www.med.uottawa.ca/sim/data/assets/documents/ DurbanSpeech.pdf (accessed 2 July 2016)

Henderson, S. and Gilding, M. (2004) "'I've Never Clicked this Much with Anyone in my Life": Trust and Hyper Personal Communication in Online Friendships', New Media and Society 6-4: 487-506

Hennink, M.; Hutter, I. and Bailey, A. (2011) Qualitative Research Methods, London: Sage Publications

Hine, C. (2000) Virtual Ethnography, London: Sage Publications Katzer, C.; Fetchenhauer, D. and Belschak, F. (2009) 'Cyberbullying: Who are the Victims?: A Comparison of Victimization in Internet Chat Rooms and Victimization in Schools', fournal of Media Psychology 21.1: 25-36

Kenney, M.R. (2001) Mapping Gay L.A.: The Intersection of Place and Politics, Philadelphia PA: Temple University Press

Kozinets, R. (2009) Netnography: Doing Ethnographic Research Online, Thousand Oaks CA: Sage Publications

Magee, J.C.; Bigelow, L.; DeHaan, S. and Mustanski, B.S. (2012) 'Sexual Health Information Seeking Online: A Mixed-Methods Study among Lesbian, Gay, Bisexual, and Transgender Young People', Health Education and Behavior: The Official Publication of the Society for Public Health Education 39.3: 276-89

Marcotte, R.D. (2015) 'Let's Talk about Sex: Australian Muslim Online Discussions', Contemporary Islam 9: 65-84

Mbugua, N. (2007) 'Factors Inhibiting Educated Mothers in Kenya from Giving Meaningful Sex-Education to their Daughters', Social Sciences and Medicine 64: 1079-89

McKenna, K.Y.A.; Green, A.S. and Smith, P.K. (2001) 'Demarginalizing the Sexual Self', Fournal of Sex Research 38.4: 302-11

Medley, A.; Kennedy, G.; O’Reilly, K. and Sweat, M. (2009) 'Effectiveness of Peer Education Interventions for HIV Prevention in Developing Countries: A Systematic Review and Meta-Analysis', AIDS Education and Prevention: Official Publication of the International Society for AIDS Education 21.3: 181-206

Obono, K. (2011) 'Media Strategies of HIV/AIDS Communication for Behavior Change in South West Nigeria', Africana 5.2: 147-70

Pascoe, C.J. (2011) 'Resource and Risk: Youth Sexuality and New Media Use', Sexuality Research and Social Policy 8.1: 37-50

Pearce, K.E. and Vital, J. (2015) 'Performing Honor Online: The Affordances of Social Media for Surveillance and Impression Management in an Honor Culture', New Media and Society 1-18 Postill, J. and Pink, S. (2012) 'Social Media Ethnography: The Digital Researcher in a Messy Web', Media International Australia, http://blogs.bournemouth.ac.uk/research/files/2013/04/PostillPink-socialmedia-ethnography.pdf (accessed 4 May 2015) 
Ralph, L.J.; Berglas, N.F.; Schwartz, S.L. and Brindis, C.D. (2011) 'Finding Teens in Their Space: Using Social Networking Sites to Connect Youth to Sexual Health Services', Sexuality Research and Social Policy 8: 38-49

Reader, B. (2012) 'Free Press vs Free Speech? The Rhetoric of Civility in Regard to Anonymous Online Comments', fournalism and Mass Communication 4: 495-513

Ridings, C.M. and Gefen, D. (2004) 'Virtual Community Attraction: Why People Hang Out Online', Fournal of Computer-Mediated Communication 10.1, http://dx.doi.org/10.1111/j.1083-6101.2004. tb00229.x (accessed 18 January 2017)

Rosenfeld, H. and Noterman, E. (2014) 'Safe Spaces: Towards a Reconceptualization', The Roestone Collective 46.5: 1346-65

Wright, S. (2006) 'Government-run Online Discussion Fora: Moderation, Censorship and the Shadow of Control', British fournal of Politics and International Relations 8: 550-568

Wellman, B.; Salaff, J.; Dimitrova, D.; Garton, L.; Gulia, M. and Haythornthwaite, C. (1996) 'Computer Networks as Social Networks: Collaborative Work, Telework, and Virtual Community', Annual Review of Sociology 22: 213-38 
This page is intentionally left blank 


\title{
New Digital Ways of Delivering Sex Education: A Practice Perspective*
}

\author{
Linda Waldman and Isabelle Amazon-Brown
}

\begin{abstract}
This article explores new, under-researched genres of sex education for adolescents in sub-Saharan Africa resulting from access to the internet through mobile phones. It examines the history of developing online health information platforms tailored for youth through the experiences of digital developers and the reflections of users. Unlike traditional sources of sex education, the internet offers portability, anonymity, informality, 'personalised' responses, and the ability to interact with peers who are not local or part of face-to-face networks. This article draws on a literature review, complemented by qualitative and quantitative material generated by EverylMobile in its production of online health communities for young people. We found massive enthusiasm for online sex education in Africa but little knowledge about how young people use, perceive and respond to this. We recommend that practitioners, funders and researchers invest more in understanding not only the many fantastic opportunities associated with digital sexual and reproductive health and rights (SRHR) information, but also the interwoven contradictions, challenges and potential for misuse.
\end{abstract}

Keywords: Sex education, digital forums, sub-Saharan Africa, adolescence, sexual and reproductive health.

\section{Introduction}

Sex education in sub-Saharan Africa has long been a contested area, with some advocating that young people need comprehensive, upto-date information on sexual and reproductive health and rights (SRHR) and others preferring these topics to remain secretive. Despite this, young people have always found ways to access sex information, although often of dubious health quality. This article explores a new and under-researched avenue for adolescent sex education in sub-Saharan Africa, namely access to the internet through mobile phones. Although sex education (Iyer and Aggleton 2015) and the availability of sexualised material on the internet has received attention, there is little exploration of the internet as a tool for delivering accurate 
sex education to young people outside the formal health and education domains, and almost nothing on social media forums that delivers this (Talukdar 2013; Simon and Daneback 2013; Guse et al. 2012). This article addresses these gaps in the literature through first examining the history of developing online health information platforms tailored for youth through the experiences of Every1Mobile, a digital development agency, and asking about the challenges that digital education practitioners experience. Second, the article explores what is currently happening in the field of digital sex education in sub-Saharan Africa through users' engagement with digital sex education services and, in particular, with an online platform named 'smartSex', in eight countries (Ghana, Kenya, Nigeria, Tanzania, South Africa, Zambia, Zimbabwe and Uganda).

\section{Background}

Adolescence and youth are times of exploration, risk taking, development and identity formulation (Anthony 2011; Simon and Daneback 2013), during which health and sexuality become increasingly prominent. As adolescents become conscious of their bodies, they experiment, explore and learn about their sexuality. They are, at the same time, exposed to a wide range of SRH challenges, including sexual activity at a very young age, HIV (human immunodeficiency virus) and sexually transmitted infections (STIs), unintended parenthood, multiple partners, intergenerational and/or forced sexual relationships and unequal power relations (Speizer 2011; Hervish and Clifton 2012). Accurate information about SRHR is thus an important means of ensuring healthy youth are able to make informed decisions that enhance their wellbeing. Yet in many parts of the world, access to SRHR information is restricted, safeguarded by gatekeepers, or, if available, it comes too late and in inaccessible formats (Anthony 2011). At the same time, health systems tend to overlook adolescent health because adolescents are generally considered to be healthy and because health statistics seldom isolate adolescents, thus making their health needs invisible (Temmerman, Khosla and Say 2014; Berer 2014; Hampshire et al. 2015, Patton et al. 2014: 385). Also, because the provision of these services to adolescents and young people is an acknowledgement of their sexual lives, which may run counter to prevailing religious or cultural ideologies that deny adolescent sexuality, there is often discomfort and reluctance about funding and enabling access to services.

Sex education, often delivered in schools as part of a national curriculum, is a highly contested area, which reflects political, moral and cultural debates (Simon and Daneback 2013). In Western countries, deliberations about whether sex education should emphasise 'fear and prohibition' or 'pleasure and empowered choice' continue (see Iyer and Aggleton 2015). In many other parts of the world, providing scholars with information on sex is seen to encourage sexual immorality and experimentation.

The internet and digital technology have resulted in an explosion of opportunities for SRHR information, which are usually outside 
formal government health and education domains. Online sites offer a wide range of innovative ways for young people to acquire SRHR information (Simon and Daneback 2013). Unlike other sources of health information, the internet offers portability, anonymity, the opportunity to formulate questions and seek 'personalised' responses, and the ability to interact with peers who are not local and not connected through face-to-face networks.

\section{Sex education and country context}

Sub-Saharan Africa has the youngest population in the world, many of whom live in poverty (Hervish and Clifton 2012). Diverse factors influence the quality of SRHR information available to these young people, making it difficult to draw conclusions across the region. The political and legal context that shapes sex education and available SRHR information varies from country to country. For example, the legal age for sexual consent in Ghana, South Africa, Zimbabwe and Zambia is 16, while it is 18 in Nigeria, Tanzania and Kenya (Hervish and Clifton 2012). Homosexuality is illegal in Ghana, Kenya, Nigeria, Tanzania, Zambia and Zimbabwe (Amnesty International n.d.). Abortion is highly restricted, with complex country-specific regulations, and health information about abortion not readily available. In addition, patriarchal sub-Saharan Africa demonstrates a wide array of sociocultural and religious factors affecting young people's sexual experiences and access to health information. These include female genital cutting; child marriage; the failure to recognise women's independence, autonomy and decision-making rights; and educational biases and faith-based or religious interpretations of men's and women's roles.

School is the primary context in which sex education takes place and all eight countries discussed in this article offer some form of comprehensive sex education in schools (Adepoju 2005; UNESCO and UNFPA 2012; Government of Ghana 2003). In sub-Saharan Africa, over 70 per cent of children attend primary school (Hervish and Clifton 2012). While there are concerns about secondary school drop-out rates affecting who has access to sex education, Kenya, Uganda, Zambia, Zimbabwe and South Africa offer some form of sex education in primary schools, and other countries, such as Ghana and Tanzania, have higher levels of progression to secondary school (UNESCO and UNFPA 2012).

SRHR information provided at schools is usually highly selective, primarily biological, and influenced by parents' and religious groups' ideas of what is appropriate. Many teachers (often male) are reluctant to teach these embarrassing subjects or include their own personal views, which may also incorporate and reinforce sexual harassment and violence (Lukale, Okondo and Racherla. n.d.). To date, there are no national comparative indicators that assess what is taught in classrooms. A review of the policies of Kenya, South Africa, Uganda, Zambia and Zimbabwe found in 2011 (UNESCO and UNFPA 2012) that, despite the wide variation between and within country-specific sex education, 
the material was age-appropriate; communication (and refusal) skills were reasonably well addressed; the biological processes of puberty were clearly presented; and some information on gender was provided. However, insufficient attention was paid to contraception methods, to the social, moral and religious context in which puberty takes place, and to gender inequality, gender-based violence, empowerment and human rights. Moreover, 'references to sexuality tended to be negative and fear-based', emphasising a moralistic approach and overlooking power dynamics and social norms that negatively influence young people's sexual health (UNESCO and UNFPA 2012: 4). In 2013, Kenya, South Africa, Uganda, Tanzania, Zambia and Zimbabwe affirmed their renewed political will to address SRHR through sex education and other means in the East and Southern Africa Ministerial Commitment meeting in Cape Town (UNESCO 2015).

In sub-Saharan Africa, first sexual encounters tend to be experienced while still young: the median age for women is $16-18$, and for men 17-20, but this varies considerably across the countries (Hervish and Clifton 2012). Contraceptive usage is low in all countries except Zimbabwe. Adolescent birth rates are high, with girls aged 15-19 accounting for 16 per cent of all births. HIV infection is also high across sub-Saharan Africa. Many of sub-Sahara's HIV-positive adolescents contracted the virus 'vertically', either before or during their birth. Most young people are, however, unaware of their HIV status. For example, in Tanzania, only 40 per cent of women and 25 per cent of men aged 15-24 have been tested. Many adolescent girls' first sexual experiences result from coercion; high rates of child marriage occur; and girls in their teens are at greater risk of sexual violence than older women (Hervish and Clifton 2012).

It is clear that, despite the diversity of legal, political, sociocultural and educational contexts in these countries, young people are engaging in a wide range of sexual activities and are not receiving comprehensive SRHR information from conventional sex education programmes in schools. Over the past ten years or so, a revolution in mobile phones and internet access has made it possible for these youth to access SRHR information through online social forums.

\section{Developing sex education online}

Young people around the world use the internet to access SRHR information (Guse et al. 2012; Best, Manktelow and Taylor 2014; Simon and Daneback 2013). New social media platforms have emerged that facilitate online digital interactions with young people and provide accurate, good-quality SRHR information. These platforms fill a much-needed gap, as few other sex education sources are actively used by young people (Gray et al. 2005).

The increasing penetration of mobile phones, including internetenabled feature phones, ${ }^{1}$ makes it possible for young people in Africa, across a range of different socioeconomic strata, to access the internet 
(see Hampshire et al. 2015; Pfeiffer et al. 2014). This is witnessed in the massive uptake of platforms such as Whatsapp, the Opera Mini mobile web browser and the South African instant messaging service, Mxit, making it possible for users to send and receive information at lower costs than standard SMS and web browsing. Opera Mini, for example, reduces feature phone web browsers' data usage by 80 per cent, and Mxit gained popularity because it allowed users to send messages at less than 1 rand (or $£ 0.05$ ) per message.

One of the first organisations to recognise the opportunities presented by this new technology was Every1Mobile, a digital development agency that leverages the reach of the mobile web to deliver social impact programmes. In 2008, upon realising the volumes of young South Africans using Mxit, Everyl Mobile started developing basic educational content and making it available to Mxit's users, at one time numbering at least 30 million (Chigona et al. 2009). The online platforms that EverylMobile developed for young people and the provision of SRHR information through these platforms form the focus of this article.

\section{Materials and methods}

This article draws on a literature review, complemented by the experiences and reflections of digital sex educators in the process of designing and developing online material.

No new data has been collected for this article. Rather it relies on qualitative data, which has been anonymised, and quantitative material, analysed at an overall population level, already gathered by EverylMobile to assess user profiles, engagement and feedback. This includes user surveys previously undertaken by Everyl Mobile that provide an indication of users' opinions on sexual health education as well as data drawn from visits to, and feedback on, mobile websites with users in Ghana, Kenya, Nigeria, Tanzania, South Africa, Zambia, Zimbabwe and Uganda and users' spontaneous commentary and feedback. Every1Mobile also collates data about the devices used to access smartSex (see Section 6). This shows that 97.5 per cent of users access the internet via mobile phone, of which 63 per cent use feature phones and 37 per cent use smartphones. Additional information about users is available to EverylMobile through users' Internet Protocol (IP) addresses, which indicate which country a user is in and whether a user is a new or repeat visitor to a particular site. Other sociodemographic information depends on whether users have registered with smartSex and on what they choose to reveal. On Mxit, users must log in, entering their age, gender and country before accessing the platform. This is ideal from a data analysis perspective, as traffic and engagement data can be correlated with demographic data, presenting a detailed picture of users and their engagement. This demographic data is, however, not always reliable, as users may provide fake information, for example, Every1Mobile has a small number of 99-year-old users! Moreover, as discussed below, Every1Mobile does not insist on registration. 


\section{Results}

\subsection{Developing an online platform}

Every 1 Mobile's first portal, called 'Bsmrt'? provided basic information on English, history, science, mathematics, biology, physics, engineering, career guidance, etc. Bsmrt had to be added as a 'contact' on the Mxit app and was not discoverable via a browser or search engine. The user had to click on the contact to open it, before browsing the service as if using a basic web page, all from within the Mxit application. ${ }^{3}$ Users could then use Bsmrt's educational or entertainment services, and add the service as a contact if they wanted to access it regularly. Once added, the contact - and hence the content - could be accessed at any time as long as the user had a small amount of data allowance to browse with.

Every1Mobile's founders believed that digital services such as Bsmrt could be developed into online communities, where users could access educational content, get advice and support, and share their experiences and opinions. The underlying idea was that services could be further developed not just to facilitate access to information or changes in attitudes, but also to change behaviours - with systems engineered to enable the tracking of such behaviours in the real world. For example, an early project, smartEyes, allowed users to learn about eye health, take basic eye tests and be directed to the closest point of delivery for a free eye test and glasses. Every1Mobile's founders believed that this 'results-based delivery' model would disrupt traditional aid models, creating a virtuous circle where attitude and behaviour change could be provoked, tracked and proven, at scale.

Before this could be achieved, however, EverylMobile needed to demonstrate that it could attract high volumes of users. It experimented with an array of topics (information on voting in the South African elections, sport scores, literacy and numeracy education) and with different types of content (spelling quizzes, games, brain teasers, short stories). All of this material was available online and free to users.

Every 1 Mobile's philosophy has been to use its communities to enhance users' resilience. The information and exchanges available in their online communities aims to improve users' ability to deal with and adapt to the challenging situations they experience living in impoverished contexts. EverylMobile has therefore tried to provide young people with a safe online space where users feel supported and listened to and can gain confidence in their ability to shape their own futures. Everyl Mobile frequently consults users via surveys on new content and service ideas, offering them opportunities to trial beta versions ${ }^{4}$ and share feedback. Through these activities, Every 1Mobile developed Bsmrt into a youthcentric online community. Bsmrt was a success with more than 42,000 users in its first year. Of 3,000 users surveyed in 2010, 70 per cent claimed to 'love it' and 76 per cent to find it useful.

Mmm I love Bsmrt more than I love my boyfriend lols ${ }^{5}$... I really enjoy your company (female, Bsmrt user, 24). ${ }^{6}$ 
Figure $1 \mathrm{~A}$ feature phone displaying the smartSex home page

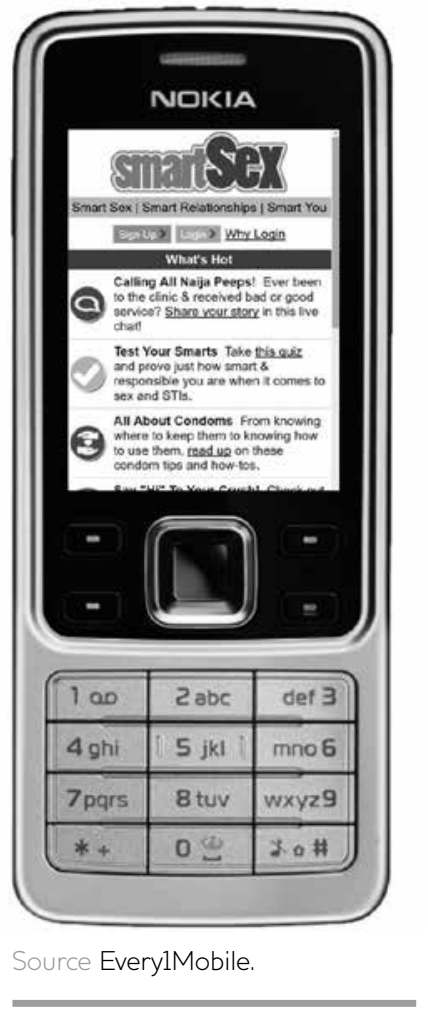

I love Bsmart coz it helps me out with my studies, I never get bored when using it... I always tell my friends to try it... but they laugh coz they already using it (male, Bsmrt user, 19).

This app... has everything you're looking for... Now we only need an app to download food (male, Bsmrt user, 17).

Every 1Mobile used Bsmrt and other 'proof of concept' online communities to show potential funders in the development sector that it is possible to reach thousands of African youth with interactive content, via mobile. This online connection can be used not only to provide young people with information, but also to engage them in an ongoing dialogue - an advantage over traditional mass communication means, such as radio or television, and school sex education programmes where students are encouraged to learn but not share their views, let alone their needs.

One organisation attracted to Every 1 Mobile's platforms and its potential for ongoing engagement wanted to research the suitability of a new menstrual cup for young South African women. It was particularly encouraged by Bsmrt's most popular feature, a sex and relationship question and answer (Q\&A) service called 'Talk and Tango' where users could ask an expert questions. Launched in October 2012, 'Talk and Tango' generated 155,000 page views in its first month. EverylMobile proposed, working with its new partner, to develop smartSex, an online community formed around the topics of SRHR. smartSex was launched on Mxit in January 2013, aiming to be the 'go-to' place for young people who wanted reliable, non-judgemental advice on sex and relationships (Figure 1). It included the following features:

1 Expert Q\&A - users send in questions, and online experts respond to a selection of questions every day, which are then published anonymously for the whole community.

2 Surveys and polls - users are asked their opinion on a wide range of topics, usually in the form of multiple choice questions.

3 Sex education 'manuals' - easy-to-understand articles on subjects such as puberty, pregnancy or masturbation.

4 Quizzes - users test their knowledge on the 'manuals' via multiple choice questions and are provided with the correct answers.

5 Peer2Peer advice swap - each week, a realistic scenario is presented and users are encouraged to share advice and support.

6 Experience sharing - users share their personal experiences on the week's topic.

7 Additional features - a 'photo booth' where users can share photographs, a feedback section, and register for free updates.

In its first three months, smartSex was accessed by over 700,000 users, primarily in South Africa, and delivered an average of 10,000 respondents to surveys commissioned by the partner organisation. 
In an effort to increase its audience and expand the number of countries reached by smartSex, EverylMobile quickly sought alternatives to the Mxit platform, as its popularity was declining. It also launched smartSex via Africa's most popular mobile browser, Opera Mini. ${ }^{7}$ Opera Mini showcased smartSex and other EverylMobile sites under its Education and Health 'suggested links' to users in South Africa, Nigeria, Ghana, Kenya, Tanzania and Zimbabwe and, more recently, Uganda and Zambia. smartSex today receives 155,000 monthly visitors from the web, while its Mxit users have dwindled to $1,678 .^{8}$

Building on the success of smartSex, EverylMobile designed and managed additional online communities (see Table 1). Some of these communities have thrived and continue to attract large numbers of users (smartchoices and HIV360) while others have not (smartSex No Yawa and No Regrets). smartSex remains the largest and most successful and, in the following section, we explore its users and related opportunities and challenges.

\subsection{The online user community}

Young people are engaging with health and sexuality online platforms and using mobile phones creatively and strategically to try to secure health care and health information (Hampshire et al. 2015: 97; Allison et al. 2012). To date, very little is known about who these users are and how they experience SRHR information online. Knowing more about the users is complicated by the technology, the users and the choices made by platform developers.

Table 1 EverylMobile's online communities

\begin{tabular}{|c|c|c|c|c|}
\hline Site name & Objectives & Funder & $\begin{array}{l}\text { Current monthly } \\
\text { users }\end{array}$ & $\begin{array}{l}\text { Current } \\
\text { geographical reach }\end{array}$ \\
\hline smartSex & $\begin{array}{l}\text { Provide reliable, open, } \\
\text { judgement-free SRHR } \\
\text { information and advice }\end{array}$ & $\begin{array}{l}\text { Original funder: women's } \\
\text { health charity; currently } \\
\text { funded by EverylMobile }\end{array}$ & 155,000 & $\begin{array}{l}\text { South Africa, } \\
\text { Nigeria, Ghana, } \\
\text { Uganda, Zambia, } \\
\text { Kenya }\end{array}$ \\
\hline smartSex No Yawa & $\begin{array}{l}\text { A targeted version of } \\
\text { smartSex }\end{array}$ & Grameen Foundation & $\begin{array}{l}\text { No longer active - } \\
\text { users redirected to } \\
\text { smartSex }\end{array}$ & Ghana \\
\hline No Regrets & $\begin{array}{l}\text { 'Edutainment' mobile series } \\
\text { to dramatise SRHR scenarios } \\
\text { in support of No Yawa }\end{array}$ & Grameen Foundation & No longer active & Ghana \\
\hline smartchoices & $\begin{array}{l}\text { Increase awareness, demand } \\
\text { and use of female-controlled } \\
\text { contraceptives }\end{array}$ & USAID & 35,000 & Zambia \\
\hline HIV360 & $\begin{array}{l}\text { Inform and support those } \\
\text { affected by HIV/AIDS }\end{array}$ & EverylMobile & 60,000 & $\begin{array}{l}\text { South Africa, } \\
\text { Zambia, Zimbabwe } \\
\text { Nigeria, Ghana, } \\
\text { Kenya, Uganda, } \\
\text { Tanzania }\end{array}$ \\
\hline
\end{tabular}


Figure 2 smartSex encourages users to $\log$ in

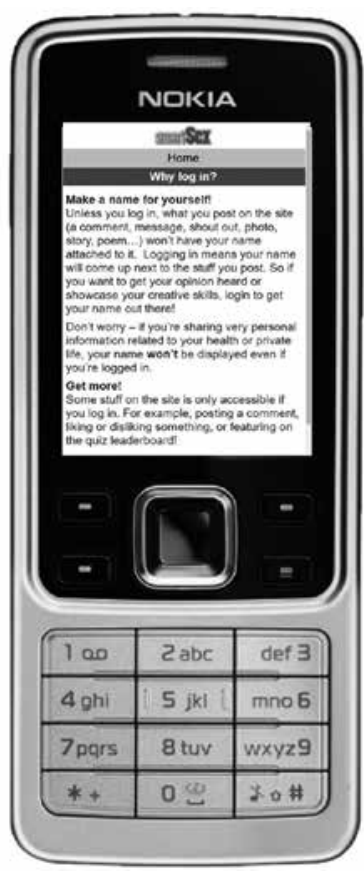

Source EverylMobile.
Users can discover smartSex through Mxit, Opera Mini or any browser of their choice and they may or may not have registered. The majority of smartSex users use the mobile web (including Opera Mini) to access the site. Here users can create an account and share information, although Every 1 Mobile does not insist on this. Rather, it encourages users to create accounts through incentives, with a user account making it possible to participate in competitions, use the 'like' or 'dislike' features and for users' names to appear on a quiz leaderboard (see Figure 2). As a consequence, EverylMobile has only a partial record of the overall demographics and user behaviours. This reflects the tension between the need to balance users' privacy and the need to gather sufficient data to tailor services to users, inform future developments and measure impact of the site.

Nonetheless, EverylMobile can at minimum track the countries where smartSex users live, based on their IP addresses; and for the smaller cohort who log in, their gender, age and additional data usage. Each of these is discussed in turn below.

\section{Users' countries of residence}

The geographic distribution of smartSex users is affected by smartSex advertising, Opera Mini's distribution patterns and by country specific factors such as infrastructure, handsets and credit affordability and web literacy. In May 2016, most smartSex users came from South Africa (35 per cent) and Nigeria (35 per cent), with Kenya providing 13 per cent of users and small proportions from Ghana ( 5 per cent), Zambia (4 per cent) and Uganda (1 per cent). These smartSex users are excited about discovering a service that is educative, provides SRHR information and allows them to talk openly about sex and sexuality:

Smrtsex you rock, keep it up, many get the chance to be free and they learn things which other parents don't talk about with their kids.

I love smart sex because it is very educative in all aspects and also a good platform to teaching the youth all about sex and its related issues.

Smrtsex teach us 2 b smrt $n 2$ respect our body, our partners nd our health as wel. it give us tips 2 be expets in sex $n 2$ knw more abt it nw $i$ undrstand many thngs abt relatgtionships $n d$ sex all thanks 2 smrtsex $i$ cn nw respect my gf $n d b$ romatic as wel.

What is unknown is the extent to which users' country origins, and therefore a range of sociocultural, political and technological factors, influence their desire to use the site. What is certain, however, is that a small pilot designed for South African teenagers has proven popular across a wide range of Anglophone sub-Saharan countries with little modification to its features or editorial approach.

\section{Gender}

Of the smartSex users who logged in between March and May 2016, 76 per cent were male and 24 per cent female. This gender balance highlights one of the significant challenges - and opportunities - of 
conducting SRHR education online. It reflects a global digital divide, where online access tends to be gendered (McMillan and Morrison 2006; Gray et al. 2005; Pfeiffer et al. 2014) because of a range of factors including sociocultural and gender norms, education levels, access to technology and money, and the freedom to spend time in an internet cafe.

For sexual health educators, this means that reaching women is more challenging than reaching men. By using additional advertising platforms, such as the popular chat app '2go', it is possible to achieve a better gender balance, but this has cost implications. More research is required to better understand how women are using smartSex and why it is accessed by fewer women and girls. Nonetheless, some young women have benefited from smartSex, particularly appreciating the women-only spaces:

I think smrtsex is great idea for all the shy girls out there. Most gals make the wrong decision coz they are misinformed, some just chose to make the wrong ones coz they are afraid to ask. Smrtsex is fun and you get to interact with other gals who know what you are going through.

The high numbers of male users is encouraging, not only as they too are neglected by health systems (Temmerman et al. 2014), but also because men tend to be the initiators and decision-makers of sexual encounters. This presents an opportunity to capitalise on their online activities, and to challenge their prevailing beliefs, practices and gender-based patterns of entitlement/responsibility. At least some male users have indicated that smartSex has made them rethink their sexual behaviours: '[The] smartSex crew is amazing cuz it... helps you making best decisions' (male, Nigeria, 15).

Age

The ages of smartSex users who logged in between February and April 2016 provides further insight into who is engaging with online sex education. The data shows that a wide range of users are represented, suggesting that both adolescents and young adults need accessible educational material. Most users (52 per cent of logged-in users) are aged 18-24; with a further 25 per cent aged 25-30. A few (6 per cent) are older, between 31 and 35 . This is influenced by the likelihood that older individuals can afford a phone, while demonstrating a need for information beyond the age groups usually targeted by sex education initiatives. It also challenges the assumption that different approaches are needed for different age groups. Indeed, the proportion of users aged 12-17 match the number of users in their early $30 \mathrm{~s}$. This is remarkable given the barriers to access, and the potential taboos associated with sexual information for young people. The proportion of users under 17 may be even higher, as evidenced by this feedback from a South African user whose profile lists him as 19:

You guys just inspire me by the amazing choices u give me(us), I mean, am just a 14 year old boy who has dreams about having sex. But you guys made me realise how I can get invested by any sicknesses. I would like to thank you for showing me the right steps and wait until my time. 
Figure 3 An example of a smartSex manual: 'Understanding Your Menstrual Cycle'

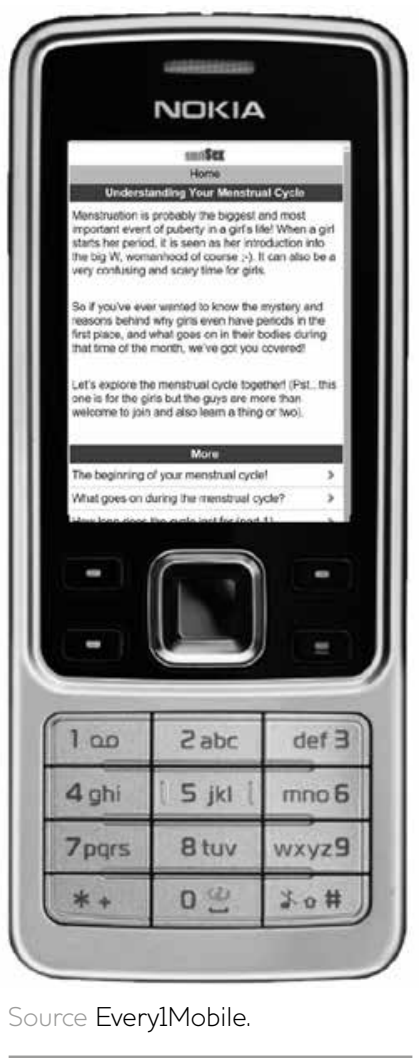

\subsection{Editorial and community management process}

smartSex designs features specifically to provide accessible and entertaining ways of receiving SRHR information. The most labourintensive features are the 'manuals' (see Figure 3), 90 of which have been published. In developing a manual, the smartSex content producer and community manager work with qualified SRHR experts, taking into account users' knowledge gaps, common myths, desired behaviours or attitude change. Topics are determined by users' frequent questions on a specific topic in the Q\&A section, direct user requests, and/or an assessment of gaps in smartSex's range of topics. In addition, smartSex may run a survey to inform a particular manual's focus and approach.

Experts also categorise and answer user questions. Over 300,000 questions have been submitted, of which around 3,000 have been answered. smartSex makes it clear that only a selection of questions are answered (discussed in more detail below). The experts prioritise questions not previously asked or those which relate to life-threatening or life-altering issues such as underage pregnancy, sexual assault or HIV.

\section{Editorial values}

smartSex takes the approach that no topic is off-limits. However, it also recognises the contested nature of sexual knowledge and information in the specific countries where smartSex is available. Thus, when producing content, smartSex staff keep in mind the different countries' gender norms and cultural contexts, yet strive to provide accurate, internationally accepted information. At all times they try and be cognisant about the ways in which information might be received and interpreted by users. smartSex has grappled with how to deliver SRHR information in conjunction with, and in recognition of, the specific cultural contexts in which users reside. It prioritises internationally recognised medical or psychological facts, placing the users' wellbeing above the laws and/or social norms of their countries. smartSex therefore explicitly recognises a range of sexual identities - gay, lesbian and heterosexual - and makes it possible for users to identify with them. Abortion - another highly contested topic - is dealt with similarly. For example, an article on underage pregnancy will talk about abortion alongside the range of other options potentially available. The article might also include a reminder that local laws differ and further advice should be sought.

\section{Language}

Key to smartSex's values is the tone and language used to deliver information. This includes everything from the way manuals and answers to users' questions are written to the way that content is curated. smartSex communicates in English, using informal language and clear, simple, non-medicalised terms. Words like penis or vagina are preferred over vernacular terms, but sometimes words like 'cum' might replace medicalised terms such as 'ejaculate', in an attempt to mimic a conversation, and to avoid appearing like a medical guide (see Figure 4). ${ }^{9}$ 
Figure 4 The smartSex manual on condom usage

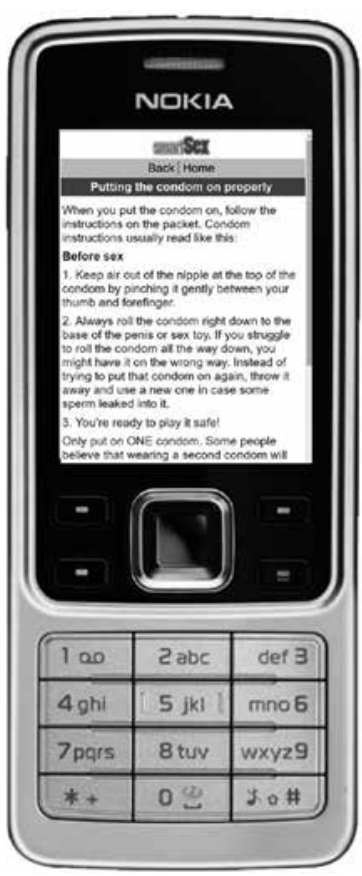

Source EverylMobile
This relaxed, non-stigmatising tone aims to make users feel comfortable and to replicate the experience of receiving information from a trusted, informed friend rather than from a parent, teacher or medical professional. Users also respond to smartSex in English, which may be a second language for many, and in 'text speak', incorporating many colloquial and non-English terms.

\section{User interaction and feedback}

smartSex does not allow users to chat privately on the site - all peer interaction is moderated before publication. This may seem to go against the concept of a community, however smartSex, as a non-funded site, does not have the resources to keep open comment areas 'safe' and protect both users' and the brand's reputation. This would require constant moderation to delete phone numbers or other inappropriate requests. Instead, users participate in curated 'peer2peer' exchanges which are reviewed by the community manager before being published. Using this mechanism, users can share experiences, advice or messages of support. Similarly, users are asked to share their experiences on specific topics. As they see experiences similar to their own, they can reflect on, and learn from them, be inspired by positive choices, and perhaps, feel a little less alone:

Sistahood has been of great help to me, it helped me alot since am in a long distance relationship $\mathcal{E}^{2}$ Going to be a teen mom very soon.. am grateful for all the experiences other sistaz have shared coz I've learnt from them (female user, 19).

Surveys are an important component of smartSex, enabling users to share their views and to communicate directly with smartSex, which are published back to the community. Since launching, smartSex has published over 50 surveys, gathering between 500 and 20,000 respondents per survey. Surveys have been undertaken for the Southern African AIDS Trust, Cell Life and Health Enabled, to gather real-time data from users on topics such as sexual health education, contraceptive use, and money spent on menstrual protection. smartSex surveys have also been used to project young people's voices in political and policy contexts. For example, during the Adolescents' Sexual and Reproductive Health Rights, Gender-Based Violence and HIV in Africa Symposium, in Zambia in 2014, young people's views on sex education were solicited and presented to representatives and policymakers from health systems, governments and non-governmental organisations (NGOs) and international partners.

Finally, quizzes, usually published hand-in-hand with manuals, are a favourite feature in smartSex. These allow users to test their existing knowledge, or see how much they have learned from a manual. Not only do they offer an interactive approach to sex education, they also make sex and sexual health less serious and scary: 'I just did the quiz and it was fun... I was corrected on things I thought were right'.

smartSex's feedback section asks users to share what they think about smartSex or what it could do better. Since the site's launch, smartSex 
has received over 11,000 feedback submissions, of which over 4,200 have been published. This user-focused approach harks back to EverylMobile's desire to make young people active participants in the development of the services they use. A systematic qualitative analysis of the feedback has never been conducted, but it is clear that smartSex is having a positive impact on young people across Africa. Users express thanks for information on topics previously closed to them, and suggest that this helps them think differently about their health, relationships and decision-making: 'Thanks guyz. I owe you one. Your advice is great and real. Am a changed person coz of you. Some habits are difficult to change but with you it's becoming easier' (South African user).

smartSex receives very little negative feedback from users. There have been very few suggestions that the service should be stopped, or that it is problematic. The most common complaint received concerns smartSex's Q\&A. The complaint is, quite simply, that a particular question posed by a particular user has not been answered. This illustrates the sheer challenge of dealing with 300,000 questions, many of which are repeat questions. This is emotionally and technologically challenging for smartSex staff, who remind users that they cannot address every single question and that many questions already have published answers.

\section{Discussion}

It is both exciting and challenging to provide comprehensive SRHR education across sub-Saharan Africa. But at the heart of this ability to educate at scale lies a significant ethical challenge. Not only do smartSex experts not have access to any contextual information about the users asking the questions, but their responses - aimed both at the individual and the smartSex community - do not refer to national laws or local service provision. Being able to provide progressive SRHR information that would otherwise be censored is considered a positive undertaking by many, and yet it is problematic not to provide locally relevant, context-specific information. smartSex experts try to provide advice that acknowledges cultural and legal differences, but establishing stronger ties with existing local SRHR service providers in order to offer a more contextually relevant service might be preferable. Indeed, this is envisaged in the Digital Inclusion 2014 report (GSMA 2014), which sees the incorporation of local content and e-government services as a significant new area of mobile development.

The focus on locally relevant content could, however, limit the range of information provided, swamping users with politically acceptable sex education on topics such as HIV/AIDS, while omitting areas such as abortion, sexual identity or homosexuality. While association with, for example, a ministry of health, could be positive in terms of formal acknowledgement, cultural alignment and service delivery, it could also put off users, restrict content and constrain the open values of the site (see Waldman and Stevens 2015). Every lMobile believes that its editorial policy is a significant factor in smartSex's success, providing users with a space free from the judgements or taboos they 
may encounter in their day-to-day lives: 'I did not have the slightest idea of this site where people can talk about Sex and its goodness and challenges without owing anyone an apology. Damn I love this, keep up the good work!' (male user, Zimbabwe, 28).

The debate on cultural relativism and human rights has long plagued development studies (Cowan, Dembour and Wilson 2001) and, in this particular context, considers outsiders' rights to provide 'progressive' sex education material against the rights of individual nations to restrict access to such information, often for cultural reasons. Yet, in a world where information flows freely, and where young people can access the internet through their mobile phones, regulation may in any case be impracticable. Increased partnerships between supportive local partners and online platforms such as smartSex, facilitated by the major donors, may provide a more comfortable middle ground, where scale can be achieved alongside more locally relevant advice. Governments, donors and other development partners could pay more attention to the needs of young people and recognise the democratic value of online services. Indeed, a 2013 poll conducted by Every1Mobile showed that young people would prefer to receive support and guidance from service providers: 49 per cent of respondents said they would ideally like to learn about sexual health from a health professional, 14 per cent from a family member, and 12 per cent from school. Only 9 per cent said they would prefer an online service. However, until shifts in local infrastructure, resources and expertise take place, and until profound changes occur in the way sex education is perceived, smartSex and its like will remain for many the only option. The notion of a middle ground - of finding consensus; of recognising the transnational culture that informs human rights; and of the ways in which aspects of human rights are already rooted in particular local practices - offers a way of moving beyond intractable debates on cultural relativism and universal human rights (Merry 2006; Prasad 2007). Such a resolution is, however, unlikely to occur through technology alone, requiring evidence, dialogue and political will. Online mobile sex education is an unprecedented opportunity for young people, health professionals and policymakers who wish to come together to acknowledge adolescent sexuality. It offers opportunities to inform young people, to better understand them, and give voice to their needs in global discussions about sexual health education provision.

Recent research has begun to review online sex education sites asking whether these sites really make a difference, concluding that while there is evidence of improved knowledge, more research is needed to confirm behavioural change (Guse et al. 2012; Allison et al. 2012). Almost half of smartSex users only visit the site once. Is this because they found answers to the questions they were looking for, or because they decided that the site was not for them? How much engagement is needed to change behavioural choices? One visit? Five? In EverylMobile's experience, users respond positively to advertising and promotion. The very high numbers of users in the first few months is partly in response 
to the excitement of Mxit in South Africa and the new possibilities of accessing online information using internet-enabled feature phones. Other peaks in user numbers can be related to specific advertising to encourage visits to smartSex and other online sites.

In-depth academic research that links online and face-to-face research, both qualitative and quantitative, into how young people are using online sex education remains in its infancy, along with understanding how these sites are changing the sex education landscape. For smartSex, better data would be provided if users were forced to log in to track their visits longitudinally and to know more about them. These very measures might alter the open and anonymous nature of the site that makes it so attractive to users. And while research remains focused on evidence of behavioural change (IICD 2014; Allison et al. 2012), few are looking at more intangible changes such as resilience and self-esteem, or attitude change.

\section{Conclusion}

Sex education, to date, has tended to reflect society's dominant political and sociocultural norms and to impose these - as expectations or threats - on adolescents and young people. Digital sex education has the potential to either reinforce or challenge these social norms and trends. It also has many advantages over conventional sex education, including its anonymity, apparent lack of adult control, ready availability and communication style (Talukdar 2013). Nonetheless, a 2013 thematic review of sex education online showed continued marginalisation of topics such as experimental sex, sexual pleasure, masturbation, abortion and of content derived from user feedback or preference (Simon and Daneback 2013). There are additional concerns: Are young people receiving paradoxical health information from multiple sources? How will young people deal with the contradiction between increased information on SRHR and a lack of medical services to address their health needs? How will Every 1 Mobile, and other internet-related facilities, address the challenge of locally relevant content (Gray et al. 2005)? How long will online space remain unregulated? Will governments increasingly seek to regulate and control these online spaces or should other international institutions play a regulatory role? What are the negative implications or unintended consequences of digital sex education that have yet to be realised? Will it be around issues of social isolation, increasing inequality, cyber-bullying, online harassment and exploitation or increased risky sexual behaviour (McMillan and Morrison 2006; Best et al. 2014; Allison et al. 2012)?

This article explores the historical development of an idea of using social media and young people's interest in online activities as a means of disseminating information, encouraging dialogue, promoting users' resilience and facilitating social development. Every 1 Mobile has not yet achieved its initial 'results-based delivery' goal, partly because of the challenges of integrating information with on-the-ground services that are often inconsistent or absent. It has, however, shown that young 
people in huge numbers and across multiple countries are interested in and excited by what smartSex has to offer. The numbers are staggering to social scientists: 155,000 monthly users, 11,000 feedback responses, survey responses of between 500 and 50,000. Yet, there are major gaps in what we know about how young people use, perceive and respond to online sex education in Africa. This is an opportunity as well as a challenge for practitioners, who find themselves sitting on an ever-growing mountain of data, with limited capacity to regularly analyse it unless the needs of a programme encourage them to do so. For funders or programme managers taking advantage of the online environment as an additional channel through which to conduct information dissemination or behaviour change, it can also be a poisoned chalice: the enthusiasm to embrace the new medium is often coupled with the reality of limited time, capacity and budgets with which to monitor and evaluate the success of the medium. It is also a challenge for researchers: how does one make sense of short SMS messages written in highly colloquial text speak? Both qualitatively and quantitatively, these data are not easy to analyse as they offer limited and disparate socioeconomic and demographic data, and are restricted in terms of length and content. The research potential of this platform is yet to be recognised and explored, both by sex education practitioners and academics.

The use of social media and online communities as a tool for SRHR information has many fantastic opportunities, and interwoven with these opportunities are contradictions, challenges and questions around how society is changing and evolving and what this means for sex education and the health of young people. Yet, for young people whose lives are increasingly online and who experience many social and formative interactions virtually, there are few contradictions. As one smartSex user commented: 'I've been using this app for a long time now and it has been so helpful and very informative... the upcoming generation would appreciate such help especially if it's online coz our lives are online' (male user, 21).

Perhaps EverylMobile's vision of a world where information about SRHR leads to attitudinal and behavioural changes at scale and where these changes can be tracked and recorded still lies in the future. Perhaps some other outcome - possibly facilitated through technology, possibly not - will materialise.

\section{Notes}

* This research benefits from the following research funding: Economic and Social Research Council (ESRG)/Department for International Development (DFID) Poverty Alleviation Scheme, grant number ES/J018651/1 and UK Aid through the Future Health Systems Research Programme Consortium and through the Research in Gender and Ethics (RinGs): Building Stronger Health Systems partnership across the Future Health Systems, ReBUILD (Research for stronger health systems post conflict) and RESYST (Resilient and 
responsive health systems) Consortiums. The views expressed are not necessarily those of DFID. Thank you to EverylMobile for the sharing of data and expertise, and to Kathryn May for her input and hard work on smartSex. The views expressed here do not necessarily reflect the UK Government's official policies nor those of EverylMobile.

1 Low-end mobile phones that provide some smartphone capabilities, such as telephone, SMS messaging, basic multimedia, internet capabilities, touchscreens, access to social networking sites and additional services offered by telecom providers.

2 SMS spelling for 'be smart'.

3 Every 1 Mobile paid Mxit a fee to advertise and feature Bsmrt to its users.

4 Unreleased software made available to a limited number of people for testing.

5 Acronym for 'Laugh[ing] Out Loud'.

6 Influenced by the limiting technology of early mobile phones, in which it was difficult and time-consuming to send text messages, text speak is commonly used in SMS and other digital communications. It uses abbreviations, has no standardised grammar or punctuation and may use phonetic writing. User feedback has been edited for clarity, for example, this original quote reads: 'Mmm i lv Bsmrt mre thn I lv mah bfrend lols\#... i rly njoy ur compane'.

7 Opera Mini has over 290 million users worldwide.

8 Mxit's reliance on feature phone technology, strong international competition, new technologies and the smartphone revolution have contributed to its demise as a social network.

9 A welcome development would be to create localised versions of the content, written either in local languages or at least using more colloquial and non-English terms and expressions. An interesting exercise would be to survey smartSex's user base about their language preferences and see how answers vary across geography and gender.

\section{References}

Adepoju, A. (2005) Sexuality Education in Nigeria: Evolution, Challenges and Prospects, Understanding Human Sexuality Seminar Series 3, Lagos: University of Lagos

Allison, S.; Bauermeister, J.A.; Bull, S.; Lightfoot, M.; Mustanski, B.; Shegog, R. and Levine, D. (2012) 'The Intersection of Youth, Technology, and New Media with Sexual Health: Moving the Research Agenda Forward', Journal of Adolescent Health 51: 207-12, DOI: 10.1016/j.jadohealth.2012.06.012

Amnesty International (n.d.) Making Love a Crime: Criminalization of Same-Sex Conduct in Sub-Saharan Africa, www.amnestyusa.org/sites/ default/files/making_love_a_crime_-_facts__figures.pdf (accessed 24 October 2016)

Anthony, D. (2011) Adolescence: An Age of Opportunity, New York NY: United Nations Children's Fund

Berer, M. (2014) 'The Sustainable Development Agenda and Unmet Need for Sexual and Reproductive Health and Rights', Reproductive Health Matters 22.43: 4-13 
Best, P.; Manktelow, R. and Taylor, B. (2014) 'Online Communication, Social Media and Adolescent Wellbeing: A Systematic Narrative Review', Children and Youth Services Review 41: 27-36,

DOI: 10.1016/j.childyouth.2014.03.001

Chigona, W.; Chigona, A.; Ngqokelela, B. and Mpofu, S. (2009) 'MXit, Uses, Perceptions and Self-Justifications', fournal of Information, Information Technology, and Organizations 4

Cowan, J.K.; Dembour, M-B. and Wilson, R.A. (2001) Culture and Rights: Anthropological Perspectives, Cambridge: Cambridge University Press

Government of Ghana (2003) Education Strategic Plan 2003 to 2015, Accra: Ministry of Education

Gray, N.J.; Klein, J.D.; Noyce, P.R.; Sesselberg, T.S. and Cantrill, J.A. (2005) 'Health Information-Seeking Behaviour in Adolescence: The Place of the Internet', Social Science and Medicine 60: 1467-78, DOI: $10.1016 /$ j.socscimed.2004.08.010

GSMA (2014) Digital Inclusion 2014, www.gsma.com/mobilefor development/wp-content/uploads/2014/11/GSMA_DigitalInclusion-Report_Web_Singles_2.pdf (accessed 24 October 2016)

Guse, K.; Levine, D.; Martins, S.; Lira, A.; Gaarde, J.; Westmorland, W. and Gilliam, M. (2012) 'Interventions Using New Digital Media to Improve Adolescent Sexual Health: A Systematic Review', fournal of Adolescent Health 51: 535-43, DOI: 10.1016/j.jadohealth.2012.03.014

Hampshire, K.; Porter, G.; Owusu, S.A.; Mariwah, S.; Abane, A.; Robson, E.; Munthali, A.; DeLannoy, A.; Bango, A.; Gunguluza, N. and Milner, J. (2015) 'Informal m-health: How are Young People using Mobile Phones to Bridge Healthcare Gaps in Sub-Saharan Africa?', Social Science and Medicine 142: 90-9, DOI: $10.1016 /$ j.socscimed.2015.07.033

Hervish, A. and Clifton, D. (2012) Adolescents and Young People in Sub-Saharan Africa: Opportunities and Challenges, Status Report, Johannesburg: United Nations Population Fund (UNFPA)

IICD (2014) ICT for Health: Five Years of Learning, The Hague: International Institute for Communication and Development Iyer, P. and Aggleton, P. (2015) 'Seventy Years of Sex Education in Health Education fournal: A Critical Review', Health Education fournal 74: 3-15, DOI: 10.1177/0017896914523942

Lukale, N.; Okondo, H. and Racherla, S.J. (n.d.) Reclaiming and Redefining Rights: Setting the Adolescent and Young People SRHR Agenda Beyond ICDP+20: Sub-Saharan Africa Region Fact Sheet, World YWCA, www.sexrightsafrica.net/wp-content/uploads/2016/09/FACTSHEET-Sub-saharan-Africa.pdf (accessed 24 October 2016)

McMillan, S.J. and Morrison, M. (2006) 'Coming of Age with the Internet: A Qualitative Exploration of How the Internet has Become an Integral Part of Young People's Lives', New Media and Society 8: 73-95

Merry, Sally Engle (2006) 'Transnational Human Rights and Local Activism: Mapping the Middle', American Anthropologist 108.1: 38-51

Patton, G.C.; Ross, D.A.; Santelli, J.S.; Sawyer, S.M.; Viner, R.M. and Kleinert, S. (2014) 'Comment: Next Steps for Adolescent Health: A Lancet Commission', The Lancet 393.1: 385-86 
Pfeiffer, C.; Kleeb, M.; Mbelwa, A. and Ahorlu, C. (2014) 'The Use of Social Media Among Adolescents in Dar es Salaam and Mtwara, Tanzania', Reproductive Health Matters 22: 178-86, DOI: 10.1016/S0968-8080(14)43756-X

Prasad, A. (2007) 'Cultural Relativism in Human Rights Discourse', Peace Review 19: 589-96, DOI: 10.1080/10402650701681236

Simon, L. and Daneback, K. (2013) 'Adolescents' Use of the Internet for Sex Education: A Thematic and Critical Review of the Literature', International Fournal of Sexual Health 25: 305-19, DOI: 10.1080/19317611.2013.823899

Speizer, I.S. (2011) 'Individual and Community-Level Tolerance of Spouse Abuse and the Association with the Circumstances of First Sex Among Youth from Six Sub-Saharan African Countries', Aids Care: Psychological and Socio-Medical Aspects of AIDS/HIV 24.3: 291-300

Talukdar, J. (2013) 'The Prospects of a Virtual Sex Education: A Review', American fournal of Sexuality Education 8: 104-15, DOI:10.1080/15546128.2013.790221

Temmerman, M.; Khosla, R. and Say, L. (2014) 'Comment: Sexual and Reproductive Health and Rights: A Global Development, Health, and Human Rights Priority', The Lancet 384.9941

UNESCO (2015) Comprehensive Sexuality Education in Teacher Training in Eastern and Southern Africa, Paris: UNESCO

UNESCO and UNFPA (2012) Sexuality Education: A Ten-Country Review of School Curricula in East and Southern Africa. Paris: UNESCO/New York NY: United Nations Population Fund

Waldman, L. and Stevens, M. (2015) 'Sexual and Reproductive Health and Rights and mHealth in Policy and Practice in South Africa', Reproductive Health Matters 23.45: 93-102,

DOI: $10.1016 /$ j.rhm.2015.06.009 
This page is intentionally left blank

42 Waldman and Amazon-Brown New Digital Ways of Delivering Sex Education: A Practice Perspective 


\title{
\#ByeTaboo: Expanding Access to Sexual and Reproductive Health and Rights Education"
}

\author{
Natalia Herbst
}

Abstract This article examines the design and implementation of the sexual and reproductive health online platform \#ChauTabú (\#ByeTaboo) in Buenos Aires, Argentina, from a practice perspective. Based on my experiences, I discuss the design process and the implementation challenges; reflect on what digital spaces can offer as education platforms, and how \#ChauTabú relates to a rights-based approach to inclusive and feminist sexual and reproductive health.

Keywords: Sexual and reproductive health, education, Argentina, digital technology, sexuality, sexual diversity.

\section{Introduction}

The aim of this practice perspective article is to review the design - considering aspects prioritised in the development of sexual and reproductive health and rights (SRHR) education content - and implementation of the online platform \#ChauTabú (Spanish for \#ByeTaboo) by the Government of the City of Buenos Aires, Argentina. In addition to considering the design and implementation, this article reflects on the steps taken and the rationale for creating the platform. It also considers the challenges that arose during implementation, related to inherent limitations of digital platforms for SRHR education and the resistance of the Catholic church and religious civil society organisations, and the ways in which these were navigated. The article discusses how some of its particular features - such as a rights-based approach and fluid understanding of sexuality - were enabled by the particular Argentinian sociocultural and legal context and what this could mean for different contexts. While the case is taken from the capital city of Argentina, the fact that it is intended for expansion on a national scale means the lessons learnt from this experience can be of relevance to other countries. Specific consideration will be given to the religious similarities with Mexico and the role of the church and Christian religious associations as gatekeepers to SRHR education. 
In Buenos Aires, data revealed high rates of internet penetration, with at least 89 per cent of the population over ten years of age having online access in their household in 2011 (INDEC 2012: 35). That access is presumed to be partly influenced by a scheme for netbook distribution among schoolchildren carried out by the national government since 2010, alongside trends of increased smartphone use in the country during the same period (La Nación 2015). In terms of sex-related use of the internet, the Argentine Internet Observatory established that online searches for pornography have increased 45 per cent in the last two years, and both young women (77 per cent) and men (94 per cent) aged 18-25 consume it widely (Rosemblat 2016). This means that pornography is an important source of information about sexuality in an environment that is mostly sexually conservative due to the influence of the Roman Catholic church. In this rather confusing situation the proliferation of pornography exists simultaneously with nipple censorship, which has caused activists who want to raise awareness on how to perform a breast self-examination to use male bodies in YouTube videos in order to avoid censorship, and to criticise it (MACMA 2016). Based on this high level of internet access, and its diverse sex-related uses, the development of a state-backed online platform to provide youth with certified information through an open channel was proposed by the local government. This could counter the abundance of inaccurate information about sexual and reproductive health (SRH) available online and the persisting challenges for the implementation of integral sex education at schools.

\section{Background}

SRHR learning 'begins early in young people's lives and, if done correctly, has potential to influence young people toward positive lifelong sexual reproductive health' (Levine 2011: 19). The World Health Organization (WHO) and the 1994 International Conference on Population and Development have attributed importance to a healthy sexual development for overall mental and physical wellbeing (Shtarkshall, Santelli and Hirsch 2007). \#ChauTabú's main innovative features as a SRHR intervention are its digital nature and its treatment of sex and sexuality through a rights-based non-heteronormative approach.

Massey (1993) considers a place to have a particular specificity formed from a particular constellation of relations. Thus, she proposes 'places':

can be imagined as articulated moments in networks of social relations and understandings. And this in turn allows a sense of place which is extroverted, which includes a consciousness of its links with the wider world, which integrates in a positive way the global and the local... there are real relations with real content, economic, political, cultural between any local place and the wider world in which it is set (op. cit.: 66).

Her 'progressive sense of place' was conceived to avoid static conceptions and instead to expand the local to the global. Such a conception is relevant to the expansion of SRHR education through the 
creation of virtual online communities and spaces for education. The idea of an online 'place' respects Massey's (1993) conceptualisation of dynamic places sustained through social interactions, which have now become digital and potentially anonymous. Hemingway (2008) has built on this idea, suggesting that digital platforms create opportunities for SRHR education in reconceptualised 'places' that have the capacity of disconcerting or displacing familiar terrain.

Scholars have identified a myriad of advantages that technologybased interventions - including online platforms - can offer. These include: their low cost; the potential for increased reach to remote and/ or underserved populations; improved flexibility for programming, customising and tailoring information (compared to alternative supports, e.g. printed material); the information available becoming of universal value; the ability to provide standardised information; interactivity; privacy and autonomy, which allow for self-directed learning; and portability (Edouard and Edouard 2012; Levine 2011; Guse et al. 2012). These features are particularly relevant in relation to online SRHR education for youth.

Berglas, Constantine and Ozer propose that a rights-based approach in youth SRH can be defined as:

the intersection of four elements: an underlying principle that youth have sexual rights; an expansion of programmatic goals beyond reducing unintended pregnancy and STDs [sexually transmitted diseases]; a broadening of curricular content to include such issues as gender norms, sexual orientation, sexual expression and pleasure, violence, and individual rights and responsibilities in relationships; and a participatory teaching strategy that engages youth in critical thinking about their sexuality and sexual choices (2014: 63).

Basing youth education projects on this type of approach offers a challenge to conventional cultural and social dynamics of sexuality through the provision of accurate information in participatory interactive youth-centred spaces. Online spaces represent a particularly attractive resource for doing this given their anonymity and privacy.

That youth seek privacy in matters relating to their bodies and their relationships is well known. Yet they should not be solely responsible for learning about SRHRs. As Shtarkshall et al. (2007) point out, parents have a role in young people's 'sexual socialisation', imparting social, cultural and religious values about intimate and sexual relationships, and health education professionals should provide 'sexual education', including information about sexuality and related social skills. Despite - or perhaps because of - these diverse roles in relation to young people's sexual education, the topic is often conflictual. This includes disagreements about: the role of the government in family life and sex education; parental control of the content of sex education; core values to be included in sex education, such as gender equality and personal 
responsibility; and what constitutes appropriate adolescent sexual behaviour (Shtarkshall et al. 2007).

In Argentina, although the Integral Sex Education law of 2006 is progressive, its implementation is incomplete as debates around it persist: while its supporters believe providing sex education from the primary level allows youth to reflect on sexuality in order to make informed choices, its detractors maintain that it incites promiscuity. Cultural and social expectations about sex, sexuality and gender norms become ingrained during childhood and adolescence (Berglas et al. 2014). In these processes certain topics often remain out of discussion, thus generating taboos. Argentina has been at the forefront of sexual rights in Latin America - it was the first country to legalise same-sex marriage in 2010 and approved the most progressive gender identity law in the region in 2012. As in many other countries in the region, prostitution itself (exchanging sex for money) is legal, but organised prostitution (brothels, prostitution rings, pimping) is illegal. But there are also still many taboos around sexuality.

The taboo topics in Argentina include abortion, adolescent sexuality and pregnancies, contraceptive methods and sexually diverse SRH education. Providing comprehensive information on these issues is fundamental, as it constitutes youth's human right to healthy development as established by national law. A recent study about youth sexual practices has shown that in Argentina 44 per cent of young people have their first sexual relations before the age of 16 . Moreover it revealed that 34 per cent do not use any contraceptive method in their first sexual relations; over 50 per cent of youth do not know how to use condoms appropriately, and their use has decreased by 10 per cent since 2005 (Kornblit and Sustas 2015: 9-15). Thus, even if the law determines many contraceptive methods - such as condoms and contraceptive pills - should be available for free, many young people do not seem to have the knowledge to use them appropriately.

Conventional sex education in Argentina is extremely variable, tending to be focused on biomedical and reproductive issues, in disregard of matters such as sexual diversity, pleasure, gender inequalities and consent (Kornblit, Sustas and Adaszko 2013). Because the education system is decentralised, regardless of the content and materials provided by the national government, each province's Ministry of Education has the discretion to adjust its curriculum. Thus, how progressive or conservative the sex education provided is depends on the local government's views. Key opinion leaders maintain that, although the 2006 Integral Sex Education law is comprehensive and progressive, it is not being applied, and that problems persist about the quality of the information provided to young people (Dillon 2013). Regardless of variations between provinces, the national Ministry of Education considers that SRHR education in Argentine schools continues to register difficulties and resistance from teachers and directors regarding the teaching of content related to gender and sexual diversity, 
challenging gender inequalities, and a lack of concern about genderbased violence (Ministerio de Educación 2015).

Sawade (2014) and Allan et al. (2008) have argued that it is vital to discuss taboos, regardless of controversy, as the failure to do so undermines young people's ability to know and claim their rights in relation to sex, sexuality and reproduction. While certain topics surrounding sexuality might have been taboo, young people's general access to the internet, and hence to diverse forms of SRHR information, provides a new space to engage with them.

\section{Methods}

This article is based on my experience of and subsequent reflections on being involved in the design and implementation of a SRHR education platform at the sub-national government level. A literature review was conducted to contextualise how the putting into practice of \#ChauTabú relates to the topics discussed by scholarship, particularly the idea of 'spaces' for education, and the potentials and limitations of digital SRHR education.

\section{Limitations}

No new data has been collected for this article. It relies on personal experience and limited quantitative data provided by the practitioners currently in charge of the project. The article is limited to discussing the design and implementation stages of the project.

The usage data presented provides a snapshot of the site's traffic. However, although online resources create an array of opportunities for targeting youth, the limits to these platforms must be problematised and contextualised (Guse et al. 2012). Berglas et al. (2014) point out, for instance, that digital platforms have reduced opportunities for young people's critical thinking and reflection processes, thus undermining their ability to strategise and come up with solutions when faced with SRHR issues. This suggests that digital platforms have to be delivered in conjunction with other forms of support and services in order to result in behaviour change. This study does not claim to be an evaluation of \#ChauTabú impact on actual behaviour change.

\section{Project overview of \#ChauTabú digital platform for young people's sex education}

\#ChauTabú is a SRHR online platform that was launched in 2013 by the Youth General Direction, a department of the Deputy Chief of Government of the City of Buenos Aires. ${ }^{1}$ While the project arose from the recognition of young people's need for SRHR education, in producing \#ChauTabú's content the opportunity to go beyond basic SRH biomedical information was seized. \#ChauTabú also tackled taboos and sought to include rights-based and non-heteronormative approaches. This guided the decision to create \#ChauTabú as a brand that could speak to youth about a range of different health-related issues in the future. A year after its launch, \#ChauTabú was expanded to host information regarding substance abuse in an independent sub-site under the main domain. 
The site was developed by the Government of the City of Buenos Aires, recognising the pressing need to offer appropriate SRHR information to young people. In addition to the national status of sex education detailed above, based on the decentralised education system, in the city of Buenos Aires' system teachers are subject to a points-based training system, with compulsory and elective training. Within this, the elective sex education training awards the least amount of points possible. This means that overworked and underpaid teachers have no incentives to be appropriately trained to comply with the 2006 Integral Sex Education law. ${ }^{2}$ In addition, studies show that faced with a problem related to sexuality, only 7 per cent of young people would approach a teacher (Kornblit and Sustas 2015: 20).

Thus, \#ChauTabú was proposed as an interim response, given the lengthy amount of time necessary to offer comprehensive education on these matters in schools (e.g. updating of teachers' training and pedagogical approval, making the sex education training compulsory for all teachers, conducting teacher training and oversight of implementation). Such a long-term project also required extensive coordination between ministries. In light of these circumstances, the team of advisers on diversity and inclusion policies working for the Deputy Chief of Government proposed an alternative online option to reach young people while these formal education policies for traditional spaces were discussed, negotiated, designed and implemented.

The objective of \#ChauTabú is to be a sexual education tool that addresses taboos, by providing information not only about sex and sexuality, but also about young people's rights in order to challenge power relations and instil agency for them to determine their needs. Thus, the focus across the site is never 'what not to do', but rather 'how to safely enjoy what you want to do or are doing'.

Underlying the development of \#ChauTabú is the insight that different 'places' are necessary for the provision of SRHR information, as these enable users to interact and express themselves with differing degrees of freedom. Thus, while the school and the family remain relevant spaces for SRHR education, they are also limited by sociocultural norms for and expectations of young people (Guilamo-Ramos et al. 2015; Wilson and Koo 2010). In contrast, a 'progressive sense of place' (Hemingway 2008; Massey 1993), in which taboos are addressed and cultural norms challenged, was followed in the creation of \#ChauTabú as a secure, discrete online space. This space would provide information and also work as a channel of direct communication between the government and the youth. Thus, this becomes an alternative and non-exclusive space for a rights-based SRH approach, which can provide greater privacy for young users than 'traditional' spaces, such as the family, or education or public health institutions where the (un)acceptability of discussing particular topics may prevent adolescents from inquiring or accessing information about issues relevant to their own experiences or interests (Wilson and Koo 2010; Sawade 2014; Allan et al. 2008). 
The privacy and anonymity that digital platforms provide also become relevant in promoting discussions on issues that may challenge social or religious norms, thus opening up space to help debunk myths and uncertainties regarding SRHR.

The sections of the \#ChauTabú website include:

Information about health and sex, with a question and answer (Q\&A) format divided into thematic areas: the body and sex organs; HIV/AIDS and sexually transmitted infections (STIs); sexuality, gender and sexual diversity; vaccinations; pregnancy and contraceptive methods; sexual and reproductive rights.

An interactive map that provides the locality of available state-run and free youth services offices, HIV/AIDS test centres, and health centres for professional consultations and dispensing of contraceptives.

'It happened to me': this section provides first-person anonymised real-life experiences regarding youth encounters with diverse SRHR issues.

Contraceptive methods: this is a responsive section in which the user chooses three methods from a list of over 20 contraceptive options. The user then gets a comparative table with information for each selected type including: type of contraceptive, description, efficiency, capacity to prevent STIs, advantages, disadvantages and availability. The user is able to change his or her selection and obtain a new comparative table as many times as necessary.

- A test: an interactive 'true or false' quiz, in which the user responds to a statement and receives further information on the subject.

An online practice: an anonymous system through which the user can ask further questions that may not be addressed by the available information on the site. These are responded to within 72 hours by a team of health professionals.

\section{Findings}

\subsection{Site usage and development}

During its first year the site received 250,000 visits to the online practice and held over 3,000 consultations, and the site users reported being 46 per cent women and 54 per cent men. However, the gender distribution of the online practice users shows a higher disparity with 71 per cent women and 29 per cent men asking questions through this channel. Seven per cent of the online practice users were below 15 years of age, 52 per cent were aged 15-19, 27 per cent aged 20-24, 7 per cent aged 25-29, and 7 per cent were 30 or older. Most of their questions related to contraceptive methods (28 per cent), sexuality (17 per cent), pregnancy (12 per cent) and STIs (11 per cent). The site's core content does not currently address issues such as fetishes or sadomasochism, and there is no available information about whether the online practice 
received questions on those topics, and if so with what frequency. The site does provide information in its Q\&A section that normalises the consumption of pornography, but highlights that no one should coerce or be coerced into consuming it.

An interesting finding is that there are currently site visits coming from outside of Argentina. While national visitors account for 82 per cent of the site's traffic, Mexican users come next with 2.5 per cent, followed by 1.88 per cent from the USA and 1.63 per cent from Spain. Given the highly geographically biased parameters used by search engines in the provision of search results, this may point to a vacant space in Mexican resources providing trustworthy local SRHR information.

In December 2015, the administration responsible for designing and implementing the programme won the national presidential elections, and it has since decided to scale it up to the national level. \#ChauTabú will thus migrate from sub-national jurisdiction to the Under-Secretary of Youth in the Ministry of Social Development. ${ }^{3}$ This is an ongoing process for which the Ministry is partnering UNICEF-Argentina to review and update the content, including the new substance abuse and gender-based violence sub-sites. This scaling-up will have an impact on the site's content (e.g. the interactive map will provide information for the whole country), as well as demanding new strategies for communication based on the specifics of different regions of the country. In the next section I will describe some of the key elements of the design process.

\subsection{Design considerations}

The aim of the project was to provide medically accurate information about SRHR. In order to do so, the team prioritised making this information inclusive and friendly for youth (15-29 years old), the main target population. With this in mind, a combination of written and graphic communication dimensions was decided on, both as a means of creating a graphic identity for the project that the user could easily recognise and to facilitate health information dissemination. The use of youth-friendly language was prioritised. A Public Health Communications team was in charge of adapting the information provided by the Ministry of Health to make it friendlier for the user. The language of \#ChauTabú focuses on being biomedically accurate and informative, while using everyday language, including the slang that young people use when talking to their peers. Throughout the site, the use of SRHR jargon or technical/scientific terms was avoided.

A set of illustrations was commissioned to help develop a user-friendly interface. These were intended to be attractive to youth, and to offer an identity that users could identify with. This allowed \#ChauTabú to have a repository of images to be used for future communication, and to represent society as diverse and not homogeneous. The images were done using a bright colour palate and using unconventional colours to represent human features, such as hair and eyes. They included people as well as everyday objects and activities (from dancing to 
kissing). The images are inclusive of lesbian, gay, bisexual, trans, queer, intersex (LGBTQI) couples, as well as representing different aesthetic styles adopted by the youth of Buenos Aires. The rationale for this imagery was to capture the diversity of the city, and to make users feel represented when navigating the site. The site also uses animations to create audiovisual content following the same principles of userfriendly language and inclusive visual representations. These include explanations about how to use condoms, HIV/AIDS transmission and prevention, and puberty and physical changes during adolescence.

\#ChauTabú was innovative in Argentina for being a state-run SRHR platform that comprehensively adopted a non-heteronormative rightsbased approach to $S R H$ directed at youth. The aim of both the written and graphic content is to adopt an inclusive perspective of sex and reproduction, which considers sexuality and gender as fluid. The information provided is relevant for the SRHR of LGBTQI partners, and provides information relevant to trans youth under Q\&A, such as: 'Is it wrong to feel that my biological sex does not match my gender identity?', 'Is a hormonal substitution treatment dangerous for trans people's health?' and 'If I am a trans person and I want to start hormonal substitution treatment, what should I do?' The site also sheds light on the meaning of diverse topics, such as, among many others, the difference between trans, transgender, transvestite, transsexual, intersex and intersexual; sexuality, sex and gender; gender identity and sexual identity; and sexual orientation. This content was given additional legitimacy by the review and approval of national LGBTQI organisations.

The site is not limited to SRH and emphasises youth rights. One of the main focuses across \#ChauTabú is young people's rights regarding access to SRH services and information. This refers both to legal frameworks already in place, and to framing sex and sexuality as pleasure, stressing the importance of individual choice and positive rights based on informed decisions and responsible practices.

Underlying this provision of information is the argument that sex education empowers people, allowing them to make informed decisions about their lives and bodies, whereas a lack of information impoverishes and disempowers people (Cornwall and Jolly 2006; Armas 2006) and may lead to unplanned and/or undesired outcomes.

Lastly, although a government-based project, \#ChauTabú benefited from the support and participation of several key civil society organisations. ${ }^{4}$ The website content was co-created with leading national HIV/AIDS, LGBT and women's rights civil society organisations, which revised a first proposal, provided feedback for its improvement and approved the final version. The presence of their logos at the bottom of the site has strengthened the legitimacy of the resource. These organisations were also encouraged to use \#ChauTabú as part of their awareness-raising efforts. Nonetheless, as discussed in the next section, \#ChauTabú did experience, and had to overcome, several challenges during its implementation. 


\subsection{Implementation challenges and proposed solutions}

Several challenges arose during the implementation of the project. While the cause - and hence the solution - of these may be grounded in different context-related conditions, they may still be relevant for practitioners designing SRH interventions in other settings.

Due to its digital nature, \#ChauTabú faces the inherent limitations that Berglas et al. (2014) point out for this type of platform, as discussed in Section 4. The interactive map on the site fulfils the function of linking this resource with other state public and free services that can deliver further support such as HIV testing, contraceptive dispense and SRHR professional services. While key complementary strategies should include progressive content in formal education spaces, meaning a proactive engagement of the state with youth SRHR, the platform addressed these limitations based on readily available resources.

A first implementation challenge relates to the information provided on the \#ChauTabú site. This included initial decisions on what information to include or exclude in the first implementation and decisions about what subsequent information was needed or desired by users. Here the questions submitted by users through the online practice function proved the best resource for getting a feel for key issues not already included. Thus, practitioners included in the project's structure the periodical monitoring of the online practice to identify recurring questions, establishing a useful mechanism to track what types of information are being sought by youth. The content relating to these issues is then used to update the site's core content accordingly. Using the interests and doubts expressed by the users through their questions to the online practice to update the site's core content represents a participatory approach, in which the state can find innovative ways of acknowledging civil society's concerns in the digital era.

A second challenge refers to how to publicise \#ChauTabú to ensure young people know of its availability. As the site contains innovative rights-based information, it has generated mixed reactions and has encountered resistance among its expected facilitators in education and health provision institutions. This means that education and health practitioners may choose to recommend the site or not based on their normative judgements on its content (Allotey et al. 2011; Meyer, Taylor and Peter 2015). Furthermore, a systematic plan to present it in schools would require considerable human and financial resources, as well as needing a long process of formal approval. Instead, in Buenos Aires, social networks were a fundamental channel of communication with users of \#ChauTabú. Facebook proved most efficient, with a fan page garnering 63,800 'likes'. In order to sustain interest in a platform such as Facebook, the constant production of content is needed to keep the page active, alongside funds to cover online publicity targeting youth at district-level. There was no censorship of imagery on Facebook, presumably because the images used are drawings rather than photographs. However, the posts collected a high number of comments 
by users, either asking further questions, or criticising the content displayed. Thus, the role of a moderator for the fan page should be considered, mostly to respond to inquiries that may arise through this channel of communication.

In countries with laptop distribution programmes for school-aged youth, the Ministry in charge of software updates has the power to make the site the homepage of the laptop's browser through remote updates. While this was under consideration for \#ChauTabú, it has not been implemented yet. This would be the most effective method in reaching the target population in areas with high school enrolment rates.

The third challenge concerns prevailing sociocultural norms and values associated with young people's sexual behaviour. When trying to design progressive, inclusive SRHR education content, different and often confronting positions tend to arise. These are often expressed as cultural, gender or religious cleavages. In the case of Buenos Aires, the Catholic church was most opposed to \#ChauTabú. It organised resistance directly through the church, and indirectly through religious civil society groups. Two online campaigns were launched to petition for the elimination of the site; however, neither reached its target of adherence set at 7,500 and 2,000 signatures (Change.org 2013; CitizenGO 2013). The church also used its weekly open-air television programme to maintain that 'while the site [\#ChauTabú] believes it is informing the youth, it is actually deforming them, disorienting them by presenting different sexual experiences as if they were all equally valid, including those that go against nature' (Aguer 2014).

The Catholic church's opposition to \#ChauTabú made the front page of one of the country's most widely read newspapers following the site's launch. In addition, Catholic lawyers' and doctors' professional organisations and Catholic school principals who supported the Catholic church's position reached their communities with messages characterising \#ChauTabú as a 'corrupter of minors' and calling on parents to protest against the 'systematic destruction of the human persona and of all the virtues and values that remit to man's transcendence, especially of children and adolescents' (infoCatólica 2013). The government's response came from key political leaders of the administration, highlighting the good reception \#ChauTabú had received among Buenos Aires' youth, based on the high number of visits and questions submitted through the online practice. The government also claimed that 'it is important for a government to address these issues, the portal is based on the principles of liberty and respect' and that 'it is worrisome to sustain that a website can incite conducts; being informed about certain things is not equivalent to inciting them' (Minuto Uno 2014).

Regardless of the caution taken to ensure that accurate medical information is provided in the design of a project such as \#ChauTabú, SRHR topics inevitably generate political opposition as there are 
opposing views and taboos steeped in social values, ideology, religion and morality to which Argentina is no exception (Allotey et al. 2011; Shtarkshall et al. 2007). Thus, projects of this nature, which address the contested issue of young people's SRHR education, need to be embarked on with firm conviction of the necessity of this kind of education and a clear position to be defended. This is what \#ChauTabú did. It also used its alliances and the participatory involvement of civil society organisations to help it legitimise \#ChauTabú in the eyes of Buenos Aires' constituencies. However, approval of the project ultimately depended on the ability of the government to transform political capital into political support and to defend a progressive approach to SRHR regardless of the political resistance experienced.

\section{Discussion and conclusions}

\#ChauTabú appears to be filling a much-needed gap in Argentina especially for women, who make up the vast majority of the users of its online practice - and, it seems, in other Latin American countries more broadly. Many of its users are Mexicans, who face limitations to sex education similar to those of the youth in Argentina (Amuchástegui et al. 2010; Amuchástegui Herrera 2001; Bárcenas Barajas 2011).

Certain aspects of the project, such as the state's support for a rights-based approach and its particular emphasis on LGBTQI issues - were possible due to a number of particular moments in politics. It started when the Buenos Aires government recognised its pressing need to update its official delivery of SRHR information to young people, and realised that following a conventional process would be highly challenging and time consuming. The alliance with the team of advisers already working on diversity and inclusion policies, the support of several key civil society organisations and the support of key political figures working in the government administration all helped to make the development of an online platform for SRHR possible. This was then further bolstered by the winning of the national presidential elections in 2015, which meant that \#ChauTabú could now be extended to the national level and which ensured support from a United Nations international development partner. These conditions and alliances all helped to create an enabling context, which has pushed agendas based on progressive LGBTQI laws regarding same-sex marriage and adoption, and trans identities.

Online platforms can offer innovative and interactive ways of delivering information on sexuality. If necessary, complementary digital content can be produced on-demand based on questions to the clinics related to issues not explicitly covered on the site. This represents a hybrid approach for sociocultural contexts in which a comprehensive approach would be unlikely to win approval either at the political or societal level.

If \#ChauTabú's main features - namely imagery, language, a rights-based approach and a fluid understanding of sex, sexuality and gender - were to be adopted and adapted in other countries, there is 
potential for social controversy. This, which is embedded in the nature of the project, should not be seen as a weakness but as an opportunity to promote public discussion. In Buenos Aires this was evident in the public stances of powerful political actors, both for and against the project, as well as in editorials in the leading national newspapers criticising the initiative, and, of course, in the church's ongoing opposition (Román 2013; Castro 2014). Rather than being discouraged, this controversy should be embraced as it creates an opportunity to launch a public conversation about the state's role in SRHR education, which may lead to transformative policies that stem from a broader agenda. Thus, \#ChauTabú and other similar initiatives should be conceived as having the potential to go beyond their immediate value as information resources and rather be seen as platforms from which to advocate for sociocultural, political and legal innovations that can advance sexual and reproductive rights (Raupp Rios 2006; Armas 2006; Cornwall and Jolly 2006).

\#ChauTabú has not undergone a comprehensive impact evaluation. The data on the number of visits to the site, questions submitted through the online practice and Facebook fan page activity suggest a positive reception of the material by young people. Even if it was initially developed at the sub-national level, because of its digital nature the resource was accessed by users nationwide. This needs to be considered in the design of the main content, while other sections (such as the interactive map) remain circumscribed to reflecting the services offered by the funding district.

The project has potential for replicability in different countries, which will be mediated mainly by levels of internet access and public support to include SRHR in the political agenda. Issues regarding public health priorities, gender dynamics, and religious and cultural sensibilities should be considered when developing the content of similar platforms in diverse localities. By using audiovisual resources (e.g. illustrations, animations) the initiative could help overcome illiteracy barriers, and it has potential to debunk taboos or misconceptions. In the case of Argentina, a government platform backed up by civil society organisations has been able to provide a trustworthy online source of information. Argentina, however, has a track record of some progressive policies with regard to sexual rights, which may have helped public trust in the service. Its potential for private access provides a space that young people can consult regarding issues they may not feel comfortable discussing in public or adult-supervised spaces, or in spaces in which they may face peer scrutiny. Considering young people navigate different types of pressures about their sexual and reproductive lives that differ across communities and social spaces, this characteristic can go a long way in providing accurate medical information, shedding light on myths and promoting discussion on taboos surrounding sexuality and sexual health. Rising awareness about SRHR could lead to an empowered youth. Further research could inquire whether this better equips them to challenge power structures relating to their sexuality. 
All in all, the aim of \#ChauTabú was to create a platform for SRHR, which is inclusive of the human side of sexuality, by considering the pleasure as well as the uncertainty and doubts that surround the subject, especially among youth. For this, the focus across the site is never 'what not to do' but rather 'how to safely enjoy what you want to do or are doing'.

\section{Notes}

* I would like to thank Pedro Robledo for sharing information about \#ChauTabú and authorising its publication. I would also like to thank Rikki Chauin, Katy Oswald, Tabitha Hrynick, Pauline Oosterhoff and Linda Waldman for their comments on earlier drafts of the article, and the anonymous reviewers for their valuable comments.

1 https://chautabu.buenosaires.gob.ar/salud/.

2 The law mandates that sex education content should be imparted across the curriculum. However, most teachers in the system are not trained to do so.

3 It should be noted that the new under-secretary at the national level is the same person that runs the programme at city level, thus no modifications should be expected with regard to the ethos that informs the project.

4 \#ChaTabú depends on the support of Fundación Huesped (HIV/AIDS), Fundalam (lactancy promotion), FALGBT (Federation of LGBT organisations), and FEIM (gender thinktank).

\section{References}

Aguer, Hector (2014) Mons. Aguer - La píldora del díadDespués [Chau Tabú] https://gloria.tv/video/ggeb2aN7qCt (accessed 5 October 2016)

Allan, Alexandra; Atkinson, Elizabeth; Brace, Elizabeth;

Depalma, Renée and Hemingway, Judy (2008) 'Speaking the Unspeakable in Forbidden Places: Addressing Lesbian, Gay, Bisexual and Transgender Equality in the Primary School', Sex Education 8.3: 315-28, DOI: 10.1080/14681810802218395

Allotey, Pascale A.; Diniz, Simone; Dejong, Jocelyn; Delvaux, Thérèse; Gruskin, Sofia and Fonn, Sharon (2011) 'Sexual and Reproductive Health and Rights in Public Health Education', Reproductive Health Matters 19.38: 56-68, DOI: 10.1016/S0968-8080(11)38577-1

Amuchástegui Herrera, Ana (2001) 'The Hybrid Construction of Sexuality in Mexico and its Impact on Sex Education', Sex Education 1.3: 259-77

Amuchástegui, Ana; Cruz, Guadalupe; Aldaz, Evelyn and Mejía, María Consuelo (2010) 'Politics, Religion and Gender Equality in Contemporary Mexico: Women's Sexuality and Reproductive Rights in a Contested Secular State', Third World Quarterly 31.6: 989-1005

Armas, Henry (2006) 'Exploring Linkages Between Sexuality and Rights to Tackle Poverty', IDS Bulletin 37.5: 21-6, http://bulletin.ids.ac.uk/idsbo/article/view/912 (accessed 4 October 2016)

Bárcenas Barajas, Karina Berenice (2011) 'Como debe ser, como Dios manda: el Estado y la Iglesia Católica en las formas de regulación de la vida familiar en México', Revista Cultura y Religión 5.1: 95-116 
Berglas, Nancy F; Constantine, Norman A. and Ozer, Emily J. (2014) 'A Rights-Based Approach to Sexuality Education:

Conceptualization, Clarification and Challenges', Perspectives on Sexual and Reproductive Health 46.2: 63-72, DOI: 10.1363/46e1114

Castro, Angeles (2014) 'Chau Tabú: Polémico sitio de orientación sexual de la ciudad', La Nación, 21 January, www.lanacion.com.ar/1657069chau-tabu-polemico-sitio-de-orientacion-sexual-de-la-ciudad (accessed 5 October 2016)

Change.org (2013) Lic. María Eugenia Vidal: Baje el portal Chau Tabú, www.change.org/p/lic-maría-eugenia-vidal-baje-el-portal-chau-tabú (accessed 1 November 2016)

CitizenGO (2013) Suspensión inmediata del portal 'Chau tabú' del Gobierno de la Ciudad de Buenos Aires, Argentina, CitizenGO, 3 December, www.citizengo.org/es/1066-suspension-inmediata-del-portalchau-tabu-del-gobierno-ciudad-buenos-aires-argentina (accessed 5 October 2016)

Cornwall, Andrea and Jolly, Susie (2006) 'Introduction: Sexuality Matters', IDS Bulletin 37.5: 1-11, http://bulletin.ids.ac.uk/idsbo/ article/view/910 (accessed 4 October 2016)

Dillon, Alfredo (2013) La educación sexual aún no llega a todos, Clarin.com, 29 August, www.clarin.com/sociedad/educacion-sexualllega_0_983301809.html (accessed 5 October 2016)

Edouard, Elizabeth and Edouard, Lindsay (2012) 'Application of Information and Communication Technology for Scaling Up Youth Sexual and Reproductive Health: Review Article', African fournal of Reproductive Health 16.2: 197-205

Guilamo-Ramos, Vincent; Lee, Jane; Kantor, Leslie; Levine, Deborah; Baum, Sarah and Johnsen, Jennifer (2015) 'Potential for Using Online and Mobile Education with Parents and Adolescents to Impact Sexual and Reproductive Health', Prevention Science 16.1: 53-60, DOI: 10.1007/s11121-014-0469-z

Guse, Kylene; Levine, Deb; Martins, Summer; Lira, Andrea; Gaarde, Jenna; Westmorland, Whitney and Gilliam, Melissa (2012) 'Interventions Using New Digital Media to Improve Adolescent Sexual Health: A Systematic Review', Fournal of Adolescent Health 51.6: 535-43, DOI: 10.1016/j.jadohealth.2012.03.014

Hemingway, Judy (2008) 'Taking Place Seriously: Spatial Challenges for Sex and Relationship Education', Sex Education 8.3: 249-61

INDEG (Instituto Nacional de Estadistica y Censos) (2012) Encuesta Nacional Sobre Acceso y Uso de Tecnologías de la Información y la Comunicación (ENTIC). Resultados Del Tercer Trimestre de 2011, Buenos Aires: INDEC, http://estadistica.cba.gov.ar/LinkClick.aspx?fileti cket $=$ q5afrYycHEI $\% 3$ D\&tabid $=503 \&$ language $=$ es-AR $($ accessed 5 October 2016)

infoCatólica (2013) Crece la indignación en Argentina ante el portal Chau Tabú, corruptor de menores, 18 December, http://infocatolica.com/ $? \mathrm{t}=$ noticia\&cod $=19452($ accessed 5 October 2016)

Kornblit, Ana Lía and Sustas, Sebastián Ezequiel (2015) 'Actitudes y prácticas sexuales de los jóvenes escolarizados en el nivel medio de la 
enseñanza pública Argentina ¿nuevos patrones?', Educación, Lenguaje y Sociedad XII.12: 1-27

Kornblit, Ana Lía; Sustas, Sebastián Ezequiel and Adaszko, Dan (2013) 'Concepciones sobre sexualidad y género en docentes de escuelas públicas Argentinas', Ciencia, Docencia y Tecnología XXIV.47: 47-78

La Nación (2015) 'La Argentina, un país a puro smartphone', 25 March, www.lanacion.com.ar/1777897-la-argentina-un-pais-a-purosmartphone (accessed 5 October 2016)

Levine, Deb (2011) 'Using Technology, New Media, and Mobile for Sexual and Reproductive Health', Sexuality Research and Social Policy 8.1: 18-26, DOI: 10.1007/s13178-011-0040-7

MACMA (2016) Movimiento Ayuda Cáncer de Mama (MACMA) Tetasx Tetas, www.youtube.com/watch?v=iZhnlkTKPYc (accessed 5 October 2016)

Massey, Doreen (1993) 'Power-Geometry and a Progressive Sense of Place', in J. Bird, B. Curtis, T. Putnam, G. Robertson and L. Tickner (eds), Mapping the Futures: Local Cultures, Global Change, London: Routledge: 50-69

Meyer, Elizabeth J.; Taylor, Catherine and Peter, Tracey (2015) 'Perspectives on Gender and Sexual Diversity (GSD) - Inclusive Education: Comparisons between Gay/Lesbian/Bisexual and Straight Educators', Sex Education: Sexuality, Society and Learning 15.3: 221-34, DOI: 10.1080/14681811.2014.979341

Ministerio de Educación (2015) La Educación Sexual Integral En La Argentina: Balances y Desafios de La Implementación de La Ley (20082015), Buenos Aires: Presidencia de la Nación, www.ossyr.org.ar/ pdf/bibliografia/547.pdf (accessed 5 October 2016)

Minuto Uno (2014) El PRO defendió Chau Tabú: Es importante que un gobierno se ocupe de esto, 21 January, minutouno.com, www.minutouno.com/notas/311184-el-pro-defendio-chau-tabues-importante-que-un-gobierno-se-ocupe-esto (accessed 5 October 2016)

Raupp Rios, Roger (2006) 'Developing Sexual Rights: Challenges and Trends in Latin America', IDS Bulletin 37.5: 46-51, http://bulletin.ids.ac.uk/idsbo/article/view/916 (accessed 4 October 2016)

Román, Valeria (2013) Un sitio oficial responde las dudas sobre sexo de los adolescentes, Clarin.com, 12 March, www.clarin.com/salud/sitiooficial-responde-dudas-adolescentes_0_1040895959.html (accessed 5 October 2016)

Rosemblat, Sergio (2016) Consumo de pornografia en Internet en Argentina, Observatorio de Internet en Argentina, http://inter.net.ar/ pornografia/img/Consumo-de-pornografi\%CC\%81a-en-Interneten-Argentina_OIA.pdf (accessed 5 October 2016)

Sawade, Olloriak (2014) 'Lessons, Challenges, and Successes While Working on the "Triangle" of Education, Gender, and Sexual and Reproductive Health', Gender and Development 22.1: 127-40, DOI: $10.1080 / 13552074.2014 .889339$

Shtarkshall, Ronny A.; Santelli, John S. and Hirsch, Jennifer S. (2007) 'Sex Education and Sexual Socialization: Roles for Educators and 
Parents', Perspectives on Sexual and Reproductive Health 39.2: 116-19, DOI: $10.1363 / 3911607$

Wilson, Ellen K. and Koo, Helen P. (2010) 'Mothers, Fathers, Sons, and Daughters: Gender Differences in Factors Associated with Parent-Child Communication about Sexual Topics', Reproductive Health 7.31, DOI: 10.1186/1742-4755-7-31 


\title{
Digital Pathways to Sex Education
}

\author{
Catherine Müller, Pauline Oosterhoff and \\ Michelle Chakkalackal
}

\begin{abstract}
For most young people in the world, sex and relationships have a big impact on their lives. However, various gatekeepers restrict reliable information on sexual health that has a positive take on pleasure and relationships. Therefore, online sex education is of vital importance for young people. Using online traffic data and information on operational realities from Love Matters - an online provider of sex education on web, mobile and social media platforms in China, Egypt, Kenya, Mexico and India - this article attempts to contribute to an understanding of how online information about sexual health education in different national contexts is accessed by users and restricted by gatekeepers. Our findings show the importance of understanding audiences, visible traditional and invisible online gatekeepers, and working with local and supranational commercial organisations for effective outreach and provision of sex education.
\end{abstract}

Keywords: sex education, gatekeepers, online, social media, censorship.

\section{Motivation}

For most young people in the world, getting reliable information about sex can be difficult. In many countries traditional gatekeepers such as religious and educational authorities are still powerfully restricting access, content and materials used for sex education. Researchers and sexual rights activists have argued that sharing information about the positive, pleasurable aspects of sexuality, rather than the risky aspects, can enhance the effectiveness of communicating sexual health information (Dyson et al. 2003; Allen 2001; Hirst 2013). The internet has been identified as a (potentially) very valuable avenue for comprehensive, interactive and youth-friendly sex education (Simon and Daneback 2013). Yet online sex education is directly and indirectly restricted in many countries by national laws that limit freedom of expression on the internet, prohibit pornography or criminalise same-sex relationships. There are also 'new' - as opposed to traditional - invisible gatekeepers, such as Facebook and Google in online spaces, which specifically restrict access to information about nudity, cleavage, adult content or sexually explicit content (APC 2010), ${ }^{1}$ and impose 
strict rules. More often than not, faceless algorithms rather than humans make decisions about what is and is not acceptable, creating a new class of challenges. Research has not looked at how these rules shape the interactions between sex educators and the new internet gatekeepers, while these are arguably key in setting boundaries on strategies for reaching out to young people with information about sex and relationships.

Online sex education platforms such as Love Matters reach millions of young people in countries where they cannot access trustworthy information otherwise. How do young people reach these sites? Do they land accidentally on a sex education site while looking for pornography or are they purposely looking for reliable information about sexuality and/or relationships? Knowing more about different user pathways would help build more effective online sex education interventions in different sociopolitical contexts and environments, as sex educators could direct users more efficiently to relevant information. This article explores digital pathways that bring users from different countries to a sex education site.

\section{Sex education in the digital age}

An increasing number of countries are approaching comprehensive sex education through the dual lens of age-appropriateness and cultural relevance, with an eye to providing scientifically accurate, realistic and non-judgemental information. ${ }^{2}$ However, few adolescents get effective, sex-positive sex education (Johnson et al. 2016). Instead, in many parts of the world, sex education focuses on the risks and biomedical aspects of sexuality such as sexually transmitted infections (STIs), contraception and the mechanics of conception. Research shows that adolescents would value more positive and realistic approaches (Allen 2006, 2007). For example, in her study of 515 New Zealanders aged 17-19, Allen found that young people lacked knowledge of and missed a discourse on the "lived" experience of sexual activity and details of this interaction' (Allen 2001: 114) as a crucial piece in their sex education.

The internet could be a valuable avenue in providing sex education (Simon and Daneback 2013; Dyson et al. 2003; Hirst 2013) from a pedagogical point of view. Indeed, Simon and Daneback (2013) report that adolescents' demands to learn about sexual experiences are likely to make the internet - with its unique characteristics of availability, acceptability, affordability and anonymity - a perfect complement to, if not substitute for, traditional sources of sex education. Online sex education could provide a more interactive space where young people could anonymously discuss experiences and questions about sexuality and relationships that they face in real life.

Indeed, as some studies show, mass media such as the internet and traditional media in the form of television, music, movies, magazines and so forth are highly influential in young people's sex-related 
knowledge, attitudes and behaviours (L'Engle, Brown and Kenneavy 2006; Lou et al. 2012). Ngo, Ross and Ratliff show that 'the internet is used to assemble sexual information that was not available from other sources such as the family and school' as well as a 'medium for expressing sexual identities and desires' (2008: S201).

In the first literature review of 36 articles focusing on use of the internet for sex educational purposes by adolescents aged 13-19, Simon and Daneback (2013) identified four distinct themes. First, adolescents engage with online sex information: depending on the sample, between 31.6 and 76.5 per cent of study participants in the United States, 20 per cent of a sample of school adolescents in Uganda, 34.3 per cent of Ghanaian adolescents, and 45 per cent of a female sample of adolescents in Nigeria had used the internet for information about sexual health. Second, the most commonly cited topics adolescents engage in online are HIV/AIDS/STIs, pregnancy and childbirth, sex acts and behaviour, contraception and protection, information about the body, relationships and social issues, and sexual identity and orientation. ${ }^{3}$ From the analyses, it was not clear whether these topics are pursued out of interest or because information on them exists; however, the authors stress that it is clear that 'adolescents are popularly engaging with information about pleasure-based and experiential sex, as well as sexual positions and behaviors' (Simon and Daneback 2013: 309). Third, several studies in the review - such as Bay-Cheng (2001), Keller et al. $(2002,2004)$ and Isaacson (2006) - suggest that user-driven and positive messaging seem to be rare, and that information about topics such as sexual orientation and identity, masturbation, and abortion are marginalised. Furthermore, indicators of quality and sources are often missing. However, while young people's knowledge should not be overestimated, their intelligence should not be underestimated; 'adolescents are savvy users capable of determining what makes an online resource trustworthy' (Simon and Daneback 2013: 310). Finally, studies show that web-based sexual health education increases awareness, knowledge and behaviour related to sexual and reproductive health issues. ${ }^{4}$

Insights from studies such as those above have helped a great deal with developing interactive and comprehensive content in online sex education. What practitioners, policymakers and researchers are missing is a better understanding of why, when and how adolescents are searching for and gathering information, what experiences they have online, and how changes in technology - which is more interactive and social nowadays - as well as legal and cultural contexts affect the use of (re)sources. This article attempts to contribute to an understanding of how online information about sexual health education offered by sex educators operating from offices in different national contexts is accessed by users and restricted by gatekeepers. We focus on online traffic data from Love Matters, an online provider of sex education in five countries: China, Egypt, Kenya, Mexico and India. 


\section{Study background - Love Matters}

Love Matters is an initiative of RNW Media, which offers sexual health information with a positive take on sexual pleasure and relationships on web, mobile and social media platforms. Love Matters aims to provide 'plain-speaking' information on love, sex, and relationships. It offers playful and thought-provoking articles, testimonials, blogs and advice columns, and lively conversations on its platforms. Love Matters works with local and international partners to reach their target audience of young people aged 18-30 in China, the Arab world (currently focused on Egypt), Africa (focusing on Kenya), Latin America (focusing on Mexico and Venezuela), and India.

Before presenting the data, we discuss the national legal and political landscapes in which each of the Love Matters sites operates and how these could relate to our findings.

\subsection{Legal and political landscape}

Love Matters operates in national contexts with many different types of legal restrictions with regard to freedom of speech, and civil and political liberties. The legal environment is an important part of the context. Even if visitors do not reside locally, national Love Matters offices have to abide by these laws in their engagement with young people about sexuality and relationships. For example, a short information film, My First Wedding Night, on the Love Matters Egypt website attracted hundreds of thousands of viewers from Saudi Arabia. ${ }^{5}$ But while audiences may be regional or global, Love Matters offices operate within national legal policy frameworks, which can be restrictive or enabling. The most prominent restrictive example is China, where there is a high degree of internet censorship. Additionally, new gatekeepers such as Facebook and Google have significant power in choosing which content to make available, searchable, and thus accessible, which consequently often defines how sex education is delivered. Disapproval messages ${ }^{6}$ from Facebook refer to broad advertising policies but also give instructions on how to fix problems (e.g. by using a different image). Google's justifications for blocking an advert, however, are not particularly extensive and make no suggestions about how to fix problems. ${ }^{7}$

Censorship of nudity not only affects sex education; it has wider implications for all public education. A recent, very prominent example was that of documentary photography by Nick Ut from the Vietnam war, showing a victim of a Napalm attack in 1972 - a naked girl running down a street. ${ }^{8}$ Additionally, some browsers are automatically fitted with ad-blocking capabilities. For example, the UC browser developed by Chinese company UCWeb, which is more popular in India than Google Chrome, with over half a billion people in China and India using it - comes with a built-in ad blocker in India, which most people do not switch off. So, regardless of content, advertisements would be blocked because they are advertisements. We briefly describe the specific legal and political landscape of each country below, with information on the status of sex and reproductive health education. 


\section{China}

China is well known for its strict censorship laws and family planning policies. Almost every piece of information going into and out of China is moderated by an extensive internet filtering system, the so-called 'Great Firewall'. International human rights organisations such as Human Rights Watch, Amnesty International and Reporters Without Borders (RSF) (Human Rights Watch 2013) have criticised China for its multi-layered internet censorship. Laws are broad and often vaguely written, leaving much room for subjectivity in their implementation. Spreading obscenity, pornography, gambling, violence, terror, or abetting the commission of a crime are illegal, but it is not clear what qualifies as pornography or obscenity. ${ }^{9}$ In response and in addition to legislation, media companies and websites also have their own house rules to avoid being punished or shut down for hosting pornographic content. Furthermore, the government often launches campaigns to purge internet pornography and immoral content. ${ }^{10}$ During these campaigns, internet companies temporarily tighten their censorship on all content related to sex and sexuality, including sex education content.

This unpredictable situation poses a constant challenge to the Love Matters editorial team, as there are no clear and consistent guidelines; it is left to the individual to err on the side of caution. As an editorial rule, no graphic content or details about sex are published, even if that material is available elsewhere in China, either online or offline. But what is 'graphic' can be the subject of debate. Although the state is committed to limiting population size and improving 'population quality' (Zhou et al. 2014), young people lack access to life skills-based education and high-quality, youth-friendly information on sexual and reproductive health and rights (SRHR) (United Nations 2015). Young people lack basic knowledge about sexual and reproductive health (UNESCO 2015).

\section{Egypt}

Internet access and freedom of expression are limited in Egypt. A multiplicity of bans and laws censor open, free discussions and information exchange (RSF 2016; Freedom House n.d.a; Amnesty International 2016). ${ }^{11}$ This situation also affects Love Matters, because authorities target writers and creative people. For example, a blogger on Love Matters was arrested for something he had written somewhere else (ANHRI 2015). Sexual and reproductive rights in Egypt are conservative and heteronormative; and people have been arrested and tried on charges of 'debauchery' for their perceived sexual orientation or gender identity. Egypt's population policy 'explicitly addresses young adults only through the provision of healthcare for girls before marriage and premarital exams and counselling' (Beamish 2003: 6).

Most sex education programmes are offered by non-governmental organisations (NGOs) (UNFPA 2014). More than once, such NGOs have abruptly been denied access to a school due to pressure from parents or teachers who are displeased with the material taught (EIPR 2014). Pornography is illegal, but pornographic sites are readily 
available on the internet (Egyptian Streets 2015). The Love Matters editorial team is constantly assessing what might be accepted and culturally appropriate. Some topics, such as sex during menstruation, have triggered angry responses because, according to some, there is a Koranic verse against it. Others argue that these verses are actually about personal hygiene, leaving Love Matters in the middle of heated debates. Love Matters in Egypt positions itself in these debates as a 'scientific', user-friendly site that avoids using erotic or provocative language, a strategy that the authorities have accepted.

\section{Kenya}

Kenya does not actively block or filter online content, and Kenyans have unrestricted access to social networking platforms such as Facebook, Twitter, YouTube, and WhatsApp, as well as pornography. Censorship is more prominent in print and mostly focused on terrorism. The Kenyan government is interested in comprehensive sex education as part of a policy to improve SRHR, but faces public opposition to this idea due to differing sociocultural views, notably from religious groups as well as from teachers who hold the same conservative beliefs (Agbemenu and Schlenk 2010; Mbugua 2007). Authorities have interpreted these laws to restrict access to sexually explicit material. For example, a Durex commercial for condoms in Kenya and the screenings of the erotic film Fifty Shades of Grey were banned on these grounds (The Star 2015; Article 19 2015).

Love Matters has lost its presence in the print edition of The Star newspaper for being too explicit. Love Matters Kenya is careful to avoid conflicts with the traditional offline gatekeepers; its main challenge regarding its online content in Kenya comes in the form of censorship by gatekeepers such as Facebook and Google.

\section{Mexico}

Although no legislation actively restricts internet access in Mexico, there are indications that the government has increased requests to media and internet service providers to remove certain content. ${ }^{12}$ However, internet freedom is severely limited by one of the highest levels of violence against journalists in the world. Online journalists, bloggers, and social media activists often risk their safety to report on local crime and corruption (Freedom House n.d.c); and Mexico is one of the most dangerous countries in the world to work in as a journalist (Committee to Protect Journalists 2016). However, these instances are usually restricted to journalists reporting on drug-related or political issues.

Since 1995, sex education has been considered a fundamental human right in Mexico, but is heteronormative and focused on health and reproductive functions (Lozano-Veruzco and Rosales Mendoza 2016; UNESCO 2015). Pornography in Mexico is legal; and the regulation of internet content largely addresses the same concerns and strategies seen elsewhere in North America and Europe, with a focus on combating the spread of child pornography and restricting child access 
Figure 1 Example of a banned Love Matters advert

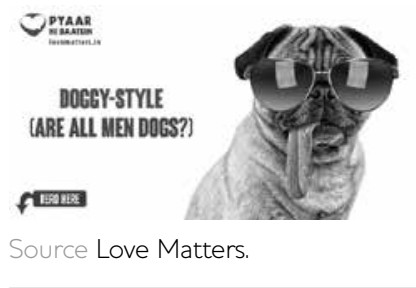

to age-inappropriate material. Facebook has also banned posts with explicit sexual images. Despite this relatively free environment, Love Matters editorial decisions are restricted on some topics. One such example is abortion, which is therefore also called 'legal interruption of pregnancy' to soften stigmas and change prejudices. This is because although abortion procedures have been decriminalised in Mexico City since 2007, they are forbidden or restricted in more than half of Mexico's 31 states. Since 2010, all 31 states have recognised same-sex marriages performed within Mexico without exception. Editors regularly include lesbian, gay, bisexual and transgender topics, with the aim of encouraging users to adopt positive and inclusive language to reduce discrimination and intolerance, and open a dialogue with conservative groups.

India

The Indian constitution guarantees freedom of speech and expression with certain restrictions related to morality, decency, public order, and so on. The Indian Penal Code allows restricting free speech on grounds of inciting religious feelings, making statements about or creating or promoting enmity, hatred or ill will between classes on grounds of religion, caste, language or race. These exceptions also extend to expressions in the media. The 1923 Official Secrets Act empowers authorities to censor security-related articles and prosecute members of the press (Freedom House n.d.b). Punishment for violations of freedom of speech generally targets political dissidents (Kant 2014). Timelines of several internet censorship bans in the past 20 years in India illustrate an environment in which, increasingly, speech is quickly censored (News Laundry 2015; Tang et al. 2015). In 2012, journalists' access to court cases was restricted and they were arrested for writing about the sexual assault and rape cases, reflecting mixed gender norms and attitudes about sexual attacks and the Indian state (Committee to Protect Journalists 2014).

In an increasingly religious and conservative political context, 12 Indian state governments have stopped providing sex education. Sex education is increasingly outsourced to non-profit or private organisations and remains off the school curriculum in most parts of India (Khomami 2015). It is not illegal to watch pornography, except child pornography, but it is illegal to distribute it (Brajesh 2011 ). This makes it difficult to implement restrictions on pornography. Recently, users flooded social media with complaints after the government blocked as many as 857 pornographic websites in an apparent bid to lower abuse against women, which resulted in a lifting of the ban on the websites. Love Matters has not faced any issue with the government or governing laws in India. In line with government rules, the website clearly states that users must be over 18 years of age. However, censorship via Google and Facebook applies here as it does for Love Matters offices in other countries. For example, a picture of a dog with sunglasses and the text 'Doggy-style (Are all men dogs?)' has been banned (Figure 1). 
Table 1 Overview of types of traffic in the dataset

\begin{tabular}{ll}
\hline Type of traffic & Explanation \\
\hline Direct & $\begin{array}{l}\text { Traffic that does not come through any channel (i.e. the user types } \\
\text { in the web address and hits 'enter') }\end{array}$ \\
Display & Traffic directed through advertisements and links \\
Email & $\begin{array}{l}\text { Traffic through a link included in an email (footer/signature) sent } \\
\text { by Love Matters that links back to website }\end{array}$ \\
Paid search & Traffic coming in through pay-per-click campaigns \\
Organic search & Traffic generated by people coming via search engines \\
Referrals & Traffic sent from other websites via links \\
Social & Traffic via a link on a social network, such as Twitter or Facebook \\
Other & $\begin{array}{l}\text { Marketing campaigns that generate traffic but do not fit into any } \\
\text { of the above categories }\end{array}$
\end{tabular}

Notes (a) Only available for three of the countries (China, Kenya and India); (b) Given the very low number of observations on this channel, we have not included it in our analysis.

\section{Data}

This study uses data from Love Matters sex education sites in China, India, Kenya, Mexico and Egypt over a period of five months, from 16 July to 16 December 2015. At the lower and higher ends of the spectrum, 570,319 and 6,834,170 sessions (individual visits to Love Matters websites) were recorded during this timeframe in China and India, respectively. The Love Matters sites in Mexico, Kenya and Egypt counted 1,032,104, 1,102,987 and 1,468,242 sessions.

Looking at different types of channels that were used to reach the Love Matters country sites and investigating some of their properties, we can draw limited but nevertheless useful information about visitors' behaviour in each country, and compare experiences across countries to find whether 'universal' pathways could be relevant for sex educators and gatekeepers beyond the study countries. Table 1 explains the different types of traffic and channels.

For each of the countries, channels and weeks between mid-July and mid-December 2015, we use the number of sessions per week as an indicator for reach and the following measures of engagement: average time spent per session; bounce rates; average number of pages viewed per session; and average time spent on site. A session is considered to have bounced when users leave the website from the same page that they entered without looking at anything else on that site. In what follows, we investigate what these numbers might tell us about how the visitors get to and interact with the websites.

\section{Empirical results}

\subsection{General observations}

Figure 2 shows the shares of different channels by which users reach Love Matters websites. Although some channels are important everywhere, 
Figure 2 Share of channels on overall traffic by country

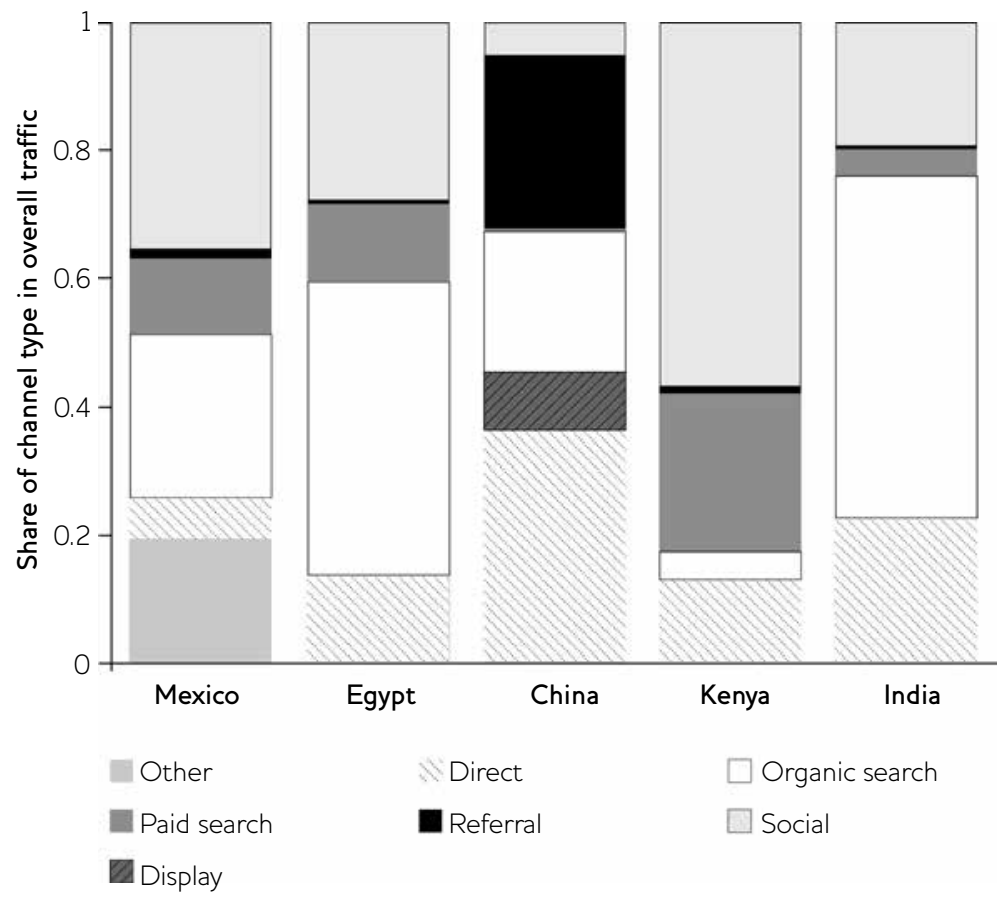

Source Love Matters Global Digital Pathways Dataset

they seem to play very different roles across countries. For example, referrals are much more frequent in China than in any other country (27 per cent of traffic comes through referrals); whereas visits to Love Matters websites through social network sites play a very minor role and paid search almost none. Furthermore, direct and display traffic seem to play larger roles in China than in the other countries. However, to a large degree this is a result of 'technical accounting'. Of the social media pages accessible in China, only one is counted as a social traffic source. Many of the other prominent social channels in China are blogs and therefore appear primarily as referrals and direct traffic in Google Analytics, which tracks and reports website traffic. The Love Matters team estimates that 85 per cent of referral traffic in China could actually be social traffic.

Organic searches, by people using search engines, are particularly important in Egypt and India (53 and 46 per cent of traffic, respectively); Kenya has the largest share of social traffic among the Love Matters countries (57 per cent of traffic); and 'other' channels only play a role in Mexico (19 per cent). One of the reasons why organic traffic figures are particularly high in Egypt and India is because both the Love Matters India and Love Matters Arabic (Egypt) websites offer pleasure-positive sex education information in local languages, Hindi and Arabic. Love Matters is the first ever, and one of very few SRHR websites in these languages. Before launching local sites in Hindi and Arabic, Love Matters conducted field research to assess the needs of 
Table 2 Average session duration on Love Matters websites

\begin{tabular}{lccc}
\hline Channel & Duration (seconds) & Page views & Bounce rate \\
\hline Display & 279.2 & 3.9 & 0.42 \\
Referral & 270.0 & 3.5 & 0.52 \\
Other & 195.5 & 2.9 & 0.68 \\
Direct & 154.3 & 2.1 & 0.70 \\
Paid search & 127.3 & 2.4 & 0.58 \\
Social & 123.4 & 1.9 & 0.76 \\
Organic search & 118.5 & 2.0 & 0.71 \\
\hline Country & Duration (seconds) & Page views & Bounce rate \\
\hline India & 239.9 & 3.0 & 0.57 \\
Kenya & 237.1 & 3.1 & 0.60 \\
Egypt & 147.7 & 2.2 & 0.70 \\
China & 135.1 & 2.8 & 0.60 \\
Mexico & 101.1 & 1.6 & 0.74 \\
\hline Sal & 13.6 & & \\
\hline
\end{tabular}

Source Love Matters Global Digital Pathways Dataset.

its audience members. Based on their feedback, Love Matters aimed to provide youth-friendly SRHR information in local languages so it would be accessible to the broadest possible audience. Therefore, if people search for sex education information in Hindi and Arabic (using modern standard Arabic, also referred to as 'literary Arabic' or fusha), Love Matters would be ranked higher by Google and thus often be listed on the first results page. The Love Matters Facebook page has a large number of users - over 4.5 million active users in 2015 - and the majority of these (95 per cent) access Facebook using mobile phones.

Table 2 gives an overview of average times spent per session, average number of pages visited per session, and average bounce rates by channel on the one hand; and by Love Matters country site on the other. Overall, visitors who spend the most time on Love Matters sites around 4.5 minutes - arrive at them primarily through advertisements and links ('Display'), closely followed by visitors who arrive from other websites ('Referral'). This indicates that advertisements and links are well placed. Furthermore, visitors who arrive through organic searches spend almost two minutes on the sites, which seems to suggest that people find the content they were looking for; and/or even if they do not find exactly what they were searching for, they still consider the information on Love Matters websites interesting and informative. This means that for an effective sex education website one needs to ensure the content is written in the appropriate local language, and that sufficient resources are allocated to search engine optimisation (SEO). 
Table 3 Most 'successful' channels by country*

\begin{tabular}{|c|c|c|c|c|c|}
\hline Country & Channel & Score & Time spent & Page views & Bounce rate \\
\hline \multirow[t]{2}{*}{ Mexico } & Referral & 3 & $\checkmark$ & $\checkmark$ & \\
\hline & Paid search & 2 & $\checkmark$ & - & $\checkmark$ \\
\hline \multirow[t]{3}{*}{ Egypt } & Referral & 3 & $\checkmark$ & $\checkmark$ & $\checkmark$ \\
\hline & Paid search & 2 & - & $\checkmark$ & $\checkmark$ \\
\hline & Other & 1 & $\checkmark$ & - & - \\
\hline \multirow[t]{4}{*}{ China } & Referral & 3 & $\checkmark$ & $\checkmark$ & $\checkmark$ \\
\hline & Display & 2 & - & $\checkmark$ & $\checkmark$ \\
\hline & Paid search & 2 & - & $\checkmark$ & $\checkmark$ \\
\hline & Other & 2 & $\checkmark$ & & $\checkmark$ \\
\hline \multirow[t]{4}{*}{ Kenya } & Referral & 3 & $\checkmark$ & $\checkmark$ & $\checkmark$ \\
\hline & Other & 3 & $\checkmark$ & $\checkmark$ & $\checkmark$ \\
\hline & Display & 3 & $\checkmark$ & $\checkmark$ & $\checkmark$ \\
\hline & Paid search & 1 & - & - & $\checkmark$ \\
\hline \multirow[t]{5}{*}{ India } & Referral & 3 & $\checkmark$ & $\checkmark$ & $\checkmark$ \\
\hline & Display & 3 & $\checkmark$ & $\checkmark$ & $\checkmark$ \\
\hline & Paid search & 1 & - & - & $\checkmark$ \\
\hline & Direct & 1 & $\checkmark$ & - & - \\
\hline & Other & 1 & - & - & $\checkmark$ \\
\hline
\end{tabular}

* Channels scoring at least one point.

Source Love Matters Global Digital Pathways Dataset.

In terms of country differences, visitors in India and Kenya seem to spend most time on Love Matters websites; and they also show the highest average number of page views and lowest bounce rates, along with China. Possible explanations are the aforementioned use of local language on the Indian website, and that Chinese visitors face longer loading times of Love Matters web pages, which in turn could indicate that they are more willing to engage with the Love Matters website.

There are also differences between the types of channels. Display and referral traffic seems to be generated by viewers who stay on a site the longest, look at most pages and bounce least often. This reflects a certain type of self-selection and 'user bias'; in other words, users who reach the Love Matters website have chosen to click on the Love Matters URL on another website because they want to know more, and most probably know what to expect. In this respect, the positive engagement indicators are then a good sign, suggesting that the users do indeed find what they are looking for. Having seen the varying 
importance of the different channels across countries, in the next section we investigate whether these averages obscure country differences, and whether the 'success' of channels differs across the countries.

\section{2 'Channel behaviour' by country}

To investigate whether country differences exist according to the performance of the various channels in attracting and holding traffic on Love Matters sex education web pages, we identify channels that are most 'successful' in each country. In the absence of information on return rates (repeat visits), we define success as engaging visitors who stay on sites for longer than on average, look at more pages per session than on average, and have below average bounce rates. ${ }^{13}$ Each of these three criteria feed into a score between zero and three, with the maximum three obtained if all criteria are met. Table 3 shows the channels in each country that scored at least one point.

Despite the country differences in the contribution of each channel to the overall share of traffic (Figure 1), there are some clear 'winners' in terms of performance. Referral is by far the most successful traffic source, followed by display and paid search traffic. The success of paid search traffic is interesting and triggers the question of what users are searching on exactly. Given the popularity of pornographic sites, it is an open question as to what extent people are looking for pornography and land on sex education pages instead. Oosterhoff, Gilder and Müller (2016, forthcoming) analysed 471,000 individual search terms by Kenyan users that brought them to the Love Matters site during the period of 16 July-16 December 2015. The five most popular search terms were 'sex' (7.9 per cent), 'love' (3.2 per cent), 'how' (3.0 per cent), 'penis' (2.8 per cent) and 'HIV' (1.17 per cent). The 'how' suggests - at least partially - audience members who are looking for educational material. Also, the low bounce rates for this type of traffic suggest this, as people looking for pornography would most probably immediately recognise the Love Matters web pages as non-pornographic.

Most referrals come from Facebook. The success of referrals could thus indicate the self-selective nature of users who engage with Love Matters websites, who come through Facebook or click on advertisements or links expecting to learn more. The success of display traffic is because advertisements and links are placed strategically; in other words, Love Matters pays more for advertisements on more relevant sites to engage its users more often. For example, in addition to promoting content using Facebook advertisements, the Love Matters Kenya team runs weekly campaigns on hot topics to attract and engage users to the Facebook page and website.

Legal and internet censorship clearly influence the content either after it is publicised or through self-censorship. But it is less clear if and how national legal censorship influences the traffic patterns we see. While politically China, Egypt, Kenya, Mexico and India may have multiple laws that restrict and/or censor freedom of expression offline 
and online, it is up to their governments to implement these laws. Implementation has often been haphazard. However, regardless of the implementation of restrictive laws, the fear of being censored, arrested or harassed affects editorial teams' decisions to publish certain content. In practice, editorial teams practise a certain level of discretion when it comes to publishing content. This could be because they want to preserve relationships with more traditional NGO and media partners.

Additionally, internet censorship by new gatekeepers has the potential to affect traffic patterns. Between December 2015 and July 2016, 24 per cent of Love Matters India's Facebook campaigns were disallowed; for Love Matters Hablemos, 27 per cent; for Love Matters Arabic, 6 per cent; and for Love Matters Kenya, 8 per cent. During that period, we estimate that 500,000 session or visits to Love Matters were potentially missed. Although marketers invariably launch a separate advertisement when one is rejected - thus probably minimising outreach loss - this still means that they spend large amounts of resources on developing campaigns and advertisements when it is often not even clear why they were rejected.

\section{Conclusions and recommendations}

Traditional gatekeepers such as governments play a role in legislating laws and policies on what kinds of information on sexuality are available and accessible for young people within state boundaries. Sex educators' relationships and networks can be endangered by pushing certain editorial content. Often it is difficult to predict when and where there will be opposition or from whom; and local staff have to make judgement calls in complex situations without clear guidelines. All country contexts are very different, but staff work with other partners and NGOs everywhere, with or without state support. In Kenya, the state and Love Matters share a commitment to SRHR for young people and both have similarly unpredictable enemies among religious authorities, some of whom - such as militant Islamist group al-Shabaab - are self-appointed and violent. In India, federal states have considerable authority to ban or allow sex education or NGO operations. In most of the countries where Love Matters operates, with the possible exception of China, the state does not hold a monopoly over legitimate use of physical force and is challenged by insurgent forces, such as ISIS or al-Shabaab. SRHR is often a contested area for both the state and these insurgent forces, which drapes layers of insecurity over editorial decisions. Therefore the challenge in each country is to figure out how to promote editorial content without jeopardising relationships with local NGOs or governmental organisations. Given the importance of wider civil and political liberties on freedom of speech in all forms, including that of online sex educators, it is important to follow these developments closely to help understand local contextual changes in the performance of national teams.

There are several aspects to the censorship of sex education online. First, government effectiveness in online censorship is dependent on resources and technological know-how, as well as the technological 
'savviness' of the population. While blocking and filtering are effective tools for non-technical audiences, countries with a growing internetsavvy population are seeing a number of techniques applied to circumvent internet censorship from the user side; for example, using circumvention software tools, cached pages, proxy websites, and so on. Thus, users are not necessarily passive recipients of online content, even if there are rules in place. Second, traditional gatekeepers share their online power with supranational commercial organisations such as Facebook and Google, which censor content based on their rules and algorithms. Our findings show that these new gatekeepers control access to information in two very powerful ways: (1) by using broad policies implemented through algorithms to restrict access to content; and (2) through monetary mechanisms, such as paid advertisements.

Sex educators are learning to engage with these commercial organisations and need to lobby private companies to acknowledge accurate, credible sources of sex education information. This is particularly important in countries where this information is censored offline and the internet is one of the few places that could offset these restrictions. Three open areas of enquiry in particular seem worth exploring here.

The first question is to what extent content providers depend on these gatekeepers for traffic, and whether users could use alternative channels to find information they seek; in other words, would overall traffic reduce drastically if one channel was restricted or would other channels gain importance?

The second question relates to the type of visitors coming from social media platforms through different channels. In our analysis, we found that referrals from Facebook are very engaged on Love Matters websites. However, part of the traffic from Facebook is captured in the 'social' traffic category, which as shown above does not seem very successful. It is crucial to understand whether this is just a technical 'categorisation issue' (i.e. whether they should be in the same category) or whether there could be inherent differences between Facebook visitors via referral and Facebook visitors via social traffic that are worth exploring.

The third question is: who exactly are the visitors to sex education websites? If Facebook is driving large amounts of traffic, then there is a high chance of a large female audience, as more women than men tend to use Facebook. They are also much more active, with more than twice as many posts on their walls and 8 per cent more friends than men. ${ }^{14}$ However, looking at discussion board entries on the Love Matters India website, we find that mainly men are actively engaged in asking questions there. It would provide insight into whether these are gender differences in terms of preference or in access to technologies.

Understanding the audience better would enable sex education providers to tailor their content and outreach activities even better. 
Another aspect related to attracting local populations is the importance of tailoring online content in local languages that are accessible and youth friendly, as shown in the high proportion of organic traffic that comes to the Love Matters India and Arabic sites. It allows them leveraging their limited resources most effectively within increasingly restrictive online and offline environments. Tailoring also means paying less money for marketing that targets young people.

The advantages of comprehensive online sex education that focuses on pleasurable aspects of sexuality have already been pointed out. These include that it is anonymous, interactive, portable, accessible at any time, and can be easily adapted based on users' needs and demands. There are five areas that we think require special attention to effectively reach out to young people and provide them with sex education in the digital age. Some of these are already happening and others are more forward looking and might need broadening coalitions:

1 Understand your audience: what do they want, what do they need, how can they engage, and how do they prefer to engage? This means more than simply providing a needs assessment. It means asking audience members how they want this information provided, in what language, with what type of imagery, and how often; and asking them to prioritise what matters to them. Sex educators need to employ and embrace online marketing and advertising mechanisms to reach their audience. In the digital era, sex educators are constantly competing for the audience's attention. With Facebook and other apps, audiences are expecting and consuming content in smaller bites (shorter visits), but more often. Content strategies need to be planned around this.

2 Understand to what extent interests of users and providers of sex education overlap or can be aligned with those of traditional gatekeepers such as the state and religious authorities, and engage and cooperate wherever possible. Limits can be pushed as long as they do not endanger people - users or staff.

3 Work with local organisations that have networks, experience and a deep understanding of the local context. They can help sex educators to understand how to deliver content, and if and how far one can push boundaries.

4 There needs to be a greater understanding of the power of invisible online gatekeepers to balance the attention given to traditional gatekeepers vs new gatekeepers, especially when it comes to return on investment. Sex educators need to invest in SEO and marketing.

5 Engage with supranational commercial organisations to make them understand the importance of sex education and push the boundaries of their understanding of 'explicit material' and 'pornography'. 


\section{Notes}

1 www.apc.org/en/system/files/EroTICsBriefingEN_0.pdf.

2 www.unesco.org/new/en/hiv-and-aids/our-priorities-in-hiv/ sexuality-education/.

3 Ordered by numbers of mentioning in the studies under review.

4 See, for example, Pendry and Salvatore (2015); Subrahmanyam, Greenfield and Tynes (2004).

5 https://lmarabic.com/news/video-wedding-night-sex.

6 'Your advert wasn't approved because it doesn't follow our Advertising Policies for advertising adult products or services. We don't allow images or videos that show nudity or cleavage, even if it's portrayed for artistic or educational reasons. How to fix: We suggest using a different image or video and checking that the destination link is compliant, too. If you think that your advert follows our policies, you can appeal against this disapproval.'

7 'This ad has been disapproved. Adult content.'

8 www.aftenposten.no/meninger/kommentar/Dear-Mark-I-amwriting-this-to-inform-you-that-I-shall-not-comply-with-yourrequirement-to-remove-this-picture-604156b.html.

9 www.hrw.org/reports/2006/china0806/3.htm.

10 See, for example, China in 2014: http://in.reuters.com/article/ china-internet-pornography-idINKBN0D704Q20140421.

11 https://freedomhouse.org/report/freedom-press/2015/egypt.

$12 \mathrm{http} / /$ /aristeguinoticias.com/0904/mundo/censura-de-internet-en13-paises-del-mundo-mexico-sera-uno-mas/.

13 Poor website navigation could also result in people spending a long time on sites, with lots of page visits, because they cannot find what they are looking for.

14 www.brandwatch.com/2015/01/men-vs-women-active-social-media/.

\section{References}

Agbemenu, Kafuli and Schlenk, Elizabeth A. (2010) 'An Integrative Review of Comprehensive Sex Education for Adolescent Girls in Kenya', Journal of Nursing Scholarship 43.1: 54-63

Allen, Louisa (2007) 'Denying the Sexual Subject: Schools' Regulation of Student Sexuality', British Educational Research Fournal 33.2: 221-34

Allen, Louisa (2006) 'Looking at the Real Thing: Young Men, Pornography, and Sexuality Education', Discourse: Studies in the Cultural Politics of Education 27.1: 69-83

Allen, Louisa (2001) 'Closing Sex Education's Knowledge/Practice Gap: The Reconceptualisation of Young People's Sexual Knowledge', Sex Education: Sexuality, Society and Learning 1.2: 109-22

Amnesty International (2016) Annual Report: Egypt 2015/2016, www.amnesty.org/en/countries/middle-east-and-north-africa/ egypt/report-egypt/ (accessed 15 May 2016)

ANHRI (2015) Egypt: Ahmed Nagi's Referral to Prosecution for Publishing Chapter of his Novel at Akhbar Al-Adab Nerespaper is a Flagrant Violation of Freedom of Expression and Creativity, 1 November, Arabic Network for Human Rights Information, http://anhri.net/?p=153552\&lang=en (accessed 20 December 2016) 
APC (2010) Media Brief: Censorship, Sexuality, and the Internet, Association for Progressive Communications, www.apc.org/en/node/10262 (accessed 15 May 2016)

Article 19 (2015) Kenya: Film Regulator Bans Screening of Fifty Shades of Grey, 13 February, www.article19.org/resources.php/resource/37851/en/ kenya:-film-regulator-bans-screening-of-fifty-shades-of-grey (accessed 15 May 2016)

Bay-Cheng, L.Y. (2001) 'SexEd.com: Values and Norms in Web-Based Sexuality Education', Fournal of Sex Research 38: 241-51

Beamish, Julia (2003) Adolescent and Youth Reproductive Health In Egypt: Status, Issues, Policies, and Programs, Policy Project, www.policyproject.com/ pubs/countryreports/ARH_Egypt.pdf: 1-27 (accessed 15 May 2016)

Brajesh, R. (2011) Pornography Laws: XXX Must Not be Tolerated, Delhi: Universal Law Co.: 61

Committee to Protect Journalists (2016) Owner of Mexican News Outlet who was Threatened for his Reporting Killed in Tabasco, 22 February, https://cpj.org/2016/02/owner-of-mexican-news-outlet-who-wasthreatened-fo.php\#more (accessed 15 May 2016)

Committee to Protect Journalists (2014) Finding the Courage to Cover Sexual Violence, https://cpj.org/2014/02/attacks-on-the-press-securitysexual-assault.php (accessed 15 May 2016)

Dyson, Sue; Mitchell, Anne; Dalton, Derek and Hillier, Lynne (2003) Factors for Success in Conducting Effective Sexual Health and Relationships Education with Young People in Schools: A Literature Review, commissioned by Shine SA, Melbourne: Australian Research Centre in Sex, Health, and Society, La Trobe University

Egyptian Streets (2015) Egyptian Courts Ban Pornography, 20 May, http://egyptianstreets.com/2015/05/20/egypt-court-banspornography/ (accessed 16 May 2016)

EIPR (2014) Sexuality Education in Egypt: A Needs Assessment for a Comprehensive Program for Youth, St Garden City, Cairo: Egyptian Initiative for Personal Rights, http://eipr.org/sites/default/files/ pressreleases/pdf/sexuality_education_english.pdf (accessed 15 May 2016)

Freedom House (n.d.a) Egypt: Freedom of the Press 2015, https://freedomhouse.org/report/freedom-press/2015/egypt (accessed 15 May 2016)

Freedom House (n.d.b) India: Freedom of the Press 2015, https://freedomhouse.org/report/freedom-press/2015/india (accessed 15 May 2016)

Freedom House (n.d.c) Mexico: Freedom of the Net 2015, https://freedomhouse.org/report/freedom-net/2015/mexico (accessed 15 May 2016)

Hirst, Julia (2013) "IIts Got to Be About Enjoying Yourself": Young People, Sexual Pleasure, and Sex and Relationships Education', Sex Education 13.4: 423-36

Human Rights Watch (2013) World Report 2014: China, Events of 2013, www.hrw.org/world-report/2014/country-chapters/china-and-tibet_ (accessed 16 May 2016) 
Isaacson, N. (2006) 'An Overview of the Role of Sexual Health Organizations, Corporations, and Government in Determining Content and Access to Online Sexuality Education for Adolescents', Sexuality Research and Social Policy 3.2: 24-36

Johnson, Bruce; Harrison, Lyn; Ollis, Deb; Flentje, Jane; Arnold, Peter and Bartholomaeus, Clare (2016) 'It Is Not All About Sex': Young People's Views About Sexuality and Relationships Education, Report of Stage 1 of the Engaging Young People in Sexuality Education Research Project, Adelaide: University of South Australia

Kant, Arjun (2014) Law Wire: Censorship in India, the Truth, http://lawinfowire. com/articleinfo/censorship-india-truth (accessed 15 May 2016)

Keller, S.N.; LaBelle, H.; Karimi, N. and Gupta, S. (2004) 'Talking About STD/HIV Prevention: A Look at Communication Online', AIDS Care 16: 977-92

Keller, S.N.; LaBelle, H.; Karimi, N. and Gupta, S. (2002) 'STD/HIV Prevention for Teenagers: A Look at the Internet Universe', Fournal of Health Communication 7: 341-53

Khomami, Nadia (2015) 'India Lifts Ban on Internet Pornography After Criticism', Guardian, 5 August, www.theguardian.com/culture/2015/ aug/05/india-lifts-ban-on-internet-pornography-after-criticisms (accessed 15 May 2016)

L'Engle, Kelly Ladin; Brown, Jane D. and Kenneavy, Kristin (2006) 'The Mass Media are an Important Context for Adolescents' Sexual Behavior', Fournal of Adolescent Health 38.3: 186-92

Lou, Chaohua; Cheng, Yan; Gao, Ersheng; Zuo, Xiayun; Emerson, Mark R. and Zabin, Laurie S. (2012) 'Media's Contribution to Sexual Knowledge, Attitudes, and Behaviors for Adolescents and Young Adults in Three Asian Cities', Journal of Adolescent Health 50.3: S26-S36

Lozano-Veruzco, Ignacio and Rosales Mendoza, Adriana Leona (2016) 'In/Formal Sex Education: Learning Gay Identity in Cultural and Educational Contexts in Mexico', Gender and Education 28.4: 1-16

Mbugua, Njeri (2007) 'Factors Inhibiting Educated Mothers in Kenya from Giving Meaningful Sex-Education to their Daughters', Social Science and Medicine 64.5: 1079-89

News Laundry (2015) Access Denied: One Info-Graphic That Tells You Everything About Internet Censorship in India Since 2012, 9 December, www.newslaundry.com/2015/12/09/access-denied-one-infographic-that-tells-you-everything-about-internet-censorship-in-indiasince-2012/ (accessed 16 May 2016)

Ngo, Anh D.; Ross, Michael W. and Ratliff, Eric A. (2008) 'Internet Influences on Sexual Practices Among Young People in Hanoi, Vietnam', Culture, Health and Sexuality 10.S1: S201-13

Oosterhoff, P.; Gilder, L. and Müller, C. (2016) 'Is Porn the New Sex Education?', IDS Rapid Response Briefing 15, Brighton: IDS

O'Reilly, T. (2005) 'What is Web 2.0: Design Patterns and Business Models for the Next Generation of Software', Communication and Strategies, https://mpra.ub.uni-muenchen.de/4578/1/mpra_ paper_4578.pdf (accessed 20 December 2016) 
Pendry, Louise F. and Salvatore, Jessica (2015) 'Individual and Social Benefits of Online Discussion Forums', Computers in Human Behavior 50: $211-20$

RSF (2016) Egypt, Reporters Without Borders, https://rsf.org/en/egypt (accessed 15 May 2016)

Simon, Laura and Daneback, Kristian (2013) “"Adolescents" Use of the Internet for Sex Education: A Thematic and Critical Review of the Literature', International Fournal of Sexual Health 25.4: 305-19

The Star (2015) 'Film Board Bans "Pornographic" Durex, Trust Condom Ads', 16 December, www.the-star.co.ke/news/2015/12/16/filmboard-bans-pornographic-durex-trust-condom-ads_c1261936 (accessed 15 May 2016)

Subrahmanyam, Kaveri; Greenfield, Patricia M. and Tynes, Bradesha (2004) 'Constructing Sexuality and Identity in an Online Teen Chat Room', fournal of Applied Developmental Psychology 25.6: 651-66

Tang, Amy; Rankin, Evan; de Caires, Brendan and Beesley, Drew (2015) Imposing Silence: The Use of India's Law to Suppress Free Speech, Toronto and London: PEN Canada, International Human Rights Program (IHRP) and PEN International, www.pen-international.org/wpcontent/uploads/2015/05/Imposing-Silence-4-WEB.pdf (accessed 15 May 2016)

UNESGO (2015) Emerging Evidence, Lessons, and Practice in Comprehensive Sexuality Education: A Global Review 2015, Paris: United Nations Educational, Scientific and Cultural Organization

UNFPA (2014) UNFPA Operational Guidance for Comprehensive Sexuality Education: A Focus on Human Rights and Gender, New York NY: United Nations Population Fund

United Nations (2015) United Nations Population Fund Country Programme Document for China, Executive Board of the United Nations Development Programme, the United Nations Population Fund and the United Nations Office for Project Services, www.unfpa.org/sites/ default/files/portal-document/China $\% 20$ CPD $\% 20-\% 20$ ODS.pdf (accessed 15 May 2016)

Zhou, Decai; Yiqing, He; Caiquan, Bai and Jichao, Lv (2014) 'Research on Evaluation for Population Quality in China Based on FAHP', Journal of Applied Sciences 14.3: 296-300 
This page is intentionally left blank 


\title{
Feeling 'Blue': Pornography and Sex Education in Eastern Africa'
}

\author{
Kristen Cheney, Annah Kamusiime and \\ Anteneh Mekonnen Yimer
}

\begin{abstract}
This study examined young people's exposure to sexually explicit media (SEM) in Ethiopia and Uganda, where comprehensive sexuality education is often lacking or even non-existent. Through mixed-method, youth-centred participatory research, young people affirmed the ubiquity of pornography - even in communities with little access to the internet. Male and female study participants aged 12-26 said they turned to pornography because they lacked adequate sex education - much of which was designed and run by adults who did not understand their diverse needs. By contrast, they felt pornography delivered the information they needed in an exciting manner. At the same time, young people recognised that pornography use could sometimes have too much influence over their developing sexual identities and practices. Youth in both countries called for more and better comprehensive sexuality education for the whole community, allowing for more open dialogue about sexuality - issues that they acknowledged can be compounded by their consumption and production of pornography.
\end{abstract}

Keywords: Ethiopia, pornography, sexual economy, sex education, sexually explicit media, social media, youth, Uganda.

\section{Introduction}

A 2013 rapid evidence assessment of pornography's effects on young people confirms that nearly all the literature available on young people's exposure to pornography and other sexually explicit media (SEM) refers to the global North. Horvath et al. (2013) found that children had widespread access to pornography and were likewise exposed almost constantly to sexually explicit imagery through a media-saturated culture. This had negative (and gendered) implications for young people's attitudes towards consent and objectification (Wright and Funk 2014), as well as unrealistic and maladaptive expectations of sex and relationships (Horvath et al. 2013).

Comprehensive sexuality education (CSE) programmes in Western countries are only now starting to deal substantively with the inundation of SEM through new and social media - of which young people are 
early adopters (Castells et al. 2007). This may be too late, however, as many children also report producing and distributing their own SEM through information and communications technology (ICT) such as phones and computers (e.g. 'sexting'). Pornography therefore continues to be the 'elephant in the room' when it comes to global sexuality education. Sex education programmes in developing countries tend to similarly discount the increasing presence of explicit media as a mode of sexual information that influences young people's sexual decisionmaking - especially in the absence of comprehensive adolescent sexual and reproductive health (ASRH) information (Horvath et al. 2013). Though studies indicate increasing mobile phone and internet use, especially among out-of-school youth (Save the Children 2014; Swahn, Braunstein and Kasirye 2014), very few studies have considered young people's exposure to SEM in developing country contexts through these and other media outlets (Day 2014). Nonetheless, our formative research findings with youth peer researchers (YPRs) in a separate Save the Children Project - which strove to better situate CSE curricula in local contexts - indicated that SEM such as violent and misogynist hard-core pornography are in fact widespread in urban and rural project areas in Ethiopia and Uganda. Qualitative interviews with youth indicated that mobile phones, internet and video are all common means of receiving and exchanging SEM - whether one owns a phone or video player or not - and that children as young as eight are consuming such media forms (Save the Children 2014).

We thus suspected that violent SEM might further undermine the quality of ASRH information and negatively affect young people's - especially girls' - freedom of choice in developing healthy sexual relationships. These factors pointed to a clear need for more in-depth research to better understand the ways and extent to which pornography and other SEM influence young people's sexual identity development and decision-making.

\section{Context}

In Ethiopia 42 per cent of the population is 10-29 years old (Central Statistical Agency 2014) while Uganda has the world's second youngest population with 78 per cent below age 30 (Republic of Uganda 2015: 3). Yet young people have many unmet ASRH needs (Republic of Uganda 2010) as well as a high risk of sexual violence. Girls in particular face severe challenges due to gender inequality - including early marriage and childbearing, sexually exploitative work and trafficking, female genital cutting, unsafe abortion, and harmful traditional practices (MWCYA 2014). In Uganda 56 per cent of women experience physical violence by age 15, and 28 per cent of women aged 15-49 experience sexual violence, compared to 9 per cent of men. Alarmingly, 98 per cent of children report physical or emotional violence, and 76 per cent report sexual violence (United Nations in Uganda 2016: 15).

CSE has been limited and unsystematic in both countries. Where available, sex education tends to focus on HIV/AIDS prevention and 
abstinence (Shuey et al. 1999; Muyinda, Nakuya, Whitworth and Pool 2004; Human Rights Watch 2005). In Ethiopia, non-governmental organisations (NGOs) have implemented extracurricular, grass-roots sex education (FGAE 2014), but these efforts are weak, fragmented and under-evaluated (Federal Ministry of Health 2015). The Ministry of Education in Ethiopia has only recently introduced a 'school-based HIV/AIDS, sexual and reproductive health intervention' (Federal Ministry of Education 2015) as part of select secondary school subjects. The Uganda Ministry of Education and Sports has only recently added sexuality education to the secondary school curriculum to be piloted in 2017 under the 'life education learning area' (Birungi 2015; Okoth 2013).

Ethiopia lags behind other eastern African countries in ICT, with 64 per cent overall mobile phone coverage (Adam 2012: 4). But mobile phone use has increased exponentially in recent years, especially among out-of-school youth: a 2014 study in Kampala by Swahn et al. found that 47 per cent of youth owned a mobile phone. Though 'ownership did not vary by sex', it was higher among independent youth over 18 (Swahn et al. 2014: 600). Our preliminary observations in both countries indicated that aside from consuming Western-produced pornography, greater access to ICT has engendered more 'home-grown' pornography - including amateur and commercial child pornography - and 'revenge porn' (private SEM shared publicly, often by an ex-lover who wishes to shame his/her ex-partner) (UK Government n.d.), with women commonly being targeted in Africa (Nakkazi 2016).

Both countries place legal and social prohibitions on SEM, but anti-pornography laws have been poorly enforced, and young people reported easy access to SEM. Pornography probably falls into the category of Obscene or Indecent Publications in the Ethiopian Penal Code (Federal Democratic Republic of Ethiopia 2004), whose production, possession, display and distribution are all punishable under the Crimes Tending to Corrupt Morals section, Articles 640-44.Though the Ethiopian government tends to place limits on people's internet freedoms due to concerns over state security, it still tolerates access to social media and SEM (CIPESA 2014: 9). Pornography is also considered obscene under Uganda's Penal Code Act section 166 (Republic of Uganda 1950), but it does not clearly define pornography. The 2014 Anti-pornography Act defines pornography as 'any representation of the sexual parts of a person for primarily sexual excitement' (Republic of Uganda 2014), but it has been misinterpreted as a law regulating women's clothing (Tajuba 2014), prompting vigilante public stripping of women (SIHA Network 2015). Even the state Minister for Ethics and Integrity keeps using the law to justify penalising indecent dressing and nudity, as in the recent case involving a Makerere University lecturer who stripped as a traditional form of protest (New Vision 2016).

\section{Objectives}

As an independent offshoot of the Save the Children project in Ethiopia and Uganda, this study aimed to establish the nature of youth SEM 
Figure 1 The Ethiopia research team - the principal investigator Kristen Cheney (back row, fourth from left) with supervisors, YPRs, and data analyst Maki Suyama (front row, second from right), July 2015

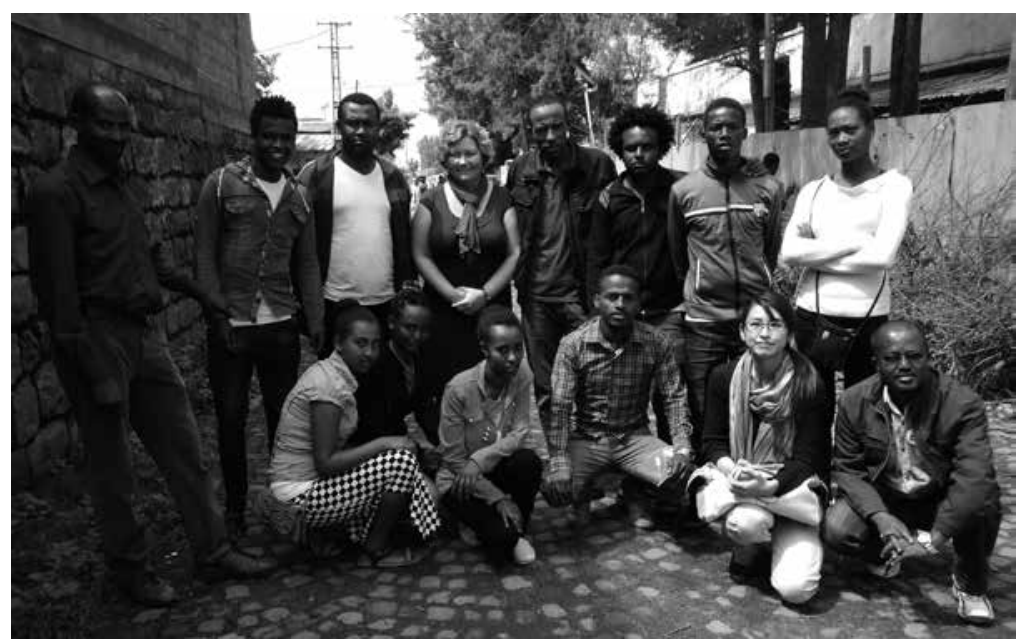

Photo Kristen Cheney

consumption as a baseline for future studies. Formative research indicated that SEM was widely available to young people in the study areas, yet little empirical evidence existed detailing young people's consumption and production of SEM, particularly in sub-Saharan Africa. Its relationship to CSE programmes could thus be further explored in order to provide a basis for strengthening local capacity relating to knowledge management about SEM and service provision of CSE. The findings could then be used to help create CSE programming that is better equipped to respond to youths' local realities.

\section{Methods}

To obtain as clear and accurate a picture as possible on a sensitive topic about which young people may hesitate to open up to adult researchers, we adopted an intersectional, youth-led participatory research approach. We recruited YPR teams from previous CSE research sites, including urban and rural areas with varying levels of ICT accessibility:

- Addis Ababa, Ethiopia (urban)

- Gelan, Ethiopia (rural)

- Kampala, Uganda (urban)

- Agago, Uganda (rural).

The team was led by the principal investigator Kristen Cheney and in each country by local research coordinators, Anteneh Mekonnen Yimer in Ethiopia and Annah Kamusiime in Uganda. International research collaboration was important for combining research experience with local knowledge to yield more comparative evidence. The coordinators were responsible for recruitment, coordination, and support of supervisors and YPRs. YPRs were chosen in consultation with supervisors based on their research and sexual and reproductive health 
and rights (SRHR) experience (for example, many had been youth peer educators), with an aim towards gender balance. The supervisors were adults in their communities - either teachers or youth group advisers who could help guide the YPRs on a daily basis, with the consultation of the local research coordinators. If the YPRs did not feel comfortable going to a supervisor, they could also consult the local research coordinator. Two in-school and two out-of-school YPRs were selected in each of four locations, for a total of 16 (Figure 1).

Training commenced with the first four YPR team workshops in March 2015, familiarising teams with basic sexuality and research concepts, as well as data-gathering techniques. YPRs also helped shape the research design through their feedback. Several issues that arose through a review of current literature about young people's exposure to pornography guided this process.

\subsection{Issues to address}

In light of their findings and identification of gaps in the literature around children's exposure to pornography, Horvath et al. (2013) recommended that research be conducted that:

1 Investigates what children and young people think pornography is and the content of what they describe as pornographic;

2 Investigates whether there are links between the pornography that children and young people are exposed to and/or access and their attitudes towards, aspirations about and feelings towards relationships and sex (op. cit.: 66).

We therefore designed our research partially around these needs. We also kept issues identified by Horvath et al. (2013) at the forefront of research design:

Pornography vs SEM. Previous studies have lacked clear and comparable definitions of pornography versus other SEM, or even previous trends in pornography, so that we do not often know whether the young study participants have the same concept of pornography as the researchers. Nor do we get a clear sense of the content they are viewing, which - given trends in the porn industry - may be much more extreme than they were even a few years ago. So we set out to have YPRs clarify what media forms and content young people considered pornographic along a sliding scale of sexual explicitness. By listing different media on a flipchart and discussing them, YPRs created a contextualised spectrum of SEM (see Figures 2 and 3). We also gathered local terminology and slang, such as 'blue movies' in Uganda and 'PB' for 'playboy' in Ethiopia, as well as colourful euphemisms such as 'software' and 'German karate'. YPRs considered forms of SEM such as music videos and magazines, while often explicit in varying degrees, were not necessarily pornographic due to their social acceptability. The definition of pornography was thus a matter of form (images and videos distributed through 
Figures 2 and 3 Working out local definitions of pornography vs SEM in the first Kampala YPR training workshop, March 2015 (left), and the last Kampala workshop, October 2015
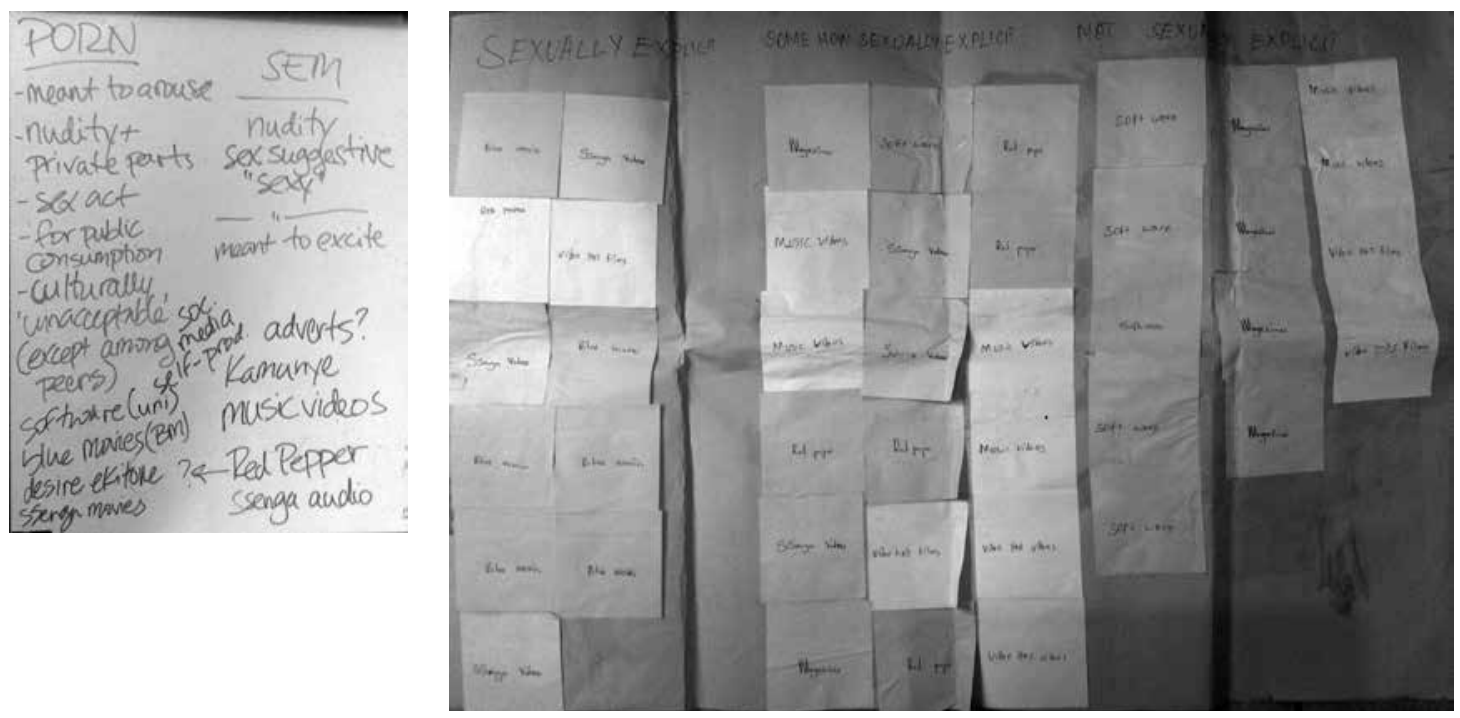

clandestine means), content (the degree and types of sexual activity being depicted) and social acceptability, i.e. pornography was widely available but not acceptable in the eyes of adult authority figures such as parents and teachers. Because of the ubiquity of SEM, however, our qualitative discussions tended to focus on young people's interactions with what they considered 'pornography'.

Access vs exposure. Horvath et al. (2013) drew a distinction between access - actively seeking out pornography - and exposure, involuntarily viewing pornographic images. This is significant because previous studies indicated that young people's experiences of access and exposure tend to be gendered: boys are much more likely to actively seek access to pornography, while girls are more often exposed through being sent unsolicited digital images, etc (ibid.). These are not mutually exclusive categories, however: an incident could start as one and become another. For example, explicit pop-up advertisements may expose a child to SEM. However, if he or she decides to click on it to access more of such images, it constitutes access. Still, the distinction is important for clarifying young people's motivations and intent in respect of pornography.

Consumption vs production. We also quickly realised in the initial workshop discussions that to track young people's actual experiences with SEM, we could not just study their consumption through access and exposure; we also had to record the incidence of young people producing and even distributing SEM through such means as social media. This would more holistically capture the reality of young people's involvement with SEM. 


\begin{tabular}{llcccc}
\hline $\begin{array}{l}\text { Demographic } \\
\text { characteristic }\end{array}$ & Category & \multicolumn{2}{c}{ Ethiopia } & \multicolumn{2}{c}{ Uganda } \\
& & Rural (\%) & Urban (\%) & Urban (\%) & Rural (\%) \\
\hline \multirow{2}{*}{ Age } & $12-17$ & 47 & 25 & 53 & 46 \\
& $18-21$ & 29 & 47 & 28 & 27 \\
& $22-26$ & 24 & 28 & 19 & 24 \\
Sex & No data & 0 & 0 & 0 & 3 \\
\hline \multirow{4}{*}{ Male } & 50 & 50 & 51 & 53 \\
& Female & 50 & 50 & 48 & 45 \\
Marital status & Single & 78 & 74 & 87 & 18 \\
& Married & 12 & 8 & 5 & 2
\end{tabular}

We decided in initial consultation with all research teams that due to lack of even basic information, we needed to conduct more comprehensive research than was initially planned (eight focus group discussions - FGDs). We therefore designed a new two-phase study plan: the first would involve administering a rapid-assessment quantitative survey to get a sense of the scope of young people's interaction with various forms of pornography. The second would probe emergent issues deeper through more qualitative methods of FGDs and interviews.

\subsection{Phase I: Survey}

We designed a general survey to first get a picture of which young people were being exposed to or accessing what kinds of SEM, with what frequency, and where: survey contents were organised around the themes of access and exposure, experiences with and attitudes towards SEM, and individual and social/cultural influences on SEM/pornography use. We also gathered basic data on their level of sex education, age of sexual debut, etc. Each YPR team then tested the tool and adjusted it to the local environment. YPRs collected more than 200 responses for each country, with fairly even gender and location distribution. YPRs surveyed a convenience sample totalling 414 people (Table 1). The data was then coded and analysed using STATA and SPSS (v.20).

\subsection{Phase II: Qualitative data}

After holding data analysis workshops with each YPR team in July 2015in which we summarised and discussed the implications of survey findings - we designed a set of informal qualitative questions to triangulate the survey data and deepen our understandings of young people's engagement with SEM in the key focus areas mentioned above, as well as discussion 
Table 2 Focus group discussions

\begin{tabular}{|c|c|c|c|c|c|}
\hline \multirow[t]{2}{*}{ Ethiopia } & \multicolumn{2}{|c|}{ Urban } & \multicolumn{2}{|c|}{ Rural } & \multirow[t]{2}{*}{ Total } \\
\hline & In-school & Out-of-school & In-school & Out-of-school & \\
\hline All-male & 1 & 1 & 1 & 1 & 4 \\
\hline All-female & 1 & 1 & 1 & 1 & 4 \\
\hline Mixed gender & 1 & 1 & 1 & 1 & 4 \\
\hline Total & 3 & 3 & 3 & 3 & 12 \\
\hline \multirow[t]{2}{*}{ Uganda } & \multicolumn{2}{|c|}{ Urban } & \multicolumn{2}{|c|}{ Rural } & Total \\
\hline & In-school & Out-of-school & In-school & Out-of-school & \\
\hline All-male & 1 & 1 & 1 & 1 & 4 \\
\hline All-female & 1 & 1 & 1 & 1 & 4 \\
\hline Mixed gender & 1 & 1 & 1 & 1 & 4 \\
\hline Total & 3 & 3 & 3 & 3 & 12 \\
\hline
\end{tabular}

of the consequences of SEM. We conducted 12 FGDs per country across the various demographics (see Table 2). Each YPR also conducted three in-depth interviews with peers, totalling 48 (24 boys, 24 girls).

Qualitative data was transcribed, coded and thematically analysed. In October 2015 we conducted final data-synthesising workshops in each country to discuss the qualitative data through various mapping and visual reporting exercises. Finally, we held discussions of our collective interpretations of the overall findings and solicited YPRs' recommendations.

\section{Summary of findings}

The findings that emerged fell into four main themes.

\subsection{Access and exposure: age, gender, and locale}

Nearly all respondents reported exposure to SEM/pornography including violent, hard-core - before the age of 18. In Uganda, rural youth reported higher levels of exposure (95 per cent) than urban youth (91 per cent). The youngest age of first exposure reported was eight years old, through observing an older sibling consuming pornographic images. In fact, 50 per cent of young people in Uganda reported being exposed to pornography by the age of 12 . We also noted a downward trend in Ethiopia, where the younger the respondent, the younger their age of first exposure, for boys and girls. More males (95 per cent) than females (90 per cent) reported having come into contact with SEM. Boys tended to seek access to pornography on a regular basis, whereas girls were more commonly exposed to pornography - often through friends (of both sexes but more commonly male friends) sending or showing them unsolicited SEM. Common exposure vectors were through mobile phones (Bluetooth) and internet cafes, video shops and video halls (Figure 4). 
Figure 4 YPR Shakirah discussing the results of the mapping exercise locating where young people gain access or are exposed to pornography in their community

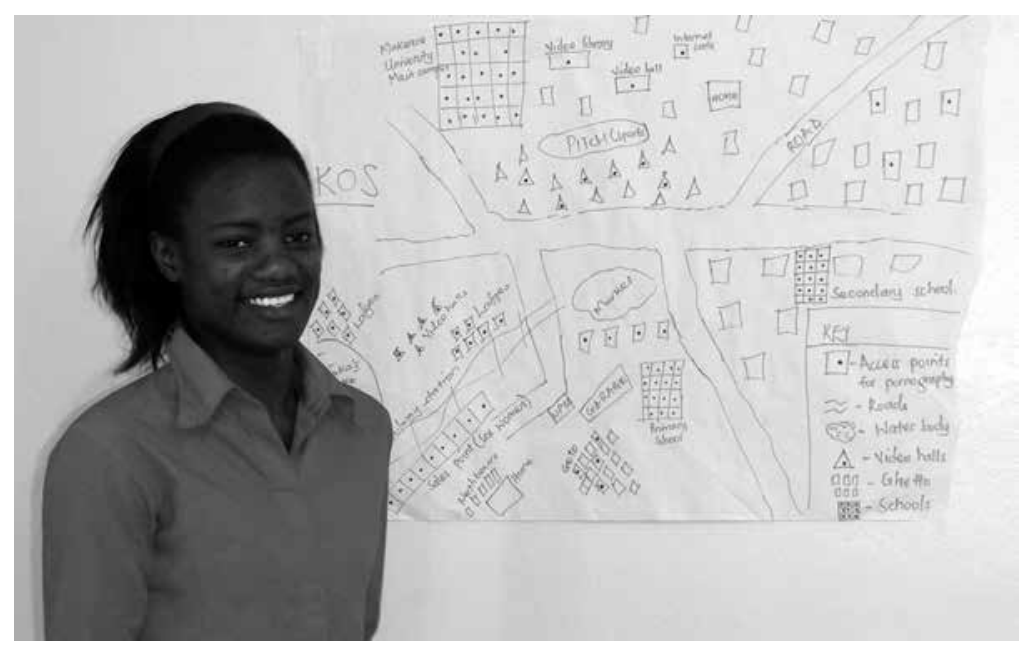

Photo Kristen Cheney.

Most reported that it was easy to access pornography due to its ubiquitous presence. As one Ugandan boy said, 'It's everywhere. It's in your hands all the time, you have it in your bed, it's on the streets, and it's in the car you travel in. Whenever you want it you will find it.' In rural Ethiopia, young people reported that schools were common places for the exchange of pornographic images, whether one still attended school or not: boys especially would gather on school grounds after hours and circulate images, some on paper but more often on their phones via Bluetooth.

One trend was that young people's interaction with pornography went beyond consumption to production, particularly with increased access to smartphones and digital cameras. For example, 11 per cent of Ethiopian survey respondents under 18 (of which 54 per cent were female) reported partners taking their pictures and posting them on Facebook or in WhatsApp groups. In one rural Uganda all-female FGD, girls explained that their partners who work outside of their communities occasionally ask them to take nude pictures of themselves and send them via WhatsApp. Similarly, participants in a mixed-gender FGD in urban Uganda said that it was 'normal' to take videos of themselves during sexual intercourse and even circulate them. While some girls expressed discomfort with this, they also felt under social pressure to consent to boys circulating images; others reported that boys sometimes filmed sex without their partners' consent.

\subsection{Motivations and expectations: the sociopolitical economy of pornography consumption and production}

In FGDs, young people - male and female - agreed that they consumed pornography primarily to get ideas about new sexual styles and positions. This was especially important to respondents in Uganda, whereas in Ethiopia, the primary objective was to 'release sexual 


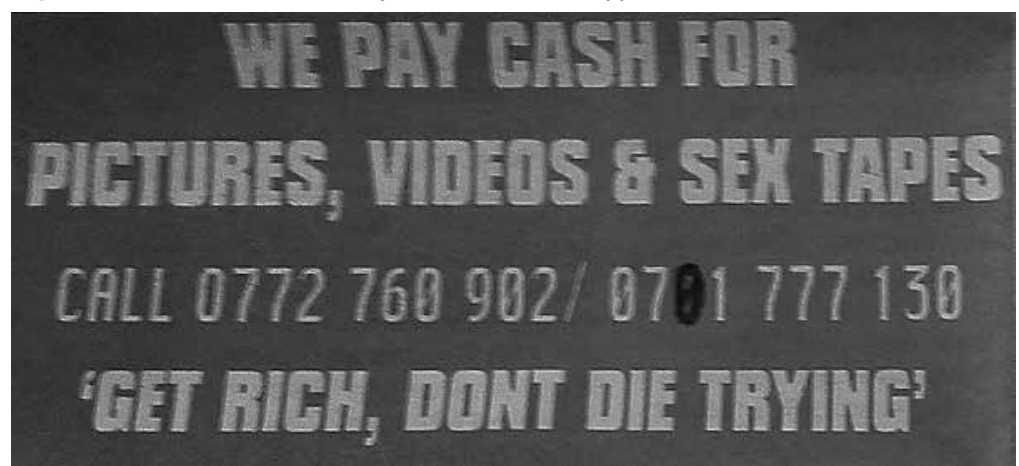

Photo Kristen Cheney.

feelings'. In both cases, though, young men and women indicated that consuming pornography was an important aspect of their social activity with peers: either they watched pornography together (which is how many were first exposed) or they spent time talking about pornography they had viewed separately. There is considerable peer pressure to stay current with the sexual trends depicted in pornography: 'During conversations, you hear your friends using terminology you are not aware of; they talk about sex styles you don't know, and you look like a villager who was left behind' (out-of-school male, 16 years, Kampala). Unemployed young men also talked of pornography as a distraction from the stress they felt at not being able to find work.

While it is impossible to prove causality, the study results indicated that pornography consumption influenced young people's sexual expectations. For example, most under-18 and in-school respondents in both countries regardless of gender tended to believe that pornography 'shows what sex is really like for normal people'. This could have adverse effects, however; girls especially complained that pornography and SEM created difficult sexual expectations of them. For example, young men and women in Kampala frequently referenced a sex tape that had been released by the ex-boyfriend of a popular singer named Desire as revenge porn after their breakup. It quickly circulated through social media, and 'everyone' had seen the tape many times over, even when they had not sought it out. Girls reported that boys consequently pressured them to 'be more like Desire'. This was a particularly difficult request, as the video revealed that Desire had had her labia extended - a cultural practice in some parts of Uganda - and produced an exceptional amount of vaginal fluid during sex. Boys were asking girls, 'Why can't you give me the same kitone' (natural gift) as Desire?' Such demands were driving girls to seek labia extensions (well after the usual age that it is done) as well as herbal remedies to produce more sexual fluids.

Such activity must also be placed in the context of the local sexual economy. Urban participants, especially in Kampala, reported incidents of boys secretly videotaping sex with girls, girls producing their own sex 
tapes or partners agreeing to make personal sex videotapes in efforts to make money or become famous. Some young women who actively engaged in sex work in both countries, or had friends who did so, said they produced and distributed SEM of themselves to recruit new clients. But even girls not engaged in sex work were encouraged by male partners to take photos or make videos in order to lend them out and make money. Such production appears to be encouraged by the broader local sexual economy: one Kampala YPR brought an advertisement from a racy tabloid paper, Red Pepper, to a workshop. It said, 'We pay cash for pictures, videos and sex tapes... Get rich, don't die trying' (Figure 5).

Social media was also facilitating the production and distribution of SEM by young women looking for partners to financially support them, particularly university women: in Addis Ababa, some FGD participants said that local sex workers complained that when a university opened in their neighbourhood, it 'ruined their business' because female students looking for 'sugar daddies' were 'stealing' clients from them. Others discussed Facebook pages such as Ethiopian Beauty, where young women were posting semi-nude pictures of themselves in hopes of finding a foreign boyfriend who would sponsor them to emigrate.

\subsection{Behaviours and attitudes: instruction in sexual violence?}

When asked how pornography made them feel, young people generally reported positive associations, using words such as 'joy' and 'excitement' to describe their reactions to pornography. This was the case for boys more than for girls, however; some girls also felt somewhat compromised by pornography in that it portrayed women as subject to men's sexual needs, reinforcing unequal power relations between men and women. As one out-of-school girl in Addis Ababa shared in an interview, 'When I see pornography, it makes me feel terrible about being a woman', because of the way she thought women were degraded in pornography. In contrast, Ethiopian boys in FGDs said that watching pornography helped them to be 'male' and 'fierce' during sexual intercourse. These findings correspond with evidence that pornography tends to focus on male heterosexuality, promoting constant male sexual readiness and men's domination of sex (Flood 2007; McLaughlin et al. 2012). Moreover, pornography consumption has also been linked to diminished tolerance among men for gender equality and greater tolerance for and participation in aggression and sexual violence against women (Flood 2010).

Regardless of how pornography made them feel, however, almost all respondents acknowledged that they were practising or were trying to practise what they saw in pornography. This can be particularly problematic when pornography contains violence, which is common. One study found that 88 per cent of popular pornography contains verbal/physical aggression - usually toward women (Bridges et al. 2010).

Participants tended to agree that watching pornography affected their peer's attitudes and behaviours (if not their own). Rural Ethiopian 
students noticed that their friends started dressing differently and changing other day-to-day behaviours once they began watching pornography regularly, as well as becoming increasingly violent after viewing violent sex. The Uganda survey positively correlated frequency of access with 'riskier' sexual attitudes. In one FGD, in-school male youth said that porn encouraged them to have unprotected sex because they found the unprotected sexual acts they saw in pornography more exciting. In Ethiopia, some boys reported lax attitudes about consent after viewing pornography. In one Gelan FGD, a boy stated: 'After I see porn, I can even go have sex with a mentally ill person', meaning someone who had limited capacity to consent. Girls reported being coerced into sex while watching pornography with a partner.

Most important for our objectives was that young people in both countries roundly considered pornography to be a greater influence on their sexual attitudes and identity development than either sex education or local culture. In Ethiopia, 73 per cent said pornography/SEM affected their sexual attitudes and behaviours, while only 45 per cent said that sex education did and 55 per cent said that local culture did. In Uganda, 84 per cent said that pornography/SEM affected their sexual attitudes and behaviours, versus 50 per cent for sex education and 56 per cent for local culture. They expressed much more satisfaction with pornography as an instructional instrument than with sex education - though this must be placed in the context of low rates of sex education coverage: only 14 per cent in Ethiopia reported receiving sex education while 56 per cent of Ugandan respondents did. This was highest among rural, out-of-school youth, who received sex education through their local youth associations. They also tended to report the highest satisfaction rates with sex education, but these topped out at 46 per cent (Ethiopian rural out-of-school) with no significant age or gender variation.

In Uganda, rural and urban youth of both sexes generally lamented that there are no longer traditional, organised, reliable sex education practices. In Agago, for example, boys used to participate in wang-oo (fireplace discussions) with their fathers while mothers would counsel the girls. In Kampala, kojas (maternal uncles) would provide sex education for boys whereas ssengas (paternal aunts) would provide girls with advice on sex according to cultural expectations. These programmes have been weakened, in Agago by war and insecurity over the last 30 years, and in Kampala by the gradual commercialisation of ssenga and koja roles (de Ridder 2013). ${ }^{1}$ What remains takes the form of what one Agago girl termed 'sexual warnings', or abstinence messages - their mothers only tell them: 'If you go around opening your legs for every boy... you are going to become pregnant and no man will marry you, not forgetting that you are going to die of HIV/AIDS.' Pornography has filled the information gap about how sex is performed, and unlike advice from adults, it is readily available; it can also be watched in hiding, at one's convenience. However, surveys revealed that especially in-school children under 18 tended not to necessarily take pornography as instructional or as a substitute for sex education. 


\subsection{Consequences}

Despite their generally positive associations with pornography, young people listed many deleterious consequences of the identified patterns of their pornography use, including the stress of peer pressure and detachment from family and community. Several boys even self-identified as pornography 'addicts', ${ }^{2}$ stating that they could not sleep before they had watched pornography. Girls also reported disproportionately suffering negative effects from pornography, such as rape and shame from the distribution of images of them by their sexual partners, including 'revenge porn', which affects their future relationships.

Young people reported that their grades would start to suffer when they watched pornography habitually. They could also suffer economically as - in Uganda, at least - young people often had to pay to watch pornography. Some ended up gambling or stealing from their parents in order to find the small sums of money needed to access pornography. However, they also acknowledged economic consequences beyond the purchase of pornography itself. As one out-of-school boy in Kampala noted, 'After watching it, you have to go and buy "a kilo", - a euphemism for sex with a prostitute.

As noted earlier, girls' production of SEM is linked to the broader sexual economy, in which this appears as one of the easier ways to earn money or find economic support. But they usually end up paying the social consequences of shame and stigma afterwards.

In sum, the study found that SEM is a part of a broader landscape of sexual violence and the sexual economy through which young people move in Ethiopia and Uganda. They seem to approach this with profound ambivalence: while SEM is omni-present and young people feel largely positive about it, study participants also suspected that it was probably a bad long-term influence on their sexual identity development in that it was out of sync with cultural norms and values. As one rural Ethiopian schoolboy quite strongly put it: 'Pornography... is totally unacceptable and against religious, social and cultural values of the country and another way of the whites' colonisation strategy on African people.'

Respondents also sent a clear message to those who design CSE programmes: they are in direct competition with pornography for young people's hearts and minds; the young turned to pornography to learn about sex because what limited sex education they received was not meeting their needs, particularly with regard to their awakening desires and emotions. Much of the sex education they had experienced was abstinence-only; while many young people said they could respect that message on some level, they complained that these programmes did not tell them how to manage their sexual urges in order to actually achieve abstinence. Pornography, on the other hand, allows for the release of emotion - positive or negative - and is thus more popular than sex education amongst youth. They also felt that sex education 
programmes were driven by adults' concerns about youth sexuality rather than their own concerns and needs. Consuming pornography was therefore seen as a way for young people to take charge of their own sexual knowledge - even though many realised it might not be the best source for information on sexual health.

\section{Conclusion: recommendations for future directions}

In our final synthesising workshops, YPRs relayed some of the recommendations from their study respondents. While they thought attempts to ban pornography would be ineffective, they thought parents, communities and government should make more effort to try to prevent it from reaching younger children, and/or to teach young people how to approach it more critically. This could be accomplished through the development of media literacy skills that would counteract the hegemonic misrepresentations of sex and relationships (Charmaraman and Low 2013: 247). Adding media literacy components to existing CSE programmes could thus help young people critically examine SEM and programmes could also use ICT to help youth access better, healthier sources of ASRH information.

Findings indicate that it would be prudent for sex education programmes to rethink their approaches, which in these contexts currently focus on abstinence and rarely make mention of pornography's influence. There is a clear need to address it head-on and develop more holistic, mediaresponsive CSE curricula that will meet the needs that pornography currently meets, but in healthier ways. YPRs recommended that sexuality education should start much earlier than it currently does (e.g. in primary rather than secondary school), and that it involve entire families, since young people felt that they could not go to their parents with their questions about sex. They called for more youth-centred sex education based on the actual needs and desires of young people, including the information they currently seek from pornography. The delivery method of sex education programmes should also be more interesting to young people. They listed the use of media, illustrations and demonstrations as well as delivery by knowledgeable, youth-friendly professionals as desirable. They also asked that sex education be available all the time, everywhere - just like pornography.

Finally, our findings also pointed to the need for more youth-participatory ASRH research in general. As noted in previous youth participatory research (Cheney 2011), we found that involving young people as co-researchers and co-creators of knowledge yielded not only more 'authentic' results from their peers but more transformative potential for our YPRs, their relationships and their communities. YPRs reported overwhelmingly positive experiences of conducting research, including increased ASRH knowledge, individual confidence, better ability to communicate across gender and generational divides, greater openness with peers and elders about sexuality, and more critical engagement with media. 
We hope to share our findings with relevant policymakers and community members, and to advocate for CSE programming that will help young people to cope with the adverse effects of pornography and other SEM on their sexual identity development and decision-making.

\section{Notes}

* We acknowledge the generous support of Share-Net Netherlands for making this research possible. We also greatly appreciate the efforts of youth peer researchers and their supervisors.

1 The queen of Buganda (central region including Kampala) has recently organised a yearly life skills youth camp called the Nabagereka's Kisakate that has become quite popular. Designed for very young adolescents up to young adults, it teaches some sex education, but as with most formal sex education programmes, it too tends to focus on abstinence.

2 We acknowledge that there is some debate over whether one can technically become 'addicted' to pornography, but we use this word because the respondents themselves used it in reference to their own problematic, habitual viewing of pornography.

\section{References}

Adam, Lishan (2012) Understanding What is Happening in ICT in Ethiopia: A Supply-and-Demand-Side Analysis of the ICT Sector, Evidence for ICT Policy Action 3, Cape Town: Research for ICT Africa, www.researchictafrica.net/publications/Evidence_for_ICT_Policy_ Action/Policy_Paper_3_-_Understanding_what_is_happening_in_ ICT_in_Ethiopia.pdf (accessed 10 October 2016)

Birungi, S.J. (2015) 'Uganda: Sexuality Education to be Taught in Schools', The Monitor, 8 October, http:/ /allafrica.com/ stories/201510091216.html (accessed 10 April 2016)

Bridges, Ana J.; Wosnitzer, Robert; Scharrer, Erica; Sun, Chyng and Liberman, Rachael (2010) 'Aggression and Sexual Behavior in Best-Selling Pornography Videos: A Content Analysis Update', Violence Against Women 16.10: 1065-85

Castells, Manuel; Fernández-Ardèvol, Mireia; Linchuan Qiu, Jack and Sey, Araba (2007) Mobile Communication and Society: A Global Perspective, Cambridge MA: MIT Press

Central Statistical Agency (2014) Ethiopia Mini Demographic and Health Survey (2014), Addis Ababa, http://phe-ethiopia.org/admin/ uploads/attachment-1939-Ethiopia_Mini_Demographic_and_ Health_Survey_2014-2.pdf (accessed 10 October 2016)

Charmaraman, Linda and Low, Brittany (2013) 'From Media Propaganda to De-Stigmatizing Sex: Exploring a Teen Magazine By, For, and About Girls', in Kate Harper, Yasmina Katsulis, Vera Lopez and Georganne S. Gillis (eds), Girls' Sexualities and the Media, New York NY: Peter Lang: 245-61

Cheney, Kristen (2011) 'Children as Ethnographers: The Importance of Participatory Research in Assessing Orphans' Needs', Childhood 18.2: $166-79$

CIPESA (2014) State of Internet Freedoms in East Africa 2014, Kampala: Collaboration on International ICT Policy in East and Southern Africa 
Day, Andrea (2014) 'Getting the "Blues": The Existence, Diffusion and Influence of Pornography on Young Peoples' Sexual Health in Sierra Leone,' Culture, Health and Sexuality 16.2: 178-89

de Ridder, Josefien (2013) 'The Ssenga in Kampala: Between Abstinence and Pornography, Mediating Messages of Sexuality and Gender', MA thesis, Social and Cultural Anthropology, VU University

Federal Democratic Republic of Ethiopia (2004) The Criminal Code of the Federal Democratic Republic of Ethiopia, www.unodc.org/ cld/document/eth/2005/the_criminal_code_of_the_federal_ democratic_republic_of_ethiopia_2004.html (accessed 10 October 2016)

Federal Ministry of Education (2015) HIV/AIDS and Sexual Reproductive Health Minimum Interventions Package for Schools (Primary, Secondary and Technical and Vocational Education Training Centers), Addis Ababa: Government of Ethiopia

Federal Ministry of Health (2015) 'Situational Analysis of Adolescent and Youth Health in Ethiopia', draft report, Addis Ababa: Government of Ethiopia

FGAE (2014) Development of a Contextualized Comprehensive Sexuality Education Curriculum: Situation Assessment Report, Addis Ababa: Family Guidance Association of Ethiopia

Flood, M. (2010) 'Young Men Using Pornography', in K. Boyle (ed.), Everyday Pornography, London: Routledge: 164-78

Flood, M. (2007) 'Involving Men in Gender Policy and Practice', Women for Women International 5.1: 9-14

Horvath, Miranda A.H.; Alys, Llian; Massey, Kristina; Pina, Afroditi; Scally, Mia and Adler, Joanna R. (2013) 'Basically... Porn is Everywhere': A Rapid Evidence Assessment on the Effects that Access and Exposure to Pornography has on Children and Young People, London: The Office of the Children's Commissioner for England

Human Rights Watch (2005) The Less They Know, the Better: AbstinenceOnly HIV/AIDS Programs in Uganda, New York NY: Human Rights Watch

McLaughlin, Colleen; Swartz, Sharlene; Kiragu, Susan; Walli, Shelina; Mohamed, Mussa (2012) Old Enough to Know: Consulting Children about Sex and AIDS Education in Africa, Cape Town: HSRC Press

Muyinda, H.; Nakuya, J.; Whitworth, J.A.G. and Pool, R. (2004) 'Community Sex Education Among Adolescents in Rural Uganda: Utilizing Indigenous Institutions', AIDS Care 16.1: 69-79

MWCYA (2014) Ethiopia Adolescent and Youth Status Report, Addis Ababa: Ministry of Women, Children and Youth Affairs

Nakkazi, E (2016) 'Revenge Porn is Rising and it Should be Addressed', Daily Monitor, 8 March, www.monitor.co.ug/artsculture/Reviews/ Revenge-porn--addressed/-/691232/2651158/-/11wo731/-/index. html (accessed 10 October 2016)

New Vision (2016) 'Lokodo Orders Police to Arrest Dr. Nyanzi for Stripping', 18 April, www.newvision.co.ug/new_vision/ news/1422385/lokodo-police-dr-nyanzi-stripping (accessed 10 October 2016) 
Okoth, C. (2013) 'New O-Level Curriculum to Focus on Life Education', New Vision, 26 September, www.newvision.co.ug/ new_vision/news/1332632/-level-curriculum-focus-life-education (accessed 10 October 2016)

Republic of Uganda (2015) Our Children, Our Future: Ensuring Child Well-Being in Uganda - A Call to Action, Kampala: Government of Uganda

Republic of Uganda (2014) The Anti-Pornography Act, Kampala: Government of Uganda

Republic of Uganda (2011) Uganda Demographic and Health Survey, Kampala: Government of Uganda

Republic of Uganda (2010) The National Development Plan, Kampala: Government of Uganda

Republic of Uganda (1950) Penal Code Act, Chapter 120, Section 166, Kampala: Government of Uganda

Save the Children (2014) Uganda Keep-It-Real: New and Social Media Assessment Findings, Kampala: Save the Children

Shuey, Dean A.; Babishangire, Bernadette B.; Omiat, Samuel and Bagarukayo, Henry (1999) 'Increased Sexual Abstinence Among In-school Adolescents as a Result of School Health Education in Soroti District Uganda', Health Education Research 14.3: 41 1-19

SIHA Network (2015) Anti-Pornography Act-Human Rights Activists and Civil Society Organizations Challenge the Legality of the Act in Constitutional Court-Uganda, Strategic Initiative for Women in the Horn of Africa, www.sihanet.org/news/anti-pornography-act-human-rightsactivists-and-civil-society-organisations-challenge-legality (accessed 10 October 2016)

Swahn, M.H.; Braunstein, S. and Kasirye, R. (2014) 'Demographic and Psychosocial Characteristics of Mobile Phone Ownership and Usage among Youth Living in the Slums of Kampala, Uganda', Western Journal of Emergency Medicine 15.5: 600-3

Tajuba, Paul (2014) 'Anti-Pornography Law: Police Warns Against Undressing Women', Daily Monitor, 25 February, www.monitor.co.ug/News/National/Anti-pornography-law--Policewarns-against-undressing/-/688334/2220210/-/omy4tbz/-/index.html (accessed 10 October 2016)

UK Government (n.d.) Revenge Porn: The Facts, www.gov.uk/ government/uploads/system/uploads/attachment_data/ file/405286/revenge-porn-factsheet.pdf (accessed 10 October 2016)

United Nations in Uganda (2016) United Nations Development Assistance Framework for Uganda 2016-2020: Delivering Together for a Nation on the Move, www.ug.undp.org/content/dam/uganda/docs/Uganda $\% 20$ UNDAF\%202016-2020.pdf (accessed 10 October 2016)

Wright, Paul J. and Funk, Michelle (2014) 'Pornography Consumption and Opposition to Affirmative Action for Women: A Prospective Study', Psychology of Women Quarterly 38.2: 208-21 
This page is intentionally left blank

98 Cheney et al. Feeling 'Blue': Pornography and Sex Education in Eastern Africa 


\title{
Blurring the Boundaries of Public Health: It's Time to Make Safer Sex Porn and Erotic Sex Education
}

\author{
Anne Philpott, Arushi Singh and Jennie Gamlin
}

\begin{abstract}
Unsafe sex is now the biggest risk factor for the death of young women globally and the second biggest for young men. Alongside this, pornography, which rarely shows safer sex, is one of the key channels for sex education globally. Higher quality research needs to explore the positive and negative impact of porn while the sex education world needs to engage with it to ensure that viewing porn can promote safe sex choices and consent, as well as pleasure. We need unbiased research and innovation into the impact of porn and recognition that can have a positive impact for public health.
\end{abstract}

Keywords: sexuality education, sexually explicit media, pornography, safe sex, pleasure, condom use.

\section{Foreplay}

'Because sex education is rarely sexy and erotica is rarely safe, putting the sexy into safer sex.'

The Pleasure Project, 2004.

Increasing access to the internet worldwide has ensured that a large amount of sex education or sexual information is received through watching pornography (referred to in this article as 'porn') - material created with the explicit purpose of sexual arousal. In this article, we firstly argue that we need more research to analyse the potential of porn for both positive and negative health impacts, and secondly that porn has the potential to educate about safer sex and can be a source of sex-positive sexuality information. In order to do this we will detail our assessment of research into porn's impact and highlight a small range of alternative ways to deliver sexual health information within this new context; from safer sex porn to sexy sex education. We argue that there needs to be more robust research into the effects of porn as an alternative type of sex education that challenges the harmful norms perpetuated in most porn, while also appealing to audiences that watch porn. 
This argument and our recommendations for sex education following it are relevant for the public health world now more than ever because, not only do we have the largest population of young people in history, but also the recent Global Burden of Disease Study showed that unsafe sex is now the biggest risk factor for young women's ill health and death, and the second highest for men of the same age (Patton, Murray et al. 2016).

Many argue that porn should be banned or censored; for example, the recent 'ban' in India (Majumder 2015). However, seeking to restrict access to porn when more than 43 per cent of the world population and 37 per cent in low- and middle-income countries currently have access to the internet (World Bank 2016) is, if not impossible, highly challenging and short-sighted. Sex education professionals need to engage and educate to ensure that viewing porn can help promote safe sex choices and consent, as well as pleasure. We believe this can be done to varying degrees by engaging with feminist and alternative porn makers, or making porn that depicts good safe sex.

We argue that there can be an overlap between the pleasure and the public health industries. For example, people who identify themselves as producers of porn can make films with the intention of not only arousing the audience, but also encouraging safe sex behaviours. People who promote safer sex can do so in a way that is erotic. Our central argument is that blurring these boundaries can lead to improved public health and encourage a move within the pleasure industry towards the intentional production of porn that challenges harmful norms such as unsafe sex, women as sexual objects whose pleasure is dependent on men, or violent and non-consensual sex as arousing. We show how a 'harm reduction' approach can be taken to produce sex education that includes discussions of pleasure. Porn is here to stay, and the public health and sexual and reproductive health community needs to wake up to both its existence in hundreds of millions of people's lives, and to its potential as a tool for positively influencing sexual and social wellbeing.

\section{Getting turned on}

For the purposes of this article we have defined 'sex education' as information presented with the primary purpose of enhancing understanding of the many elements of sexual health or sexual relationships, while porn is a 'subtype of sexually explicit material' (SEM) produced primarily for generating sexual pleasure or arousal (Watson and Smith 2012). Although commonly understood as explicit material with the intention of increasing sexual pleasure, a quick look through history shows us how wide the definitions of porn actually are: from novels to wall paintings in Pompeii. However, detailing a history of porn is too wide a remit for this article, and indeed today porn comes from a variety of different producers, from that commercially funded by large corporate houses to amateur films and personal home-made mobile phone videos (Forrester 2016). So we recognise the challenges of defining these two forms of communication when many viewers will 
learn from porn or might get turned on by sex education; it is, however, the primary purpose that is critical in the definition.

Sexual pleasure remains a highly significant, if not primary, motivating factor for sexual behaviour (WAS 2008). It is hard to define, is understood in diverse ways, and arousal often has a culturally distinct basis for each of us; however, it is still often associated with shame, and the pursuit of sexual pleasure is usually positioned as a cause of, or contributor to, disease. Public health and sex education have almost exclusively followed that culture to focus on what not to be or do rather than on what you want to do (Vance 1984; Foucault 1978; Rubin 1984; Knerr and Philpott 2012). It is the authors' position that this has biased the nature of research into sexuality and sexual health, and with this, pre-empted a disease- and risk-focused public health understanding of the role of porn in wellbeing.

However, while negativity about sex is found in many cultures, people all over the world are pursuing sexual pleasure through watching porn (Pornhub 2016). Public health, including sex education initiatives, on the other hand, focuses on delivering safer sex messaging with an aim to reduce 'risk taking', assuming individuals make 'rational' sexual decisions based only on health considerations. However, there are other factors affecting sexual decision-making, including gender, culture, notions of intimacy and/or authenticity, and desire (Knerr and Philpott 2012). For example, rational choices can be those that make individuals have unsafe sex because they believe it increases intimacy or for economic survival.

\section{The staying power of porn}

Porn is one of the most explicit ways that most people encounter sex remotely or in the media. Regardless of the judgements passed on this particular form of media, it is undeniable that porn has an effect on sex lives around the world and is a key source of information on sexuality. While most types of porn are exploitative and perpetuate disempowering visions of gender, race and sexuality, we argue that porn also has the potential to be a medium through which we could promote sexual health, question traditional gender roles, and create empowering social scripts.

By the end of 2015, 3.2 billion people were estimated to be internet users, an eightfold increase on the year 2000 when only 400 million had access (World Bank 2016). While this rate is still disproportionally tilted towards developed countries, 37 per cent of households in the developing world have internet access. These statistics only count households with internet access, and we estimate that, once public venues such as internet cafes, schools and libraries as well as smartphone access are added in, large parts of the population in developing countries are probably connected. The World Bank (2016) estimates that over 50 per cent of the world's population has access to a mobile phone and by 2017 the number of mobile phone users is forecast to reach 4.77 billion. 
Porn is often maligned for reinforcing negative, limiting and harmful gender norms. For example, studies in the UK have pointed to the negative impact of porn and the 'pornification' of culture (Smith 2010; Perrin et al. 2008), including the rise in access to internet porn as a cause for the huge increase in numbers of women seeking labiaplasty to try and make their vulvas look more like those they see in porn (Jones and Nurka 2015).

However, porn is a huge and expanding global industry with a growing audience. A simple Google search in June 2016 shows that 'porn' returns 1.8 billion search references, while 'sex education' returns only 13.5 million results. Some research suggests that around 25 per cent of all search engine requests are for porn (Watson and Smith 2012). However, we have been unable to find reliable datasets that disaggregate the search terms for types of sex acts. And what is classified as a search for porn might be for sex education and vice versa. One of the most popular adult sites in the world is LiveJasmin.com, a webcam site that, according to Worthofweb (a site that generates internet statistics), gets almost 300 million visitors a month. ${ }^{1}$ According to the study by Ogas and Gaddam (2011), this one site alone is used by 2.5 per cent of internet users each month. The production of porn is from a wide range of producers - from being commercially funded, to people sharing their own home-made porn on their phones, to Snapchat. There are multiple stakeholders and producers.

Ogas and Gaddam (2011) point out the exponential jump humans have made in the last decade in terms of access to porn on the internet. They suggest that with huge numbers of people globally using their computers routinely for sexual gratification:

[i] t's hard to imagine a more revolutionary development in the history of human sexuality. With a visit to an adult video site like PornHub you can see more naked female bodies in a single minute than the most promiscuous Victorian would have seen in an entire lifetime. But there is an even more dramatic change. We don't have to interact with anyone to obtain erotica.

\section{Getting down to it: what does research into porn tell us?}

Despite the increasing access to porn globally, robust research of its impact is rare, moral judgements abound, and public health practitioners shy away from research into porn that uses these channels to also educate about sexual health or healthy sexual relationships. We argue in this article that research has to date been largely biased and focuses on the damage porn can cause - how it can create alternate psychological expectations of sex, reinforce negative gender norms that disempower women, and create an environment in which violent or coercive sex is more acceptable.

In an exploratory literature review we sought to identify research studies on the positive role of porn in sex education, health and wellbeing. 
This was not a systematic review but sought to describe the breadth of scientifically reliable research and in particular to focus on studies that were not designed from the outset to identify harm. The search was primarily conducted using a Medline search with the terms 'porn' or 'sexually explicit media' and 'public health' or 'wellbeing' and 'education'. There was no date limit, but no suitable studies were identified that had been written before 1988. The reference lists of all key studies were also hand checked for relevant research that we may have missed. This process was repeated with Google Scholar, and because of the paucity of peer-reviewed literature a number of non-peer-reviewed studies have been included in our review, one of which is explained individually as evidence of the existence of subtle and hidden forms of bias.

The impact of sexually explicit media (SEM) and porn use is not a new area for public health research. We know of its potential for causing harm, in particular to psychosocial wellbeing, potential for the objectification of women, and for generating harmful negative stereotypes (see e.g. Perrin et al. 2008; Wright and Tokunaga 2016); we also know that it has been found to increase risky sexual behaviour (Jonas et al. 2014; Eaton et al. 2012). Our review brought up many such studies. Notwithstanding the importance of recognising potential for negative outcomes, we believe that this 'harm impact' approach has dominated literature about porn, to the virtual exclusion of a counter perspective, and with this review attempt to correct this bias.

Although the statistics on porn usage might be hard to specify, a large proportion of literature is focused on demonstrating that watching porn can create a culture of unhealthy expectations of violence, sexism and multiple sex partners, and much of this material comes from questionable sources. An example of this is the Covenant Eyes report, Porn Statistics (2015). At first glance this report appears to be produced by a group concerned with 'Internet Accountability and Filtering' and only further investigation into the groups' origin identifies their mission as one of 'fighting internet temptation'. They also generate an app called 'Overcome Porn: The 40 Day Challenge' with the advertising line that 'porn enslaves, it ruins relationships and keeps you from achieving your dreams' (www.covenanteyes.com). The report itself does not divulge this information, and the company was named as one of the 'Best Christian Places to Work' in 2007. Although there is arguably less obvious bias in peer-reviewed publications and papers such as Perrin et al. (2008), many studies take it as a given that 'there is a general consensus that porn endangers the wellbeing of others' (op. cit.: 11).

\section{Learning how to do it right: is there any good research into porn's impact?}

Research about whether porn has negative or positive impacts on our health remains inconclusive and fraught with bias and methodological inadequacies. Through a review of public health literature, we reveal that there is considerable inconclusive, biased and methodologically 


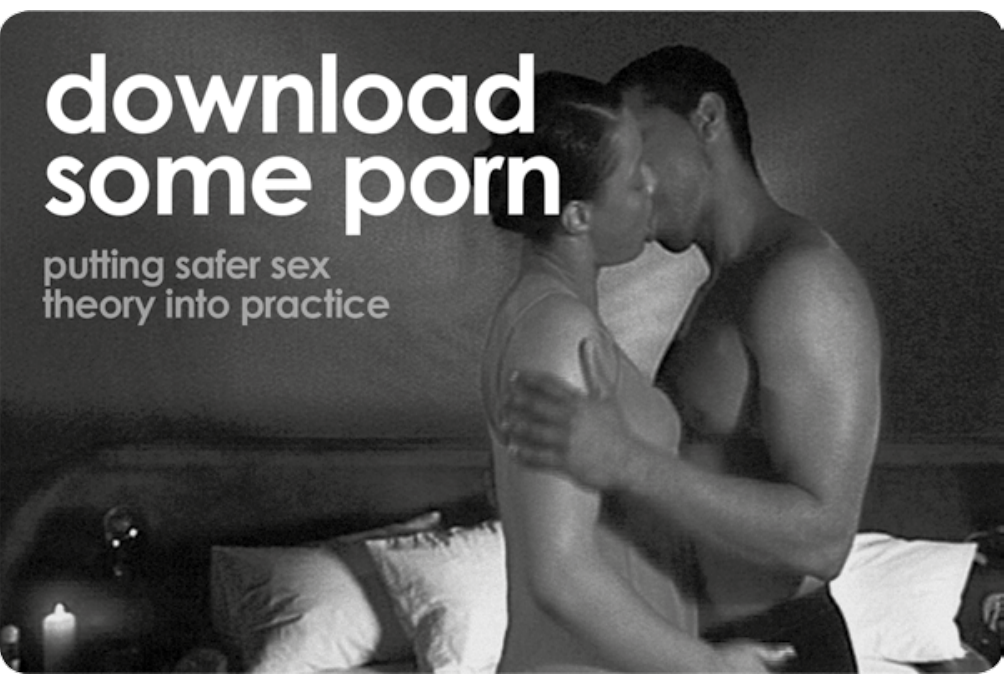

Source Reproduced with kind permission of The Pleasure Project.

weak research on whether porn encourages a norm or environment of unsafe sex, and little research on how we might use the communication channel of porn to encourage safer sex, improve self-esteem, enhance body image, challenge gender norms, or empower the viewer (Knerr and Philpott 2012).

Good quality research with a large sample size is rare, and most studies rely on a self-selected or convenience sample with a cross-sectional study design. Furthermore, the research questions being asked focus overwhelmingly on exploring porn's potential for harm, as opposed to potential benefits. A case in point is a study by Traeen $e t$ al., which sought to explore the hypothesis that ' $[\mathrm{t}]$ here is a direct association between consumption of SEM depicting non-condom use and STI [sexually transmitted infection] related sexual risk behaviour among men' (2014: 4). The study was based on a cross-sectional internet-based survey and confirmed this 'negative impact' hypothesis.

It may also be the case that there is a bias towards reporting negative findings. Braun-Courville and Rojas report on a survey of 'Exposure to Sexually Explicit Web Sites and Adolescent Sexual Attitudes and Behaviours' to confirm their hypothesis, 'Adolescents who frequent these web sites are more likely to engage in high risk sexual behaviours' (2009: 159). While their conclusions mention that SEM serves an 'educational purpose' and plays an important role in 'sexual socialisation', only data that confirm their hypothesis are presented.

The biased and selective methodology of the studies we found leads to the conclusion that porn is predominantly harmful. We would argue that unbiased and inclusive methodology may lead to a different 
outcome and could show that porn has both negative and positive impacts. These positive impacts need to be explored and exploited further to increase public health and reduce harm.

Because of inherent partiality or methodological weaknesses that can lead to bias, the fact that evidence of the harmful effects of porn predominates is not equivalent to a conclusion that porn is per se harmful. By far the majority of studies rely on self-reporting, a self-selected or volunteer sample and a study design with a negative hypothesis. Some studies have, to some extent, overcome this by triangulating data from different sources; for example Jonas et al. (2014), who describe an association between viewing risky practices - in this case 'bareback' porn - and safe sex intentions, conducted two separate studies, one online and the other in a sex club, in order to reach their conclusions. However, a recent study by Wright and Tokunaga (2016), published in the wake of a globally prominent case of campus sexual assault, used a 'volunteer' population of university students and an online survey to assess the relationship between 'men's objectifying media consumption' and 'attitudes supportive of violence against women'. Although the paper does not describe how volunteers were recruited, it does make mention of the possibility of reverse causality (i.e. that the supposed effect might also be the cause) due to the crosssectional nature of their study. Both studies were published in the reputable Archives of Sexual Behavior journal. It should also be noted that over-represented in research are studies with men who have sex with men (MSM) and young people, since from a risk perspective these are populations of greater interest.

Of particular interest to the authors of this article is a recent study by Scrimshaw, Antebi-Gruszka and Downing (2016) based on an online self-reported study of MSM and who view SEM, which provides the paradigmatic conclusion that simply viewing porn is not in itself a risk factor for high-risk practices. While viewing a greater proportion of SEM containing condomless sex was a risk factor for more condomless anal sex encounters, the opposite was also true: viewing a greater proportion of SEM where condoms were used was associated with higher condom use, showing that the causal uni-directional links between porn and risky practices cannot be assumed, and that it is viewing risky sex rather than SEM itself that leads to more risky sexual practices. The implications of these findings are that while viewing 'risky practices' in porn can be a risk factor for riskier sexual behaviour, viewing safer sex - for example, SEM where the actors make condoms part of the show - can also promote safer sex practices and increase condom use. (We acknowledge that it cannot be automatically assumed that this pattern might also be true in heterosexual relationships.)

We recognise that it is challenging to infer cross-culturally and across hetero- and homosexual sexualities, and that research agendas and resources have been driven by public health notions of risk and humans as vectors of disease; however, a number of studies do cross these lines 
to explore the impact of condoms in SEM. A small number of studies that set out to define and explore the benefits of viewing porn back up Schrimshaw et al.'s (2016) conclusions that viewing more condomed sex in SEM can increase condom use. A research synthesis of the effectiveness of sexual risk reduction interventions that integrated a safer sex eroticisation component, which included interventions with heterosexuals and MSM, found an overall improvement in condom use, HIV-related knowledge, communication with sexual partners and other positive behaviours (Scott-Sheldon and Johnson 2006). Wilkerson et al. (2013), who studied the acceptability of HIV prevention messages in SEM viewed by MSM, found that a majority (83 per cent) of participants endorsed the use of porn as a medium for communicating prevention messages. A further review study concerned with SEM and both heterosexual and MSM that 'does affect users' sexual behaviour and pleasure' (Watson and Smith 2012: 123) covers a range of negative, neutral and positive findings and puts forward the concern that 'the anti-porn narrative may create a hostile climate that undermines the value that SEM may have in certain settings' (ibid.).

\section{Time to kiss and make up: can porn be education?}

Porn is already a primary source of education on sex and sexuality, particularly among young people, and the average age at which a person (in the USA) first sees porn online is estimated to be 11 years (Vogel 2011). This is combined with school-based sex education that is often limited and inadequate, focusing primarily on the biological aspects of sexuality and avoiding information on how to have sex or the pleasurable aspects of sexuality (Watson and Smith 2012; Vogel 2011; Hare et al. 2015). In the USA, the pedagogy of institutionalised sexuality education reportedly leaves young people feeling that 'to have impure thoughts, even touch their own bodies, is a sin' (Kirkham and Skeggs 1996: 9). Some findings in fact refer to an unmet need for realistic and private sources of sex and sexuality information that de-stigmatise and normalise sex and sexuality (Albury 2014; Hare et al. 2015).

It is no surprise then that increasing proportions of young people cite the internet and sexually explicit websites as their main source of information on sexual practices, and refer to the importance of SEM as a guide for knowing what to do sexually. The UK's National Survey on Sexual Attitudes found that 4.1 per cent of 16-24-year-olds consider porn to be their primary source of information about sex (Tanton et al. 2015), and numerous studies emphasise the significant role of porn as a source of sexual socialisation for young people, particularly regarding sexual confidence (Sun et al. 2016; Kimmel 2008; Albury 2014; Tjaden 1988; Watson and Smith 2012).

Porn is often the 'only source of sex education people get' (McKee 2007: 6). In a Population Council Study of 100,000 young people in Andhra Pradesh, India which asked young people where they learnt about sex, 5 per cent of young men said internet porn (Tripathi and Sekher 2013). In China, Li, King and Winter (2009) found that porn 
was an important source of information about sex for adolescents in Beijing; it ranked as the fourth most mentioned source for boys and the ninth for girls. In Ethiopia, Tadele (2006) found that porn viewed at public cinemas was usually the only source of information about sex for street boys, while a study of porn in Bangladesh found it to be among the top three sources of information mentioned by women (Faiz Rashid and Akram 2014).

In order to understand the role that porn plays in comprehensive sexuality education, we must differentiate between learning about the biological process of reproduction and risks of STIs, and acquiring non-judgemental social knowledge about sex, sexuality and the body that is needed to make informed decisions regarding relationships and sexual behaviour. Porn is an important opportunity to learn - in private - about sex and sexuality that is not taught in a school-based setting (Litras, Latreille and Temple-Smith 2012; Albury 2014). While the forms of sex displayed in SEM may not be representative of real-life experiences, and are often very limited in their portrayal of any types of sexuality beyond a fantasised routine script of hyper-sexed, largely heterosexual, toned bodies, they often provide the only opportunity for young people to see sex performed by real people. Men/boys in particular can suffer from low self-esteem regarding sex when they are inexperienced due to prevalent gender norms that expect boys and men to be more sexual and sexually experienced, and a lack of knowledge and understanding makes them more vulnerable (Litras et al. 2015).

According to Watson and Smith, porn may allow for the creation of social spaces where, 'isolated, socially or sexually anxious or disenfranchised individuals can communicate, find romantic partners, or practice some sexual behaviour in a safe setting' (2012: 126). It has also been found to function as a source of sex education for young people that can 'provide information about the human body and sexual practices, thus increasing a sense of sexual competence and liberalisation and decreasing sexual shame' (Sun et al. 2016: 991). As one participant in a UK study of young people's views on sex education remarked, 'In class you only get what happens explained to you, whereas in porn you can see exactly what is going on' (Measor 2004: 156). There are of course numerous caveats to this argument - that the information acquired through porn may be culturally inappropriate or that since the sex is dramatised it may be unrepresentative of real-life experiences - in addition to the concern that young people in particular may learn unhealthy practices.

Mainstream porn often negates any variety in sexual practice, according to sexual or gender identity, or representation of variations in religion, geography and class beyond stereotypes. The point we wish to make is that, however biased or unhealthy, porn plays a large role in young people's sexuality education and fills a gap in people's knowledge that formal education does not seek to address. 
7 Getting to know you better: what else do we need to know to come together for sexy safer sex

While internet usage is considerably higher in Western nations, porn is by no means confined to the West, yet research into the relationship between porn and public health is dominated by studies carried out in North America, Australia and Europe. This may be a reflection of the fact that the majority of studies appear to have been financed by individual public health and medicine (academic) departments or institutions in Western countries. Furthermore, the biggest single funding agency is the US National Institute of Health, and understanding the role of porn in sexual health does not appear to have attracted support or interest from international or UN agencies such as the World Health Organization (WHO) or the Joint United Nations Programme on HIV/AIDS (UNAIDS) that hold the global mandate for health or AIDS. Generally, research in this field has followed the 'risk-focused' norm of linking research to biomedical outcomes, with a reluctance and/or lack of funding to address sexuality more broadly. Although the focus on MSM in the context of AIDS has allowed for more productive research into porn's positive impact, it has to some extent excluded those same questions being asked of heterosexual sexualities, which has to a large extent been boxed in with, or problematised, as reproduction-related health. Our concern is that the moral judgement is a very sex-negative one - the public health perspective is to look at human beings as vectors of disease rather than as people having the right to a healthy, satisfying (sexual) life.

We suggest that the heavy weight of evidence in support of a public health case against porn is not a reflection of the immensity of risk and harm, but a reflection of the lack of good research into the non-harmful effects of porn and lack of willingness to challenge the prevailing moral concern and risk-centred focus on sexual health that exist within the global public health community. So, within the caveat that research is limited, we can infer that porn viewers learn about and copy positions, practices and techniques that they watch, and overall research suggests that SEM influences sexual practices and safe sex practices, in both positive and negative ways. We know that porn does sometimes cause harm to some viewers, but there is not enough robust evidence that porn per se leads to violence and no consensus of evidence that it leads to more degrading views of women (McKee 2007).

Ultimately, big chicken and egg questions such as does porn directly contribute to aggression against women, or, on the other hand, do sexually aggressive men gravitate towards porn remain unanswered (Watson and Smith 2012).

\section{Making safer sex porn and sexy sex education: doing it better next time?}

The combining of sex industry and public health expertise has huge potential to reach a wider audience in a positive and appealing way. The public health world can detail safer practices or support research on impact - while the pleasure world and porn actors and directors can 


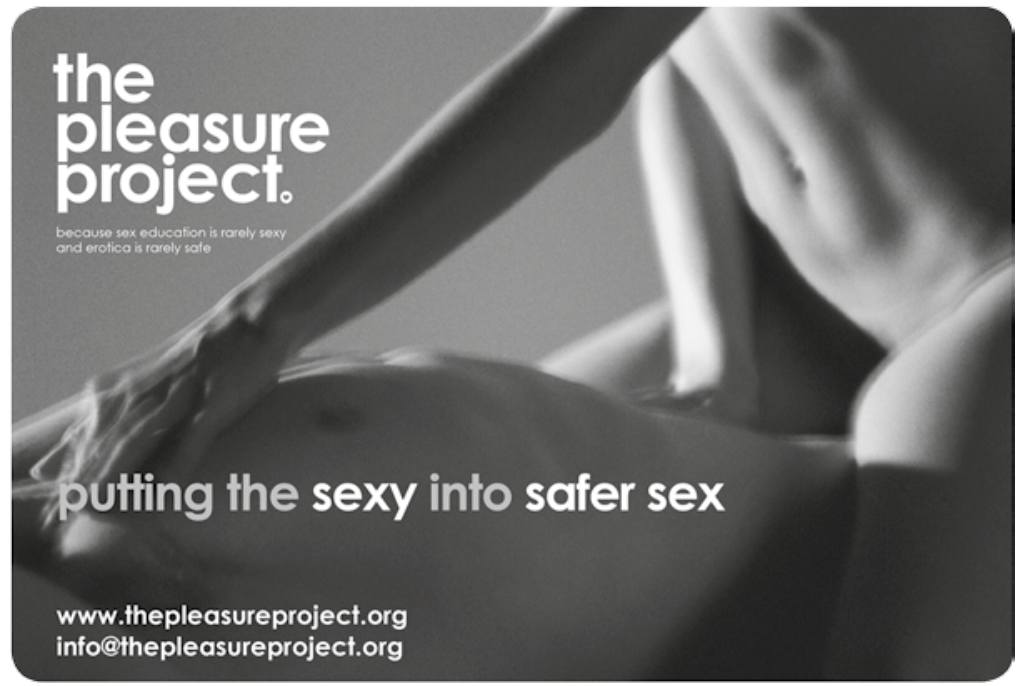

Source Reproduced with kind permission of The Pleasure Project.

turn us on. Research into porn's positive impact can underpin how to do this well to maximise safer sex and public health impact.

Porn can also be made in different ways and with different intentions from how it is now; there are emerging examples of new ways to make porn, from feminist to queer independent porn, and of course the mobile phone video function allows for home-made porn to be uploaded direct, such as on YouPorn. In fact, all but one of the examples we provide later in this article are women-led, i.e. porn made by women, sexual health interventions run by women and sex workers, etc. Thus, we are highlighting the alternative methods of information exchange and production when it comes to SEM. While porn is usually produced for the male gaze, women do watch porn as well; however, we cannot say how it affects women's understanding or expression of their own sexuality since there is not enough evidence around this. Typically, the dynamics of heterosexual porn production follow global patriarchal norms. However, we believe that an alternative form of SEM could be one that highlights more gender equitable porn, a wider range of sexuality and sexual identities, and love and romance.

This section includes examples of how this can be done by blurring the boundaries to create safer sex porn or sexy sex education as very short case studies. They draw out key themes and lessons in terms of engaging with film-makers or erotica to show that we might be able to challenge the norms of porn, what moral decisions need to be made and the barriers that could be faced. This range of examples is drawn from The Global Mapping of Pleasure (Knerr and Philpott 2008). ${ }^{3}$ 


\section{condoms}

the rub

Ask (or tell) your partner to insert it and rub the outed ring on your clitoris or labia using fingers or penis.

the bump

Many people find the inner ring super stimulating when a hard cock or dildo bumps up against it. If you like it, tell your portner to get bumpin"!

not just for the ladies

In Zimbabwe, a new word in Shona - kefecyenzo - was invented to describe the gorgeous tickle that men feel when the inner ring of the female condorn rubs on their penis, And in Ghana, men liked it so much they bought the femole condom solely for the murpose of masturbating by nubbing the inner ing their penis (courtesy: the Sociefy of Women against A(DS, Ghang). show and tell

insert it while your portner watches. Tell him or her they can look but not touch.

nothing like the first time

Women in India reported their first orgosms as they inserted the lubricated female condom inside themselves (courtesy: Hinduston Latex Limited). feel the heat

The polyurethane that the female condom is made of is much thinner than latex so you can feel the heat tronsfer from your partner to you.

make it slippery

As for lube, any oils or water-based lube will work. Oil-based lubricants do not break down the female condom the woy they do mole condems, so you avoid breakage.

sexy sounds

The femole condom often makes a squishy or crinkjy noise during intercourse. Experienced users say the hoise goes away once it warms up. or maye they nist gon thear it anymore over the Jus don't heor it anymore over ine moans Some women tell their portners, 'It only makes that sound when you're doin' it right...

\section{the project.}

Source Reproduced with kind permission of The Pleasure Project.

Modern Loving: The Ultimate Guide to Sexy Pleasure is a 100 per cent safer sex erotic film that was made in the UK aimed to created kinky, fun, pleasurable sex with real couples. It also showed how to use condoms in a sexy way. The Pleasure Project was the 'condom consultant' on the film set and worked to find creative ways to include condoms and safer sex in the film scenes, while also building the actors' confidence in using condoms during shooting. The film was conceptualised, produced and scripted by women with the intent to create an alternative type of content. The actors also discussed how they found using male and female condoms, and there were many scenes to show the wide range of safer sex practices that are possible. ${ }^{4}$

Selina Fire is a sex blogger and writer with a difference - she writes to make safer sex hot without it being a big deal. Her sex blog, Sex in the City - The Real Version, includes lots of pornographic and arousing descriptions of safer sex. She also writes a column for Penthouse Forum magazine and dedicated a whole column (April 2007) to ideas for kinkier safer sex, including mutual masturbation, tit sex, fisting, getting her partner to come on her face, and exhibitionism. Selina writes about safer sex with the intention to arouse.

The Kama Sutra for Sexy Safe Sex: Durbar Mahila Samanwaya Committee, Sonagachi, in West Bengal, India is a sex workers' co-operative which takes a pioneering sex-positive approach to sex workers' rights and health, and has had success in lowering rates of HIV among its workers. Among their many ground-breaking projects and achievements is that they have used the Kama Sutra to teach sex workers how to give clients a high degree of sexual pleasure with less penetrative sex. They have also shared information in workshops about sexy safer sex techniques and tips. 
Safe Sex is Hot Sex Porn: Chi Chi LaRue is an erotic film director, drag queen and performer in the USA. She is considered one of the gay adult industry's most successful directors and also directs straight and bisexual erotic films. A long-time advocate for condom use in gay porn, LaRue announced she would no longer produce films for Vivid Video in 2006 because they adopted a condom-optional policy. LaRue set up the production company Channel 1 Releasing, which requires actors to use condoms in all of its films. In response to recent reports of a rise in HIV among gay men and an increase in 'bareback' porn, LaRue created a four-minute public service video explaining the risks of barebacking, and the responsibility of porn consumers to avoid anal sex without using a condom, in order to protect the health and lives of porn actors. The video had the message to 'wrap it up' because 'safe sex is hot sex', while gay porn video clips run in the background.

The Pleasure Project is an international education and advocacy organisation working to eroticise safer sex. It builds bridges between the health sector and the sex world, and helps to develop the evidence base for a sex-positive approach to safer sex. It promotes sexual health and prevention of STIs, including HIV, by encouraging sex education with an emphasis on 'good sex', and by focusing on one of the primary reasons people have sex - the pursuit of pleasure. Since 2004, The Pleasure Project has had a wide range of media coverage and is widely credited as leading advocacy in the public health world to 'put the sexy into safer sex' (Figures 1, 2 and 3). It has provided condom consultancy for erotic films, and has mastered the art of erotic condom demonstration. ${ }^{5}$

There are other examples of how to create safer sex porn or break down the safe sex education/porn binary to reach audiences with sexual health information in an arousing way. The Make Love not Porn website $^{6}$ allows people to upload films of their own sex life. The Berlin Porn Festival, hosted annually, showcases independent porn and creates a space for discussion on financing, feminist porn and safer sex, and issues awards for the 'best independent porn'.

\section{Conclusion: coming together at last}

With unsafe sex being the biggest risk factor for premature death and illnesses for young women globally and the second biggest for young men, and HIV being the single most common cause of death of adolescent girls in Africa, the public health world does not have time or the moral 'luxury' to shun working with the porn industry, either directly or recognising its influence. Porn is one of the key channels, if not the key channel for sex education globally. The public health world, those responsible for sex education, academia and the porn industry need to start to understand and then respect the advantages they bring to the others' work. There is also a need for sex education organisations and academics to engage in research that is open to the hypothesis that porn can cause both negative and positive impacts on 
Box 1 When will I see you again: a future research agenda?

Based on our literature review, we propose a new research agenda in porn research. We believe that there needs to be more research on, and knowledge of, the porn industry by sex education organisations and academics, rather than assumptions about how it operates or who works in it. In order to harness the huge audiences that porn has been able to capture, public health needs to research the following:

- How sex education and porn access is changing in low-income countries in Asia and Africa with increased access to mobile phones and the internet.

The incentives and structural drivers that could increase safer sex, challenge normative depictions of gender and encourage fair working practices and conditions within different parts of the porn industry.

What impact would different types of sex education/porn that aim to increase safer sex and condom use have, and to what degree?

- What type of safer sex in porn would have the biggest behaviour change impact? For whom? Whether porn with love and romance has the potential to make sex better and safer.

- How do we make porn safe and still reach the right audience to have impact?

How can we disentangle the influence of porn from wider social roles of men and women and their unequal power relationships? Do men and women get influenced by porn in different ways?

It is largely men who make and watch porn; would alternative means of production and makers of films make a difference in terms of their messages or impact? Would films made by those usually objectified, such as women, trans people or sex workers create safer spaces for behaviour change?

What could incentivise alternative and safer porn? For example, whether de-criminalisation in countries where making porn is illegal would help actors ask for protection under labour or health legislation, or whether unionisation of pleasure industry staff enables them to demand improved health and safety standards and other labour rights.

- Given the increasing consumption of porn, to what extent have agencies with the expressed mandate for young people's health or HIV prevention or sex education (for example, WHO, UNAIDS, UNESCO) addressed the need to discuss and tackle its impact? 
public health. The research we found was limited, assumed a negative impact of porn viewing and has been methodologically flawed. This bias limits the ability of the public health and sex education world to know how to use this media channel to ensure positive behaviour change. In addition, international agencies with a mandate for sexual and reproductive health need to engage with porn; a future paper will address to what extent they actually do. In conclusion, we call for more unbiased research and programme innovation into the impact of porn, and its potential positive impact, and a recognition that SEM can have a positive impact for public health.

\section{Notes}

1 LiveJasmin.com is a webcam site where viewers can choose their model, select women using a variety of identifiers including hair colour, ethnicity, body type, use of toys, cigarettes, etc. Viewers pay to access the webcam of their preferred woman. The site also offers TV channels. The site does not appear to offer porn that is outside the stereotypical norm and there is no reference to an option for 'feminist porn' in the search choices. We cannot verify the reliability of Worthofweb or their statistics.

2 Anal sex without a condom.

3 Pleasure Map at www.thepleasureproject.org/pleasuremap.

4 www.amazon.co.uk/Modern-Loving-Ultimate-Sexual-Pleasure/dp/ B0002YCYEY.

5 www.thepleasureproject.org.

6 http://makelovenotporn.com.

\section{References}

Albury, Kath (2014) 'Porn and Sex Education, Porn as Sex Education', Porn Studies 1.1-2: 72-81

Braun-Courville, Debra and Rojas, Mary (2009) 'Exposure to Sexually Explicit Web Sites and Adolescent Sexual Attitudes and Behaviours', Fournal of Adolescent Health 45: 156-62

Covenant Eyes, Internet Accountability and Filtering (2015) Porn Statistics, $250+$ Facts, Quotes, and Statistics about Porn Use, www.covenanteyes.com/pornstats (accessed 24 October 2016)

Eaton L.A.; Cain D.N.; Pope, H. and Cherry, C. (2012) 'The Relationship Between Porn Use and Sexual Behaviour Among At Risk HIV Negative Men Who Have Sex With Men', Sexual Health 9.2: 166-70

Faiz Rashid, S. and Akram, O. (2014) Porn, Pleasure, Gender and Sex Education in Bangladesh, Brighton: IDS

Forrester, K. (2016) 'Making Sense of Modern Pornography', New Yorker, 26 September, www.newyorker.com/magazine/2016/09/26/ making-sense-of-modern-pornography (accessed 24 October 2016)

Foucault, Michel (1978) The History of Sexuality, New York NY: Pantheon Books

Hare, Kathleen; Gahagan, Jacqueline; Jackson, Lois and Steenbeek, Audrey (2015) 'Revisualising "Porn": How Young Adults' Consumption of Sexually Explicit Internet Movies can Inform Approaches to Canadian Sexual Health Promotion', Culture, Health and Sexuality 17.3: 260-83 
Jonas, K.J.; Hawk, S.T.; Vastenburg, D. and Groot, P. (2014)

" "Bareback" Porn, Consumption and Safe Sex Intentions of Men Having Sex With Men', Archives of Sexual Behaviour 43.4: 745-53

Jones, Bethany and Nurka, Camille (2015) 'Labiaplasty and Porn: A Preliminary Investigation', Porn Studies 2.1: 62-75

Kimmel, M. (2008) Guyland: The Perilous World Where Boys Become Men, New York NY: Harper

Kirkham, Pat and Skeggs, Beverly (1996) 'Pornographies, Pleasures and Pedagogies in U.K. and U.S.', Jump Cut 40: 106-13

Knerr, Wendy and Philpott, Anne (2012) Everything You Ever Wanted to Know About Pleasure, Health and Sex but Were Afraid to Ask, Oxford: The Pleasure Project, http://thepleasureproject.org/wordpress/ wp-content/uploads/2012/07/TPP-20-Questions_v6.pdf, (accessed 10 October 2016)

Knerr, Wendy and Philpott, Anne (2008) The Global Mapping of Pleasure: A Directory of Organizations, Media and People Who Eroticize Safer Sex, Oxford and Delhi: The Pleasure Project

Li, Ling; King, Mark E. and Winter, Sam (2009) 'Sexuality Education in China: The Conflict Between Reality and Ideology', Asia Pacific Fournal of Education 29.4: 469-80

Litras, Amy; Latreille, Sarah and Temple-Smith, Meredith (2015) 'Dr Google, Porn and Friend-of-a-Friend: Where are Young Men Really Getting Their Sexual Health Information?', Sexual Health 1: 488-94

McKee, Alan (2007) " "Saying You've Been at Dad's Porn Book is Part of Growing Up": Youth, Porn and Education', Metro Magazine 155: 118-22

Majumder, S. (2015) India Porn Ban: How the Government Was Forced to Reverse Course', BBC News, 8 August, www.bbc.co.uk/news/ world-asia-india-33810775 (accessed 24 October 2016)

Measor, Lynda (2004) 'Young People's Views of Sex Education: Gender, Information and Knowledge', Sex Education 4.2: 153-66

Ogas, O. and Gaddam, S. (2011) A Billion Wicked Thoughts: What the World's Largest Experiment Tells Us About Sexual Desire, London: Penguin Books

Patton, George C.; Murray, Christopher J.L. et al. (2016) 'Global Burden of Disease, Injuries, and Risk Factors for Young People's Health During 1990-2013', The Lancet, Commission on Adolescent Health, DOI: 10.1016/S0140-6736(16)00648-6

Perrin, P.C.; Madanat, H.N.; Barnes, M.D.; Carolan, A.; Clark, R.B.; Ivins, N.; Tuttle, S.R.; Vogeler, H.A. and Williams, P.N. (2008) 'Health Education's Role in Framing Pornography as a Public Health Issue: Local and National Strategies with International Implications', International Union for Health Promotion and Education 15.1: 11-18, DOI: $10.1177 / 1025382307088093$

Pornhub (2016) Pornhub's 2015 Year in Review', 6 January, www.pornhub.com/insights/pornhub-2015-year-in-review (accessed 10 October 2016)

Rubin, Gayle (1984) 'Thinking Sex', in C. Vance (ed.), Pleasure and Danger: Exploring Female Sexuality, Boston MA: Routledge and Kegan Paul 
Scrimshaw, Eric; Antebi-Gruszka, Nadav and Downing, Martin (2016) 'Viewing of Internet Based Sexually Explicit Medial as a Risk Factor for Condomless Anal Sex Among Men Who Have Sex With Men in Four U.S. Cities', PLOS ONE, 27 April

Scott-Sheldon, Lori and Johnson, Blair T. (2006) 'Eroticizing Creates Safer Sex: A Research Synthesis', Journal of Primary Prevention 27.6: 619-40

Smith, Clarissa (2010) 'Pornographication: A Discourse for all Seasons', International Fournal of Media and Cultural Politics 6.1: 103-8

Sun, Chyng; Bridges, Ana; Johnson, Jennifer and Ezzell, Matthew B. (2016) 'Porn and the Male Sexual Script: An Analysis of Consumption and Sexual Relations', Archives of Sexual Behaviour 45: 983-94

Tadele, Getnet (2006) Bleak Prospects: Young Men, Sexuality, and HIV/AIDS in an Ethiopian Town, Research Report 80, African Studies Centre, Leiden University, https://openaccess.leidenuniv.nl/bitstream/ handle/1887/4641/ASC-1236144-149.pdf? sequence=1 (accessed 1 February 2017)

Tanton, C.; Jones, K.G.; Macdowall, W. et al. (2015) 'Patterns and Trends in Sources of Information about Sex Among Young People in Britain: Evidence from Three National Surveys of Sexual Attitudes and Lifestyles', BMF Open 5.3: e007834, http://bmjopen.bmj.com/ content/bmjopen/5/3/e007834.full.pdf (accessed 4 January 2017

Tjaden, Patricia (1988) 'Porn and Sex Education', fournal of Sex Research 24: 208-12

Traeen, Bente; Hald, Gert Martin; Noor, Syed; Lantaffi, Alex; Grey, Jeremy and Rosser, Simon (2014) 'The Relationship Between Sexually Explicit Media and Sexual Risk Behaviour in Men Who Have Sex With Men: Exploring the Mediating Effects of Sexual Self Esteem and Condom Use Self Efficacy', International fournal of Sexual Health 26.1: 13-24

Tripathi, Niharika and Sekher, T.V. (2013) 'Youth in India Ready for Sex Education? Emerging Evidence from National Surveys', PLOS ONE 8.8: e71584, DOI:10.1371/journal.pone.0071584

Vance, Carol (1984) Pleasure and Danger: Exploring Female Sexuality, London: Routledge and Kegan Paul

Vogel, L. (2011) 'Public Health Advocates Push for Safer Sex in Pornographic Film Industry', Canadian Medical Association fournal 183.5: E261-2

Wallace Bowman, Hannah (2016) 'Love Matters: Evidence on Using Pleasure to Promote Safer Sex', presentation at 'Sex and the SDGs Session' at Women Deliver 4th Global Conference, Copenhagen, 16-19 May 2016

WAS (2008) Sexual Health for the Millennium: A Declaration and Technical Document, Minneapolis MN: World Association for Sexual Health, http:/ / 176.32.230.27/worldsexology.org/wp-content/ uploads/2013/08/millennium-declaration-english.pdf (accessed 4 January 2017)

Watson, Mary Ann and Smith, Randyl (2012) 'Commentary, Positive Porn: Educational, Medical and Clinical Uses', American Fournal of Sexuality Education 7: 122-45 
Wilkerson, Michael; Lantaffi, Alex; Smolenski, Derek; Horvath, Keith and Rosser, Simon (2013) 'Acceptability of HIV Prevention Messages in Sexually Explicit Media Viewed by Men Who Have Sex With Men', AIDS Education and Prevention 25.4: 315-26

World Bank (2016) World Development Report 2016, Washington DC:

World Bank, www.worldbank.org/en/publication/wdr2016 (accessed 24 October 2016)

World Bank (2012) Mobile Phone Access Reaches Three Quarters of Planet's Population, press release, www.worldbank.org/en/news/pressrelease/2012/07/17/mobile-phone-access-reaches-three-quartersplanets-population (accessed 10 October 2016)

Wright, P.J. and Tokunaga, R.S. (2016) 'Men's Objectifying Media Consumption, Objectification of Women and Attitudes Supportive of Sexual Violence Against Women', Archives of Sexual Behaviour 45.5: 955-64 


\section{Glossary}

ASRH adolescent sexual and reproductive health

CODESRIA Council for the Development of Social Science Research in Africa

CSE comprehensive sexuality education

DFID Department for International Development

ECCD Early Childhood Care and Development

ESRC Economic and Social Research Council

FGAE Family Guidance Association of Ethiopia

FGD focus group discussion

GSD Gender and Sexual Diversity

HIV human immunodeficiency virus

ICRW International Center for Research on Women

ICT information and communications technology

IDS Institute of Development Studies

IHRP International Human Rights Program

IICD International Institute for Communication and Development

INDEC Instituto Nacional de Estadistica y Censos

IP Internet Protocol

LGBTQI lesbian, gay, bisexual, trans, queer, intersex

MSM men who have sex with men

MSW Masters of Social Work

NGO non-governmental organisation

OVC orphans and vulnerable children

Q\&A question and answer

RinGs Research in Gender and Ethics

RSF Reporters Without Borders

SEM sexually explicit media

SEO search engine optimisation

SRHR sexual and reproductive health and rights

STI sexually transmitted infection

UNAIDS Joint United Nations Programme on HIV/AIDS

UNESCO United Nations Educational, Scientific and Cultural

Organization

UNFPA United Nations Population Fund

USAID United States Agency for International Development

WAS World Association for Sexual Health

WHO World Health Organization

YCSRR Youth Coalition for Sexual and Reproductive Rights

YPR youth peer researcher 
This page is intentionally left blank 


\section{Volume 47 (2016)}

No. 1 Opening Governance

No. 1 A Connecting Perspectives on Women's Empowerment

No. 2 Development Studies - Past, Present and Future

No. 3 Ruptures and Ripple Effects in the Middle East and Beyond

No. 4 Foresight in International Development

No. 5 Power, Poverty and Inequality

No. 2A States, Markets and Society - New Relationships for a New Development Era

No. 6 Engaged Excellence

\section{Volume 46 (2015)}

No. 1 Towards Systemic Approaches to Evaluation and Impact

No. 2 Graduating from Social Protection?

No. 3 Business, State and Society: Changing Perspectives, Roles and Approaches in Development

No. 4 Beijing+20: Where Now for Gender Equality?

No. 5 What is the Unique Contribution of Volunteering to International Development?

No. 6 Life in a Time of Food Price Volatility

\section{Volume 45 (2014)}

No. 1 Undressing Patriarchy: Men and Structural Violence

No. 2-3 New Perspectives from PhD Field Research

No. 4 China and International Development: Challenges and Opportunities

No. 5 Localising Governance

No. 6 Rethinking Impact Evaluation for Development

Periodical ID statement The IDS Bulletin (ISSN 0265-5012 print) is published bi-monthly in January, March, May, July, September and November. Mailing agent: Gary Edwards, Institute of Development Studies, Library Road, Brighton BN1 9RE, UK. Tel: +44 (0)1273 606261 idsbulletin@ids.ac.uk

Postmaster Send all address changes to IDS Bulletin, Gary Edwards, Institute of Development Studies, Library Road, Brighton BN1 9RE, UK. Tel: +44 (0)1273 606261 idsbulletin@ids.ac.uk

Journal customer services For ordering information, claims and any enquiry concerning your journal subscription please contact Gary Edwards, Institute of Development Studies, Library Road, Brighton BN1 9RE, UK. Tel: +44 (0)1273 606261 idsbulletin@ids.ac.uk

Print details printed in the UK by Nexus Design \& Print Ltd, Studio 38, Adur Business Centre, Little High Street, Shoreham-by-Sea BN43 5EG, UK.

Delivery terms and legal title Prices include delivery of print journals to the recipient's address. Delivery terms are Delivery Duty Unpaid (DDU); the recipient is responsible for paying any import duty or taxes. Legal title passes to the customer on despatch.

ISSN 0265-5012 (print), 1759-5436 (online) 


\section{Sex Education in the Digital Era}

Institute of

Development Studies

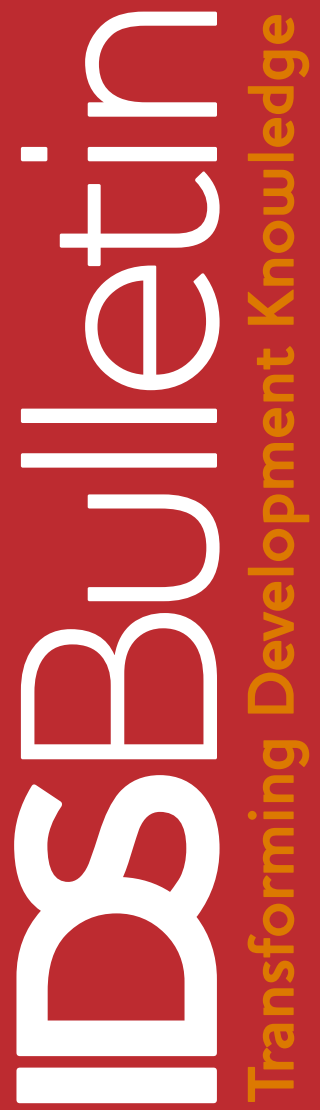

Editors Pauline Oosterhoff, Catherine Müller and Kelly Shephard

Volume 48 | Number 1 | January 2017

Introduction: Sex Education in the Digital Era

Pauline Oosterhoff, Catherine Müller and Kelly Shephard

Enabling Online Safe Spaces: A Case Study of Love Matters Kenya Maaike van Heijningen and Lindsay van Clief

New Digital Ways of Delivering Sex Education: A Practice Perspective Linda Waldman and Isabelle Amazon-Brown

\#ByeTaboo: Expanding Access to Sexual and Reproductive Health and Rights Education

Natalia Herbst

Digital Pathways to Sex Education

Catherine Müller, Pauline Oosterhoff and Michelle Chakkalackal

Feeling 'Blue': Pornography and Sex Education in Eastern Africa Kristen Cheney, Annah Kamusiime and Anteneh Mekonnen Yimer

Blurring the Boundaries of Public Health: It's Time to Make Safer Sex Porn and Erotic Sex Education

Anne Philpott, Arushi Singh and Jennie Gamlin

'Young people need access to new types of digital sex education environments that are realistic, emotionally attuned, non-judgemental and open to the messages they themselves create, and sex educators cannot help build such environments until they understand how they work.' 